Florida International University

FIU Digital Commons

FIU Electronic Theses and Dissertations

University Graduate School

$6-2016$

\title{
Antenatal Stressful Life Events and Postpartum Depression in the United States: the Role of Women's Socioeconomic Status at the State Level
}

Soumyadeep Mukherjee

Florida International University, smukh004@fiu.edu

DOI: $10.25148 /$ etd.FIDC000695

Follow this and additional works at: https:// digitalcommons.fiu.edu/etd

Part of the Epidemiology Commons, Maternal and Child Health Commons, Medical Humanities Commons, Obstetrics and Gynecology Commons, Other Mental and Social Health Commons, Psychiatric and Mental Health Commons, Psychiatry Commons, Quantitative Psychology

Commons, and the Women's Health Commons

\section{Recommended Citation}

Mukherjee, Soumyadeep, "Antenatal Stressful Life Events and Postpartum Depression in the United States: the Role of Women's Socioeconomic Status at the State Level" (2016). FIU Electronic Theses and Dissertations. 2631.

https://digitalcommons.fiu.edu/etd/2631

This work is brought to you for free and open access by the University Graduate School at FIU Digital Commons. It has been accepted for inclusion in FIU Electronic Theses and Dissertations by an authorized administrator of FIU Digital Commons. For more information, please contact dcc@fiu.edu. 


\title{
FLORIDA INTERNATIONAL UNIVERSITY
}

Miami, Florida

\section{ANTENATAL STRESSFUL LIFE EVENTS AND POSTPARTUM DEPRESSION IN THE UNITED STATES: THE ROLE OF WOMEN'S SOCIOECONOMIC STATUS AT THE STATE LEVEL}

\author{
A dissertation submitted in partial fulfillment of the \\ requirements for the degree of \\ DOCTOR OF PHILOSOPHY
}

in

PUBLIC HEALTH

by

Soumyadeep Mukherjee

2016 
To: Dean Tomás R. Guilarte

Robert Stempel College of Public Health and Social Work

This dissertation, written by Soumyadeep Mukherjee, and entitled Antenatal Stressful Life Events and Postpartum Depression in the United States: the Role of Women's Socioeconomic Status at the State Level, having been approved in respect to style and intellectual content, is referred to you for judgment.

We have read this dissertation and recommend that it be approved.

$\begin{array}{r}\hline \text { Stefany Coxe } \\ \hline \text { Kristopher P. Fennie } \\ \hline \text { Purnima Madhivanan } \\ \hline \text { Mary Jo Trepka, Major Professor }\end{array}$

Date of Defense: June 14, 2016

The dissertation of Soumyadeep Mukherjee is approved.

Dean Tomás R. Guilarte Robert Stempel College of Public Health and Social Work

Andrés G. Gil Vice President for Research and Economic Development Dean of the University Graduate School

Florida International University, 2016 
(C) Copyright 2016 by Soumyadeep Mukherjee

All rights reserved 


\section{DEDICATION}

I dedicate this dissertation to my parents, Mrs. Shikha Mukherjee and Dr. Dibyendu

Mukherjee, for being my role models and for making countless sacrifices to ensure that I have the best possible educational opportunities.

This dissertation is also dedicated to all the participants in the Pregnancy Risk Assessment Monitoring System (PRAMS) Survey 2009-2011, the data from which have been used for this dissertation. 


\section{ACKNOWLEDGMENTS}

I want to thank the Department of Epidemiology, Florida International University (FIU); my dissertation committee; and the University Graduate School (UGS), FIU for their generous support throughout my doctoral studies. I would like to express my heartfelt gratitude to my major professor, Dr. Mary Jo Trepka, for her continuous guidance, invaluable feedback at all stages of the dissertation, and unwavering belief in my abilities. I thank Dr. Stefany Coxe for patiently explaining to me the statistical analytic methods through numerous in-person meetings and emails. I would like to thank Dr. Fennie for offering his insights whenever I encountered any issue related to the dissertation, and Dr. Madhivanan for her advice, feedback, and encouragement.

The Presidential Fellowship and the Dissertation Year Fellowship from the University Graduate School, FIU have supported me at different stages of my doctoral education. I am also indebted to funding supports in the form of Graduate Assistantship in the Department of Epidemiology; Research Assistantship in the Department of Epidemiology under Dr. Trepka; and Research Assistantship under Dr. Richard Beaulaurier in the School of Social Work.

My sincere thanks to the PRAMS Working Group for allowing me to use the Pregnancy Risk Assessment Monitoring System (PRAMS) 2009-11 data for this dissertation, and for preparing and sending the dataset with the requested variables. I am grateful to Mr. Brian Morrow, Mathematical Statistician at the Centers for Disease Control and Prevention (CDC), for his guidance with certain variables. I would thank the respondents to this survey administered by the CDC. 
I am thankful to a number of FIU facilities, including the Green Library, the Computer Lab at the Graham Center, the Office of Academic Writing \& Publication Support, and the Health and Wellness services at Modesto A. Madique (MMC) campus. I want to thank my parents and all my friends here and back home, whose emotional support, encouragement, and belief in me have enabled me to navigate this long journey. Last but not the least, special thanks to my fellow students in the Department of Epidemiology, whose advice proved extremely useful at crucial moments. 


\title{
ABSTRACT OF THE DISSERTATION
}

\section{ANTENATAL STRESSFUL LIFE EVENTS AND POSTPARTUM DEPRESSION IN THE UNITED STATES: THE ROLE OF WOMEN'S SOCIOECONOMIC STATUS AT THE STATE LEVEL}

\author{
by
}

Soumyadeep Mukherjee

Florida International University, 2016

Miami, Florida

Professor Mary Jo Trepka, Major Professor

The purpose of this dissertation was to examine patterns of antenatal stressful life events (SLEs) experienced by women in the United States (U.S.) and their association with postpartum depression (PPD). It further explored the role of women's state-level socio-economic status (SES) on PPD; the racial/ethnic dispartites in SLE-PPD relationship; and the role of provider communication on perinatal depression.

Data from 2009-11 Pregnancy Risk Assessment Monitoring System (PRAMS) and SES indicators published by the Institute of Women's Policy Research (IWPR) were used. Latent class analysis (LCA) was performed to identify unobserved class membership based on antenatal SLEs. Multilevel generalized linear mixed models examined whether state-level SES moderated the antenatal SLE-PPD relationship. Of 116,595 respondents to the PRAMS 2009-11, the sample size for our analyses ranged from $78 \%$ to $99 \%$. 
The majority (64\%) of participants were in low-stress class. The illness/death related-stress class $(13 \%)$ had a high prevalence of severe illness $(77 \%)$ and death $(63 \%)$ of a family member or someone very close to them, while those in the multiple-stress (22\%) class endorsed most other SLEs. Eleven percent had PPD; women who experienced all types of stressors, had the highest odds (adjusted odds ratio [aOR]: 5.43; 95\% confidence interval $[C I]: 5.36,5.51)$ of PPD. The odds of PPD decreased with increasing state-level social/economic autonomy index (aOR: 0.75; 95\% CI: 0.64, 0.88), with significant cross-level interaction between stressors and state-level SES. Among non-Hispanic blacks and non-Hispanic whites, husband/partner not wanting the pregnancy (aOR: 1.47; 95\% CI: 1.14, 1.90) and drug/drinking problems of someone close (aOR: 1.37; 95\% CI: 1.21, 1.55) were respectively associated with PPD. Provider communication was protective.

That 1 out of every 5 and 1 out of every 8 women were in the high- and emotional-stress classes suggests that SLEs are common among pregnant women. Our results suggest that screening for antenatal SLEs might help identify women at risk for PPD. The finding that the odds of PPD decrease with increasing social/economic autonomy, could have policy implications and motivate efforts to improve these indices. This study also indicates the benefits of antenatal health care provider communication on perinatal depression. 


\section{TABLE OF CONTENTS}

CHAPTER

PAGE

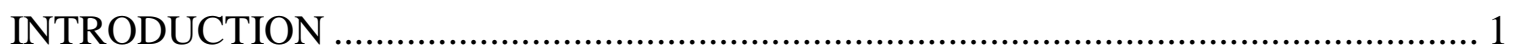

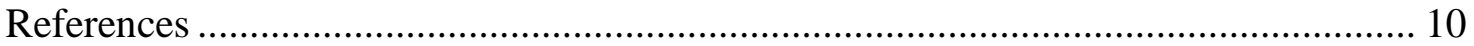

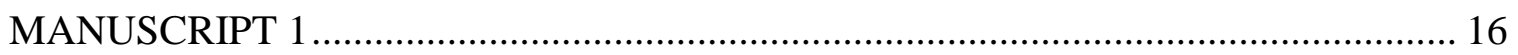

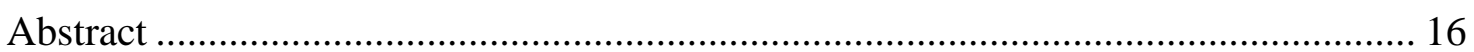

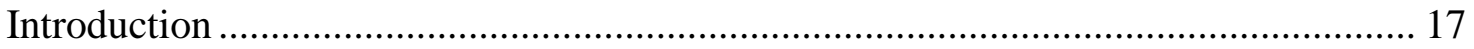

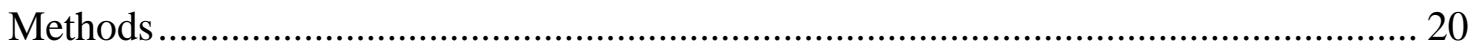

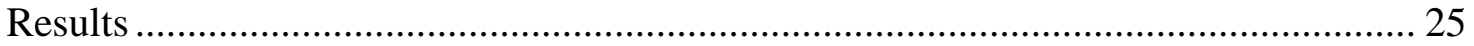

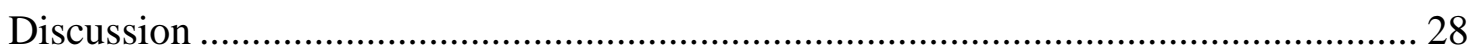

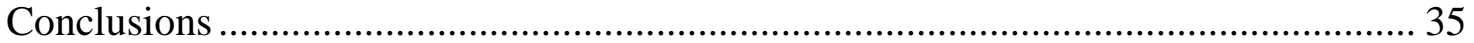

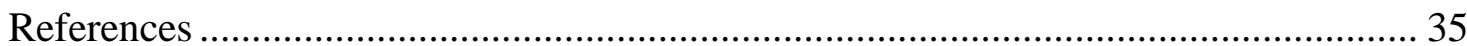

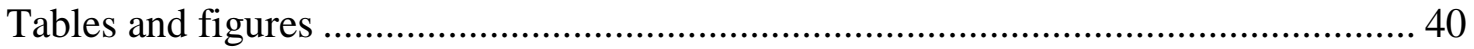

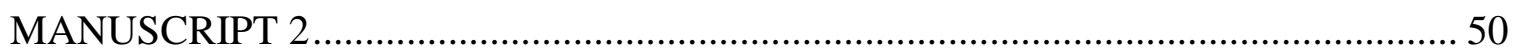

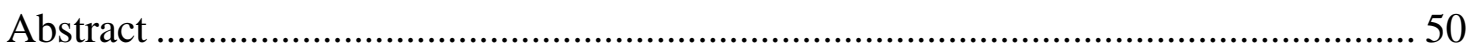

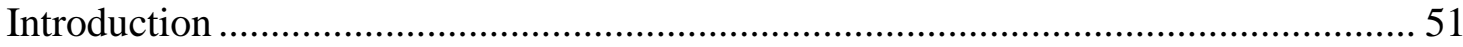

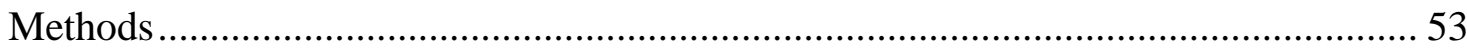

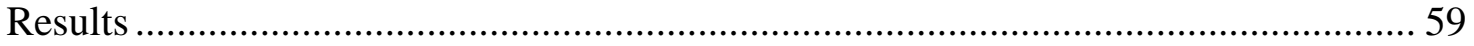

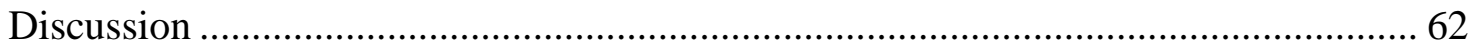

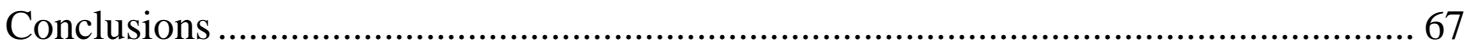

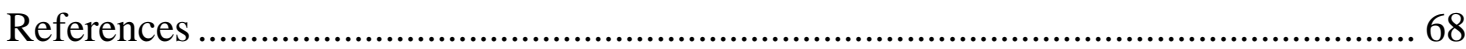

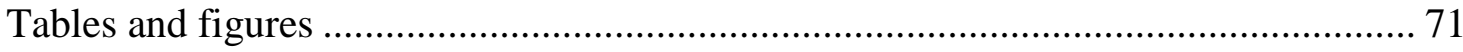

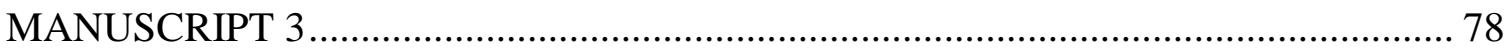

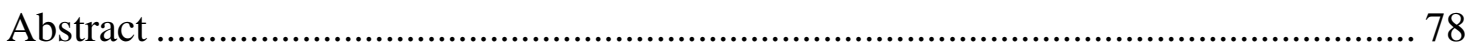

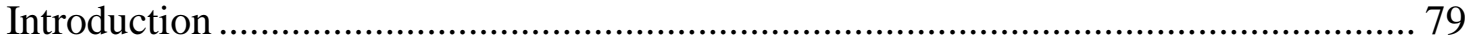

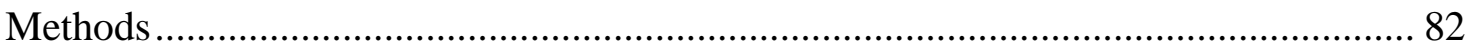




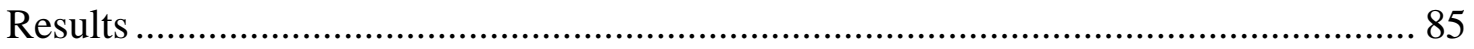

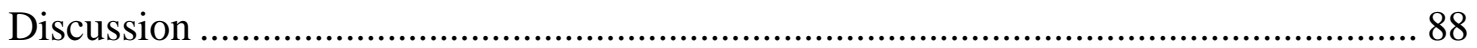

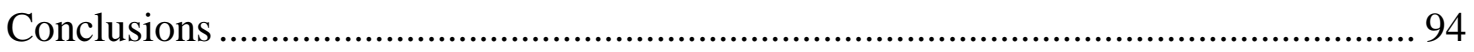

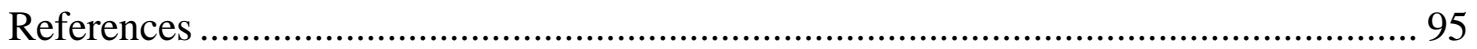

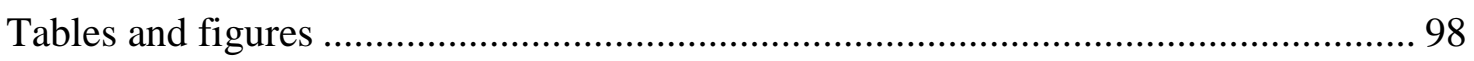

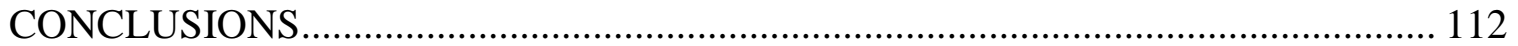

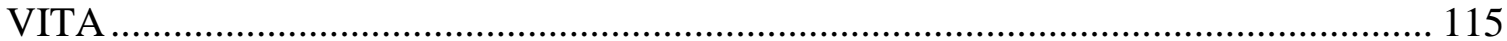




\section{ABBREVIATIONS AND ACRONYMS}

$\begin{array}{ll}\text { CDC } & \text { Centers for Disease Control and Prevention } \\ \text { CI } & \text { Confidence interval } \\ \text { aOR } & \text { Adjusted odds ratio } \\ \text { PPD } & \text { Postpartum depression } \\ \text { PRAMS } & \text { Pregnancy Risk Assessment and Monitoring System } \\ \text { SES } & \text { Socioeconomic status } \\ \text { SLE } & \text { Stressful life event } \\ \text { US } & \text { United States }\end{array}$




\section{INTRODUCTION}

\section{Stressful life events during pregnancy}

Stressful life events (SLEs) are changes occurring suddenly in a person's life that can significantly disturb his/her daily routine with a potential impact on health, especially mental health (Turner \& Wheaton, 1995; Wagner et al., 1988; Hammen, 2005). Such events may be negative or undesirable (such as death of a close friend or relative, serious illness of a family member), positive or desirable (such as promotion at work, engagement, marriage, an intended pregnancy), or, have a mixture of both desirable and undesirable components (such as moving to a new place) (Holmes \& Rahe, 1967; Koenders et al., 2014). Stressful experiences and the resulting reactions can lead to a variety of negative health consequences (Dohrenwend, 2000; Thoits, 1995). Usually undesirable SLEs are more of a concern with respect to their negative health outcomes, than desirable SLEs.

Although pregnancy has traditionally been expected to be a happy time for women, it is a major life event and can be stressful depending on the situations. Pregnant women experience a number of stress factors, such as, physical and hormonal changes, pregnancy-specific anxiety, concerns related to the fetus and fear of pain during delivery (Van der Bergh, 1992). Various other experiences can lead to stress during pregnancy, such as negative life-events (such as divorce, serious illness or death in the family, or losing a job or home), catastrophic events (such as earthquakes, hurricanes, or terrorist attacks), long-lasting stress (due to financial problems, being abused, having serious health problems), and discrimination or racism (March of Dimes, 2012). Stress due to 
daily-life hassles as well as the major life events can adversely affect pregnancy; the latter usually have a more significant impact (Dunkel Schetter \& Tanner, 2012). Multiple stressors can be present and exacerbate the experience of antenatal distress.

Stress during pregnancy has been linked with adverse fetal outcomes, such as spontaneous abortion (Neugebauer et al., 1996), preterm birth, and low birth weight (Copper et al., 1996), and maternal complications, including hypertension (Landsbergis and Hatch, 1996), nausea and vomiting (Kuo et al. 2010), antenatal depression (Zayas, 2002), and postpartum depression (O’Hara and Swain, 1996). Stressful life events during pregnancy might even be associated with impaired mental and motor development of the newborn baby during infancy (Huizink et al., 2003) and psychiatric conditions during childhood, adolescence, and adulthood (Beydoun and Saftlas, 2008). Various mechanisms have been proposed to explain the relationship of antenatal stress and negative perinatal outcomes. Response of the maternal hypothalamus-pituitary-adrenal cortex system (HPA axis) to stress is hypothesized to play a key role. Stress can lead to an increased secretion of the corticotropin releasing hormone (CRH) from the hypothalamus, leading to a cascade of events that include increased release of maternal glucocorticoids and catecholamines, stimulation of release of placental $\mathrm{CRH}$, decreased uteroplacental blood flow, and adverse effects on the fetal neurotransmitters and nervous system (Mulder et al., 2002). Stressed women might also be more likely to engage in negative health behaviors, such as delayed antenatal care, higher rates of tobacco and alcohol use, and poor diet and nourishment, which in turn lead to poor maternal and fetal outcomes (Costa et al., 2000; Hobel \& Culhane, 2003; Hobel et al., 2008; Hoffman \& Hatch, 1996; Larrieux et al., 2004). Stress-induced release of glucocorticoids and 
catecholamines can impair maternal cellular immunity and increase vulnerability to infections (Hobel \& Culhane, 2003; Wadhwa et al., 2001).

Nearly $65-70 \%$ of pregnant women in the United States (U.S.) have reported at least one stressful life-event (SLE) experience during pregnancy (Herrick, 2000; Whitehead et al., 2002). The limited exploration of racial/ethnic distribution of antenatal SLE suggests that disparities may exist. An analysis of Los Angeles County Department of Health data for the year 2010 indicated that the most common SLE during pregnancy — moving to a new address — was experienced by nearly one-third of women and did not differ considerably between the racial/ethnic groups. On the other hand, $14.5 \%$ of black and $8.5 \%$ of Hispanic, compared to $2.9 \%$ of white women, got divorced or separated from their husband or partner when they were pregnant. As many as one in ten black pregnant women were homeless during pregnancy, compared to $5 \%$ of Hispanics and $1 \%$ of whites. During pregnancy, 22\%, 15\%, and 10\% of Hispanic, black, and white women's husband/partner lost his/her job respectively. Having more than the usual number of arguments with a husband/partner was also fairly common and variedit was reported by $20 \%$ of Asians, $22 \%$ of whites, $29 \%$ of Hispanics, and $43 \%$ of blacks. Inability to pay a lot of bills during pregnancy was reported by $32 \%$ of blacks, compared to $14 \%$ of whites. During pregnancy, $8 \%$ of black and $1 \%$ of white women were involved in a physical fight, while $8.6 \%$ of black and $1.4 \%$ of white women (or her husband/partner) went to jail (County of Los Angeles Public Health, 2010). An analysis of Pregnancy Risk Assessment Monitoring System (PRAMS) 2000 data from 19 states revealed that that the mean number of stressful life events experienced during the 12 months before delivery was the highest among non-Hispanic black and American 
Indian/Alaska Native women. Even after adjusting for sociodemographic differences, non-Hispanic black women were $13 \%$ and $48 \%$ more likely to report emotional and partner-associated stressors respectively (Lu \& Chen, 2004). Burns et al. (2015), in their study using multi-state PRAMS 2010 data, reported that the proportion of women experiencing at least one antenatal SLE was the highest among non-Hispanic blacks (76.5\%) and the lowest among Asians/Pacific Islanders (56.9\%). A similar pattern was observed for each type of SLE. In addition, the mean number of SLE was the highest for non-Hispanic blacks (2.32), followed by those of other racial/ethnic groups (2.04), Hispanics (1.92), non-Hispanic whites (1.70), and Asians/Pacific Islanders (1.11) (Burns et al., 2015)

The few studies on maternal antenatal SLE have either clustered the different life events into domains such as financial, emotional, traumatic, and partner-associated (Nkansah-Amankra et al., 2010), or counted the total number of events experienced (Whitehead et al., 2002). While both of these approaches focus on the events, they do not identify sub-groups of women based on similar life-event experiences during pregnancy.

\section{Postpartum Depression}

It is common for a woman, who has recently had pregnancy and childbirth, to experience feelings of depression, anxiety, and anger and be upset towards her new baby, her partner, or her children. This phase, characterized by crying, sleep disturbances, having trouble eating and making choices, and being doubtful about their ability to care for their baby, is known as postpartum blues. This typically begins 2-3 days after childbirth and usually gets better within a few days or 1-2 weeks without treatment 
(American College of Obstetricians and Gynecologists, 2013). Previous estimates suggest that the prevalence of postpartum blues can range from 25\% to 85\% (Altshuler et al., 2001; Beck et al., 1992). However, sometimes a postpartum woman experiences severe sadness, anxiety, or despair leading to impairment in daily activities, and this is postpartum depression. This usually starts about 1-3 weeks after childbirth and can occur up to 1 year after childbirth. Some of the risk factors for postpartum depression are difficulty in getting pregnant, unplanned pregnancy, history of depression, anxiety or other psychiatric disorders, multiple pregnancy, miscarriage, stillbirth or neonatal death, premature labor and delivery, having a baby with a birth defect, complications during pregnancy and childbirth, having an operative delivery, relationship problems with husband/partner, lack of social support, hospitalization of the baby, and stressful life events (American College of Obstetricians and Gynecologists, 2013; Robertson et al., 2004; Beck, 2001; O’Hara \& Swain, 1996).

Postpartum depression affects 10-20\% of postpartum women in the U.S. (O'Hara \& Swain, 1996; Centers for Disease Control and Prevention, 2008). Studies have had contrasting results with respect to the racial/ethnic distribution of postpartum depression. Among low-income women in rural North Carolina, racial disparities in post-partum depression were not observed (Hutto, 2011). Similarly, in a sample of Caucasian, Asian/Pacific Islander women, differences by ethnicity were not found for postpartum depression or anxiety (Onoye et al., 2009). However, minority race was significantly associated with self-reported depressive symptoms in a large cohort of mothers of children born at Yale-New Haven Hospital, Connecticut (McCue Horwitz, 2007). The proportion of postpartum women in Massachusetts, who self-reported having depressed 
mood always or often, was the highest among Hispanics, followed by non-Hispanic blacks, Asians/Pacific Islanders, and non-Hispanic whites. This difference was no longer significant after adjusting for SES. However, Asians/Pacific Islanders had a significantly higher likelihood of loss of interest in doing things, compared with non-Hispanic whites after adjusting for socioeconomic status (Liu \& Tronick, 2013). Racial and ethnic differences in the prevalence of postpartum depression have been noted among women in Massachusetts (Liu and Tronick 2014) and New York City (Liu et al., 2013). A study conducted in Massachusetts revealed that antenatal stress did not predict postpartum loss of interest among non-Hispanic whites, but high relational stress and high financial stress were respectively associated with loss of interest among non-Hispanic blacks, and Hispanics and Asians/Pacific Islanders (Liu et al., 2016). However, multistate populationbased studies exploring the racial/ethnic disparities in the prevalence of postpartum depression and the relationship between antenatal stressful life events and postpartum depression are difficult to find. One of the U.S. Department of Health and Human Services Healthy People 2020 objectives, is to decrease the proportion of women with a live birth, experiencing postpartum depressive symptoms (Office of Disease Prevention \& Health Promotion [ODPHP], 2016).

\section{The role of women's socio-economic status at the state level}

Various theories have been proposed to explain the occurrence of depression among women, with special emphasis on the higher incidence and prevalence compared to men. At the micro-level, the focus is on biological mechanisms, such as, genetic differences, gender differences in neurotransmitters and hormones (Ussher, 1991; Walsh 
et al., 1995), and psychological factors, such as differential help-seeking behaviors, style of coping and self-efficacy. At a higher level, the focus is on the epidemiological risk factors for depression, such as intimate partner violence, childhood abuse, and social isolation (Nolen-Hoeksema, 1990, 2001; Nolen-Hoeksema \& Girgus, 1994; NolenHoeksema et al., 1999). These factors are often differentially distributed between men and women. The most macro-level, proposed by Walsh et al., looks at the broader sociocultural and economic factors, their influence on women's access to resources and gender differences in health (Walsh et al., 1995). At this level, the focus is on the social, economic and political arrangements that influence the distribution of power and resources between men and women and contribute to gender differences in physical and mental health, including a higher prevalence of depression among women (Connell, 1987; Diez-Roux, 1998; Macintyre et al., 2002).

A multiple determinants framework for perinatal health includes proximal risk factors, which are biomedical and behavioral responses to distal risk factors, such as the woman's physical, economic, social and political environment (Misra et al., 2003). As the state has increasingly become the unit to legislate, fund, and implement policies and programs in the U.S., states with policies favoring gender equality in social-economic, political and reproductive rights can encourage an environment that is friendlier towards women and family (Daniels, 1997). On the other hand, states' tolerance of women's unequal social status and disadvantaged positions can result in adverse physical and mental health consequences for women (Chen et al., 2005). The importance of state-level women's status has been examined in the context of depression (Chen et al., 2005), violence against married women (Yllö, 1984), global and cause-specific mortality rates 
among both women and men, low birthweight, teen pregnancy, and infant and teen mortality (Kawachi et al., 1999; Koenen et al., 2006). State-level women's status indices, or, their interaction with individual-level antenatal risk factors have not been considered in the context of postpartum depression. After taking individual correlates into account, women living in states ranking high on employment and earnings index, and economic autonomy index had significantly lower depression scores, compared with women living in states ranked lower on the same indices (Chen et al., 2005). However, state-level women's status indices, or, their interaction with individual-level antenatal risk factors have not been considered in the context of postpartum depression.

\section{Provider communication on perinatal depression}

Previous research suggests that interventions delivered during pregnancy can be effective in preventing postpartum depression, especially among those with antenatal depression symptoms (Clatworthy, 2012; Sockol et al., 2013). The US Preventive Services Task Force (USPSTF) has recently concluded that in addition to screening for depression in pregnant and postpartum women, a variety of treatment options, including antidepressants and behavioral therapy, should be available (Siu and the US Preventive Services Task Force [USPSTF], 2016). Providing pregnant women with information about perinatal depression can be empowering, and contribute to an increased awareness on this health issue and its symptoms, so that they can seek necessary care and support early enough (Youash et al. 2013). An analysis of data from the 2011 Pregnancy Risk Assessment Monitoring System (PRAMS) revealed that nearly 72\% women reported a discussion on perinatal depression with their health care provider during antenatal care 
(Farr et al., 2016). Farr et al. (2016) also noted that $67.5 \%$ and $72.3 \%$ of women with and without postpartum depressive symptoms had discussions about perinatal depression with their prenatal health care provider. But there has been little, if any, research on the impact of provider communication on the occurrence of postpartum depression, after taking other socio-demographic factors into account.

The objective of this dissertation was to examine patterns of antenatal stressful life events (SLE) experienced by women in the United States (U.S.) and their association with postpartum depression (PPD). It further aimed to explore the role of women's statelevel socio-economic status (SES) on PPD, after taking into account individual-level correlates. Finally, this study examined the relationship between antenatal SLE and PPD, by race/ethnicity, and the role of provider communication on perinatal depression. These objectives were achieved through three studies. The aims of the first study were to: (1) identify groups of women in the U.S. with similar patterns of stressful life event experiences during pregnancy and to examine the socio-demographic correlates of these groups, and (2) compare the prevalence of maternal health outcomes, including hypertensive disorders during pregnancy; severe nausea, vomiting or dehydration; preterm labor and premature rupture of membranes, which are associated with preterm birth; and postpartum depression, between these latent classes. The second study aimed to examine the association between antenatal SLEs and PPD, among women in the U.S. who have had a recent live birth and to explore whether state-level SES moderated the relationship between antenatal SLE and PPD. The third and final study aimed to: (1) examine racial/ethnic disparities in the relationship between different antenatal stressful life events and postpartum depression, among women in the U.S. who have had a recent 
live birth, and (2) explore whether provider communication about perinatal depression was associated with a lower risk of postpartum depression and whether the effect (if any) varied according to maternal race/ethnicity.

\section{References}

Altshuler, L. L., Cohen, L. S., Moline, M. L., Kahn, D. A., Carpenter, D., \& Docherty, J. P. (2001). The Expert Consensus Guideline Series. Treatment of depression in women. Postgraduate Medicine, (Spec No), 1-107.

American College of Obstetricians and Gynecologists. Frequently Asked Questions Labor, Delivery, and Postpartum Care [Internet]; 2013. Available from:

https://www.acog.org/ /media/For\%20Patients/faq091.pdf?dmc=1\&ts=20140330T19034 35854. Accessed April 23, 2016.

Beck, C. T., Reynolds, M. A., \& Rutowski, P. (1992). Maternity blues and postpartum depression. Journal of Obstetric, Gynecologic, \& Neonatal Nursing, 21(4), 287-293.

Beck, C. T. (2001). Predictors of postpartum depression: an update. Nursing Research, 50(5), 275-285.

Beydoun, H., \& Saftlas, A. F. (2008). Physical and mental health outcomes of prenatal maternal stress in human and animal studies: A review of recent evidence. Paediatric and Perinatal Epidemiology, 22(5), 438-466.

Burns, E.R., Farr, S.L., \& Howards, P.P. (2015). Stressful life events experienced by eomen in the year before their infants' births - United States, 2000-2010. MMWR. Morbidity and Mortality Weekly Report, 64(9), 247-251.

Centers for Disease Control and Prevention (CDC). (2008). Prevalence of self-reported postpartum depressive symptoms--17 states, 2004-2005. MMWR. Morbidity and Mortality Weekly Report, 57(14), 361.

Chen, Y. Y., Subramanian, S. V., Acevedo-Garcia, D., \& Kawachi, I. (2005). Women's Status and Depressive Symptoms: a multilevel analysis. Social Science \& Medicine, 60(1), 49-60.

Clatworthy, J. (2012). The effectiveness of antenatal interventions to prevent postnatal depression in high-risk women. Journal of Affective Disorders, 137(1), 25-34.

Connell RW. (1987). Gender and power: Society, the person and sexual politics. Stanford University Press. 
Copper, R.L., Goldenberg, R.L., Das, A,, Elder, N,, Swain, M., Norman, G., ...\&\& Jones, P. (1996). The preterm prediction study: Maternal stress is associated with spontaneous preterm birth at less than thirty-five weeks' gestation. Obstetrics \& Gynecology, 175(5), 1286-1292.

Costa, D. D., Dritsa, M., Larouche, J., \& Brender, W. (2000). Psychosocial predictors of labor/delivery complications and infant birth weight: a prospective multivariate study. Journal of Psychosomatic Obstetrics \& Gynecology, 21(3), 137-148.

County of Los Angeles Public Health. (2010). Stressful life events during pregnancy. Available at http://publichealth.lacounty.gov/mch/LAMB/Results/2010Results/2010_LAMB_Surveill ance_Report.html accessed April 15, 2016.

Daniels, C. (1997). The Paradoxes of State Power. In C. Daniels \& R. Brooks (Eds.), Feminists Negotiate the State: The Politics of Domestic Violence (pp. 1-4). Lanham, Maryland: University Press of America.

Diez-Roux, A. V. (1998). Bringing context back into epidemiology: variables and fallacies in multilevel analysis. American Journal of Public Health, 88(2), 216-222.

Dohrenwend, B. P. (2000). The role of adversity and stress in psychopathology: Some evidence and its implications for theory and research. Journal of Health and Social Behavior, 41(1), 1-19.

Dunkel Schetter, C., \& Tanner, L. (2012). Anxiety, depression and stress in pregnancy: implications for mothers, children, research, and practice. Current Opinion in Psychiatry, 25(2), 141.

Farr, S. L., Ko, J. Y., Burley, K., \& Gupta, S. (2016). Provider communication on perinatal depression: a population-based study. Archives of Women's Mental Health, 19, $35-40$.

Hammen, C. (2005). Stress and depression. Annual Review of Clinical Psychology, 1, 293-319.

Herrick, H.W.B. (2000). The effect of stressful life events on postpartum depression results from the 1997-1998 North Carolina Pregnancy Risk Assessment Monitoring System (PRAMS). SCHS Studies 121. Available: http://www.schs.state.nc.us/SCHS/pdf/SCHS121.pdf. Accessed December 18, 2015.

Hobel, C., \& Culhane, J. (2003). Role of psychosocial and nutritional stress on poor pregnancy outcome. The Journal of Nutrition, 133(5), 1709S-1717S.

Hobel, C. J., Goldstein, A., \& Barrett, E. S. (2008). Psychosocial stress and pregnancy outcome. Clinical Obstetrics and Gynecology, 51(2), 333-348. 
Hoffman, S., \& Hatch, M. C. (1996). Stress, social support and pregnancy outcome: a reassessment based on recent research. Paediatric and Perinatal Epidemiology, 10(4), 380-405.

Holmes, T. H., \& Rahe, R. H. (1967). The social readjustment rating scale. Journal of Psychosomatic Research, 11(2), 213-218.

Huizink, A. C., Robles de Medina, P. G., Mulder, E. J., Visser, G. H., \& Buitelaar, J. K. (2003). Stress during pregnancy is associated with developmental outcome in infancy. Journal of Child Psychology and Psychiatry, 44(6), 810-818.

Hutto, H. F., Kim-Godwin, Y., Pollard, D., \& Kemppainen, J. (2011). Postpartum depression among White, African American, and Hispanic low-income mothers in rural Southeastern North Carolina. Journal of Community Health Nursing, 28(1), 41-53.

Kawachi, I., Kennedy, B. P., Gupta, V., \& Prothrow-Stith, D. (1999). Women's status and the health of women and men: a view from the States. Social Science \& Medicine, 48(1), 21-32.

Koenders, M. A., Giltay, E. J., Spijker, A. T., Hoencamp, E., Spinhoven, P., \& Elzinga, B. M. (2014). Stressful life events in bipolar I and II disorder: Cause or consequence of mood symptoms?. Journal of Affective Disorders, 161, 55-64.

Koenen, K. C., Lincoln, A., \& Appleton, A. (2006). Women's status and child well-being: A state-level analysis. Social Science \& Medicine, 63(12), 2999-3012.

Kuo, S. H., Yang, Y. H., Wang, R. H., Chan, T. F., \& Chou, F. H. (2010). Relationships between leptin, HCG, cortisol, and psychosocial stress and nausea and vomiting throughout pregnancy. Biological Research for Nursing, 12(1), 20-27.

Landsbergis, P. A., \& Hatch, M. C. (1996). Psychosocial work stress and pregnancyinduced hypertension. Epidemiology, 7(4), 346-351.

Larrieux, C., Grigorescu, V., Bouraoui, Y., Miller, K., \& Paterson, D. (2004).The experience of stressful life events in pregnant women. MI PRAMS Delivery, 3(2), 1-4. Family and Community Health, Michigan Department of Community Health.

Liu, C. H., \& Tronick, E. (2013). Re-conceptualising Prenatal life stressors in predicting post-partum depression: Cumulative-, specific-, and domain-specific Approaches to Calculating Risk. Paediatric and Perinatal Epidemiology, 27(5), 481-490.

Liu, C. H., \& Tronick, E. (2013). Rates and predictors of postpartum depression by race and ethnicity: results from the 2004 to 2007 New York City PRAMS survey (Pregnancy Risk Assessment Monitoring System). Maternal and Child Health Journal, 17(9), 15991610. 
Liu, C. H., \& Tronick, E. (2014). Prevalence and predictors of maternal postpartum depressed mood and anhedonia by race and ethnicity. Epidemiology and Psychiatric Sciences, 23(02), 201-209.

Liu, C. H., Giallo, R., Doan, S. N., Seidman, L. J., \& Tronick, E. (2016). Racial and ethnic differences in prenatal life stress and postpartum depression symptoms. Archives of Psychiatric Nursing, 30(1):7-12.

Los Angeles County Department of Public Health, Maternal, Child and Adolescent Health Programs (MCAH), Los Angeles Mommy and Baby Project, 2012 Surveillance Report. Available: http://publichealth.lacounty.gov/mch/lamb/Results/2012Results/2012\%20LAMBSurveill ance.pdf. Accessed July 29, 2015.

Lu, M. C., \& Chen, B. (2004). Racial and ethnic disparities in preterm birth: the role of stressful life events. American Journal of Obstetrics and Gynecology, 191(3), 691-699.

March of Dimes Foundation. (2012). Emotional and life changes. Available from: http://www.marchofdimes.com/pregnancy/stress-and-pregnancy.aspx. Accessed April 23, 2016.

Macintyre, S., Ellaway, A., \& Cummins, S. (2002). Place effects on health: how can we conceptualise, operationalise and measure them? Social Science \& Medicine, 55(1), 125139.

McCue Horwitz, S., Briggs-Gowan, M. J., Storfer-Isser, A., \& Carter, A. S. (2007). Prevalence, correlates, and persistence of maternal depression. Journal of Women's Health, 16(5), 678-691.

Misra, D. P., Guyer, B., \& Allston, A. (2003). Integrated perinatal health framework: A multiple determinants model with a life span approach. American Journal of Preventive Medicine, 25(1), 65-75.

Mulder, E. J. H., De Medina, P. R., Huizink, A. C., Van den Bergh, B. R. H., Buitelaar, J. K., \& Visser, G. H. A. (2002). Prenatal maternal stress: effects on pregnancy and the (unborn) child. Early Human Development, 70(1), 3-14.

Neugebauer, R., Kline, J., Stein, Z., Shrout, P., Warburton, D., \& Susser, M. (1996). Association of stressful life events with chromosomally normal spontaneous abortion. American Journal of Epidemiology, 143(6), 588-596.

Nkansah-Amankra, S., Luchok, K. J., Hussey, J. R., Watkins, K., \& Liu, X. (2010). Effects of maternal stress on low birth weight and preterm birth outcomes across neighborhoods of South Carolina, 2000-2003. Maternal and Child Health Journal, 14(2), 215-226.

Nolen-Hoeksema S. (1990). Sex differences in depression. Stanford University Press. 
Nolen-Hoeksema, S., \& Girgus, J. S. (1994). The emergence of gender differences in depression during adolescence. Psychological Bulletin, 115(3), 424.

Nolen-Hoeksema, S., Larson, J., \& Grayson, C. (1999). Explaining the gender difference in depressive symptoms. Journal of Personality and Social Psychology, 77(5), 1061.

Nolen-Hoeksema, S. (2001). Gender differences in depression. Current Directions in Psychological Science, 10(5), 173-176.

Office of Disease Prevention \& Health Promotion [ODPHP]. (2016). Healthy People 2020 Maternal Infant and Child Health Objectives. Available at https://www.healthypeople.gov/2020/topics-objectives/topic/maternal-infant-and-childhealth/objectives. Accessed on April 23, 2016

O'hara, M. W., \& Swain, A. M. (1996). Rates and risk of postpartum depression-a metaanalysis. International Review of Psychiatry, 8(1), 37-54.

Onoye, J. M., Goebert, D., Morland, L., Matsu, C., \& Wright, T. (2009). PTSD and postpartum mental health in a sample of Caucasian, Asian, and Pacific Islander women. Archives of Women's Mental Health, 12(6), 393-400.

Robertson, E., Grace, S., Wallington, T., \& Stewart, D. E. (2004). Antenatal risk factors for postpartum depression: a synthesis of recent literature. General Hospital Psychiatry, 26(4), 289-295.

Siu, A.L., \& the US Preventive Services Task Force. (2016). Screening for depression in adults: US preventive services task force recommendation statement. JAMA 315 (4): 380387.

Sockol, L. E., Epperson, C. N., \& Barber, J. P. (2013). Preventing postpartum depression: a meta-analytic review. Clinical Psychology Review, 33(8), 1205-1217.

Thoits, P. A. (1995). Stress, coping, and social support processes: Where are we? What next?. Journal of Health and Social Behavior, 53-79.

Turner, R. J., \& Wheaton, B. (1995). Checklist measurement of stressful life events. In S. Cohen, R. C. Kessler \& L. U. Gordon (Eds.), Measuring stress: A guide for health and social scientists (pp. 29-58). New York, New York: Oxford University Press, Inc.

Ussher, J. M. (1992). Women's madness: Misogyny or mental illness? Amherst, Massachusetts: University of Massachusetts Press.

Van den Bergh, B. (1992). Maternal emotions during pregnancy and fetal and neonatal behaviour. Fetal behaviour: Developmental and Perinatal aspects. 1992, 157-178.

Wadhwa, P. D., Culhane, J. F., Rauh, V., \& Barve, S. S. (2001). Stress and preterm birth: neuroendocrine, immune/inflammatory, and vascular mechanisms. Maternal and Child Health Journal, 5(2), 119-125. 
Walsh, D. C., Sorensen, G., \& Leonard, L. (1995). Gender, health, and cigarette smoking. Society and Health, 131-171.

Wagner, B. M., Compas, B. E., \& Howell, D. C. (1988). Daily and major life events: A test of an integrative model of psychosocial stress. American Journal of Community Psychology, 16(2), 189-205.

Whitehead, N., Hill, H. A., Brogan, D. J., \& Blackmore-Prince, C. (2002). Exploration of threshold analysis in the relation between stressful life events and preterm delivery.

American Journal of Epidemiology, 155(2), 117-124.

Yllö, K. (1984). The status of women, marital equality, and violence against wives a contextual analysis. Journal of Family Issues, 5(3), 307-320.

Youash, S., Campbell, K., Avison, W., Peneva, D., Sharma, V., \& Xie, B. (2013). Influence of health information levels on postpartum depression. Archives of Women's Mental Health, 16(6), 489-498.

Zayas, L. H., Cunningham, M., McKee, M. D., \& Jankowski, K. R. (2002). Depression and negative life events among pregnant African-American and Hispanic women.

Women's Health Issues, 12(1), 16-22. 


\section{MANUSCRIPT 1}

Stressful life event experiences of pregnant women in the United States: A latent class analysis

\section{Abstract}

Objectives: Nearly 65-70\% of pregnant women in the United States (U.S.) experience one or more stressful life events (SLEs), which can lead to adverse maternal and/or fetal outcomes. This study aimed to identify groups of women, with similar patterns of antenatal SLE experiences, and to examine their socio-demographic correlates. Methods: Data from 2009-11 Pregnancy Risk Assessment Monitoring System (PRAMS) were used and latent class analysis (LCA) performed $(\mathrm{N}=115,704)$, to identify unobserved class membership. The relative likelihood of membership in each latent class was explored using mutinomial logistic regression. Results: A three-class model was most appropriate, with majority (64\%) in low-stress class. The illness/death related-stress class (13\%) had a high prevalence of illness (77\%) and death (63\%) of a family member/someone close, while those in the multiple-stress $(22 \%)$ class endorsed most other SLEs. Unmarried and lowest-poverty women were respectively more (adjusted odds ratio [aOR]: 2.46; 95\% confidence interval $[\mathrm{CI}]: 2.20,2.74)$ and less likely (aOR: $0.13 ; 95 \% \mathrm{CI}: 0.10,0.16)$ to be in the multiple-stress class. Severe pregnancy-associated nausea/vomiting, preterm labor, and postpartum depression had a markedly higher prevalence in the group experiencing multiple-stress, followed by illness/death and low-stress classes. Conclusions: That 1 out of every 5 and 1 out of every 8 women were in the multiple- and illness/death relatedstress classes respectively suggest that SLEs are common among pregnant women. The 
high prevalence of different stressor types, as well as, the higher likelihood of adverse maternal health outcomes in the multiple-stress class suggests the importance of addressing SLEs as a whole.

Keywords: Stressful life events; pregnancy; PRAMS; latent class analysis; adverse maternal health outcomes

\section{Introduction}

Pregnancy is a major life event, during which women experience a number of stress factors, such as physical and hormonal changes, pregnancy-specific anxiety, concerns related to the fetus, and fear of pain during delivery (Van den Bergh, 1992). Various other experiences can lead to stress during pregnancy, such as negative life events (e.g. divorce, serious illness or death in the family, or losing a job, or homelessness), catastrophic events (e.g. earthquakes, hurricanes or terrorist attacks), long-lasting stress (e.g. financial problems, abuse, chronic health problems) and discrimination or racism (March of Dimes Foundation, 2012). While stress due to both daily-life hassles and major life events can adversely affect pregnancy, major life events usually have a more significant impact (Dunkel Schetter \& Tanner, 2012), especially when multiple such events occur at the same time. Stress during pregnancy has been linked with adverse fetal outcomes, such as spontaneous abortion (Neugebauer et al., 1996), preterm birth, and low birth weight (Copper et al., 1996), and maternal complications, including hypertension (Landsbergis \& Hatch, 1996), nausea and vomiting (Kuo et al. 2010), antenatal depression (Zayas, 2002), and postpartum 
depression (O’hara \& Swain, 1996). Stressful life events during pregnancy might even be associated with impaired mental and motor development of the newborn baby during infancy (Huizink et al., 2003) and psychiatric conditions during childhood, adolescence and adulthood (Beydoun \& Saftlas, 2008).

Nearly $65-70 \%$ of pregnant women in the United States (U.S.) have reported at least one stressful life event during pregnancy (Herrick, 2000; Whitehead et al., 2002); and the prevalence appears to vary by race/ethnicity. An analysis of Pregnancy Risk Assessment Monitoring System (PRAMS) 2000 data from 19 states revealed that the mean number of SLEs experienced during the 12 months before delivery was highest among non-Hispanic black and American Indian/Alaska Native women ( $\mathrm{Lu}$ and Chen, 2004). Burns et al. (2015), in their study using multi-state PRAMS data, reported that the proportion of women experiencing at least one antenatal SLE was the highest among non-Hispanic blacks and the lowest among Asians/Pacific Islanders.

The primary objective of this study was to identify groups of women in the U.S. with similar patterns of stressful life event experiences (SLEs) during pregnancy and to examine the socio-demographic correlates of these groups. We also aimed to compare the prevalence of maternal health outcomes, including hypertensive disorders during pregnancy; severe nausea, vomiting or dehydration; preterm labor and premature rupture of membranes, which are associated with preterm birth; and postpartum depression, between these latent classes. The few studies on maternal antenatal stressors have either clustered the different life events into domains, such as financial, emotional, traumatic, and partner-associated (Nkansah-Amankra et al., 2010; Burns et al., 2015), or counted the 
total number of events experienced (Whitehead et al., 2002). While both of these approaches focus on the events, they do not identify sub-groups of women based on similar life event experiences during pregnancy. Our study aimed to compute unobserved group membership, based on the reported probabilities of stressful life event experiences, using latent class analysis, which has been used to explore the patterns of behavioral health problems, including the patterns of victimization, suicide attempts, and posttraumatic stress disorder (PTSD) among adolescents (Karsberg et al., 2014), adolescent loneliness and psychiatric morbidity (Shevlin et al., 2014), impact of maternal behaviors during pregnancy on birthweight (Petherick et al., 2012), the heterogeneity in trauma profiles among adolescents (McChesney et al., 2015), and the clustering of cancer risk behaviors among college students (Kang et al., 2014). However, this technique has not yet been used to examine SLEs. Studies using population-based multi-state datasets to examine the relationships between antenatal major life events and adverse maternal outcomes have been rare. Identifying latent classes of women and their correlates, based on how various SLEs co-occur during pregnancy, and the relationships of these classes with maternal health outcomes, can inform interventions to prevent such experiences or to mitigate their adverse consequences. 
Methods

Dataset and study subjects

The study used data for the years 2009-11, collected by the PRAMS, which is an ongoing surveillance project of the Centers for Disease Control and Prevention (CDC) and state health departments. Each year, participating states sample 1300 to 3400 women with recent live births, divided among three to six strata, from a sampling frame of eligible birth certificates (CDC, 2013). The sampling frame does not include mothers who give birth outside their state of residence, and those who have multiple birth greater than three (CDC, 2010). The annual sample size ensures that statewide risk factor proportions can be estimated within $3.5 \%$ at $95 \%$ confidence; and within-strata proportions can be estimated within $5 \%$ at $95 \%$ confidence. The sampling, nonresponse, and noncoverage components are multiplied together to yield the analysis weight, which can be interpreted as the number of women like herself in the population that each respondent represents (CDC, 2013). The standardized data collection methodology used in the PRAMS surveillance system enables between-state comparisons and optimal data use for single-state or multi-state analyses. This survey is conducted by mailed questionnaires with telephone follow-ups for the non-respondents, and the responses are linked to extracted birth certificate variables. Mailings start two to four months after delivery (CDC, 2013). Topics addressed in the PRAMS questionnaire include barriers to and content of prenatal care, obstetric history, maternal use of alcohol and cigarettes, physical abuse, contraception, economic status, maternal stress, and early infant development and health status (CDC, 2015). 
Variables

The main variables of interest were antenatal stressful life events. The PRAMS core questionnaire (CDC, 2015) includes 13 questions, which ask about each of the following events that might have happened to a woman during 12 months immediately prior to the birth of her new baby: 1 . A close family member was very sick and had to go to the hospital; 2. She got separated or divorced from her husband or partner; 3 . She moved to a new address; 4. She was homeless; 5 . Her husband/partner lost his job; 6. She lost her job although she wanted to continue working; 7. She argued with her husband/partner more than usual; 8. Her husband/partner did not want her to be pregnant; 9. She had a lot of bills that she could not pay; 10. She was involved in a physical fight; 11. Her husband/partner or she herself went to jail; 12 . Someone very close to her had a problem with drinking or drugs; 13 . Someone very close to her died.

After classifying the women based on their stressful life events (described under data analysis), associations were examined with socio-demographic variables, such as maternal age, race/ethnicity, educational status, marital status, federal poverty level (FPL), and health insurance plan for prenatal care. FPL was computed following the guidelines issued by the U.S. Department of Health \& Human Services (HHS) for the years 2009, 2010 and 2011, using annual household income and number of dependents including the woman herself. Information about health insurance was collected through questions on whether or not the insurance was from each of the following sources: job of herself, her husband/partner, or parents; payment by herself or someone else (but not from job); Medicaid; Tricare or other military health care; and any other. The 
relationships of the latent classes were examined with maternal health outcomes including hypertensive disorders during pregnancy (including pregnancy-induced hypertension, preeclampsia, or toxemia); severe nausea, vomiting, or dehydration during pregnancy; preterm labor; and premature rupture of the membranes, each of which was assessed by a yes/no question. Postpartum depression was assessed by whether a women felt down, depressed or helpless; hopeless; or slowed down, since the birth of her new baby. For each of the three questions, respondents had to choose between the following options: never, rarely, sometimes, often, and always, with corresponding scores of 1 to 5 respectively. Therefore, the total score ranged from 3-15. Based on CDC recommendations, any woman with a score of 10 or higher was considered to have postpartum depressive symptoms. When only two or one question(s) were/was answered, the cut-offs were 7 and 4 respectively (Guidelines for Analyzing Phase 6 Core Depression Question, unpublished report, 2012).

Maternal age, race/ethnicity (computed from individual variables ethnicity and race), education, and marital status were variables obtained from birth certificate. All the stressful events, FPL, insurance status, and the maternal health outcomes were responses to the PRAMS core questions.

Data analysis

There were a total of 116,595 respondents in the PRAMS 2009-11 dataset, of which 891 women had missing data for all thirteen SLE variables. After excluding these 891 women, there were 115,704 respondents. 
First, descriptive statistics were calculated to examine the prevalence of each SLE. SAS procedures that account for survey design (Proc Survey) were employed to adjust for the analysis weights and sampling design.

Based on women's responses to the thirteen stressful life events during pregnancy, a latent class analysis (LCA) was performed to identify subgroups of women based on their similar SLE experiences. LCA is a statistical method to identify unobserved class membership among subjects based on observed variables, using an exploratory and iterative model building technique (Hagenaars and McCutcheon, 2002). We began with a 2-class model and then increased the number of classes one at a time to six. To determine the optimum number of classes, posterior probabilities of membership to specific latent classes were determined by simultaneously estimating prevalence of each class (class probabilities), and the probabilities of endorsing specific items (item probabilities) (Hagenaars and McCutcheon, 2002). In addition to considerations of parsimony and substantive meaning, various fit indices, including Akaike Information Criteria (AIC) (Akaike, 1987), Bayesian Information Criteria (BIC) (Schwarz, 1978), and sample size adjusted BIC (ssaBIC) (Sclove, 1987) were used to determine the optimal model. The smaller values of these indices suggest better fit. Entropy value (Celeux and Soromenho, 1996) and the Lo-Mendell-Rubin adjusted likelihood ratio test (LRT) (Lo et al., 2001) were also considered. Entropy values closer to 1 indicate clearer classification, whereas a non-significant LRT suggest that a latent class model with one less class was the more parsimonious option. 
After the optimal number of classes was determined, frequencies of the 13 stressful events across and within classes were examined. Chi-square tests of independence were used to assess the distribution of these classes with maternal sociodemographic variables, including age, race/ethnicity, education, marital status, FPL and source(s) of health insurance. Women were also categorized into those who experienced at least one event during pregnancy, and those who experienced none. Sociodemographic correlates of experiencing at least one event were examined. Mean number of events was compared between the socio-demographic groups.

SAS $^{\circledR} 9.4$ software (SAS Institute, Cary, NC) and Mplus software (Muthen and Muthen, 1998-2012) were used. In Mplus, the "auxiliary" option was used with "type=mixture" to identify covariates of the categorical latent variable that are important predictors of the latent classes, using a three-step approach (r3step) (Vermunt, 2010; Asparouhov and Muthen, 2014). Latent class membership included all the 115,704 observations with at least one indicator value; that is, if a woman had a valid response to even one of the thirteen stressful life event questions. The default "type=missing" option in Mplus used the full information maximum likelihood (FIML) method to estimate the LCA model. As a part of the 3-step process, mutinomial logistic regression was performed to explore the relative likelihood of being a member of each latent class, with respect to a baseline class. Age group, race/ethnicity, educational status, income category and marital status were covariates in the logistic regression model. The distribution of maternal health outcomes were compared between the latent classes. For multinomial logistic regression, the women with non-missing data for all the covariates $(\mathrm{N}=98,567)$ were used. In order to adjust for analysis weights and sampling design, "type=complex" 
option was used. While examining the relationship between latent classes and the maternal health outcomes, those with valid responses to the outcome of interest, as well as the latent classes, were included in the analyses.

\section{Results}

Among the 115,704 women, the most commonly experienced SLE during pregnancy was reported to be moving to a new address (33\%) (table 1). Involvement in a physical fight (3.7\%) and homelessness (3.9\%) were the least frequent antenatal stressors. A comparison between the fit indices for the two to six class LCA models (table 2) shows that the $\mathrm{AIC}, \mathrm{BIC}$ and ssaBIC values progressively decrease with increasing number of classes. The LRT value becomes statistically significant $(\mathrm{p}<0.0001)$ for the three vs two class model. The entropy value is the highest $(0.73)$ for the two-class model. Taking all the fit indices into consideration and based on the interpretation of the three-class model vs. the two and four-class models, the three-class model was chosen as the most preferred. The latent class profile plot is shown in Fig. 1.

Twenty two percent of the sample was in class 1 (figure 1), and they had the highest rates of endorsing each of the antenatal stressful events, with the exception of the illness and death related stressors. Having more than usual arguments with husband/partner (66\%), moving to a new address (59\%), and having a lot of bills that could not be paid (60\%), had a particularly high prevalence in this class, which will henceforth be referred to as the multiple-stress class. Class $2(13 \%)$ had high rates of endorsing sickness and hospitalization of a family member (77\%) and death of someone 
very close $(63 \%)$, with relatively low endorsement rates for other SLEs. We labeled class 2 as the illness/death related-stress class. The majority (64\%) of women were categorized into class 3 (figure 1); respondents in this class had the lowest probabilities of endorsing each of the stressful events, except separation/divorce and homelessness, which had a slightly higher prevalence in class 3 , compared with class 2 . Class 3 can therefore be considered as the low-stress class.

The mean number of stressful events, the proportion of women who experienced one or more stressful events, and the distribution of women into the three classes varied by socio-demographic characteristics (table 3). Compared with older women, a higher proportion of less than 25-year olds were in the multiple-stress class. More than $30 \%$ of non-Hispanic black and American Indians/Alaska Natives, compared to 18\% of nonHispanic whites and less than $10 \%$ of Asians/Pacific Islanders belonged to the multiplestress class. Membership in multiple-stress class decreased with decreasing poverty levels. Nearly $36 \%$ of unmarried respondents were categorized in the multiple-stress class, compared with only $12 \%$ of those married. More than one-thirds of women whose health insurance plan for prenatal care was paid through Medicaid belonged to the multiple-stress class, compared with $11 \%$ whose insurance was paid from the work of herself, her husband/partner, or her parents. The proportion of respondents in the illness/death-related stress class was slightly higher among women in the lowest poverty, compared with those living in highest poverty

Multinomial multivariable logistic regression results (table 4) show that after adjusting for other socio-demographic correlates, women in the lower poverty groups had 
lower odds of being in the multiple-stress class. Hispanics (aOR: 0.70; 95\% CI: 0.59, 0.82) and Asians/Pacific Islanders (aOR: 0.40; 95\% CI: 0.31, 0.52) had significantly lower odds, than the non-Hispanic whites, of being in the multiple-stress class. Unmarried women were nearly 2.5 times (aOR: 2.46 ; 95\% CI: 2.20, 2.74) as likely as those married to be a member of multiple-stress class. Compared with non-Hispanic whites, Hispanics (aOR: 0.62; 95\% CI: 0.49, 0.79) and Asians/Pacific Islanders (aOR: 0.39; 95\% CI: 0.32, 0.48) were less likely, and American Indians/Alaska Natives were more likely (aOR: 1.57 ; $95 \%$ CI: $1.20,2.07)$ to be in the illness/death related-stress class. Women whose prenatal health care insurance was through Medicaid, had significantly higher adjusted odds of being in the multiple- and illness/death related-stress classes, compared with those whose insurance plans was not through Medicaid.

The influence of the interaction of maternal race/ethnicity with FPL categories on the average number of SLEs experienced was also tested, and the results were statistically significant $(\mathrm{p}<0.0001$; results not shown in table). The mean number of stressors was lower in the lowest poverty, than the highest poverty category for all the racial/ethnic groups, but the patterns varied (table 5). While the mean number of stressors experienced by non-Hispanic whites decreased uniformly with decreasing poverty levels, nonHispanic blacks and Hispanics had a far more non-uniform and gradual decrease, except between the $301-400 \%$ and $\geq 401 \%$ FPL categories.

Figure 2 shows the distribution of the maternal health outcomes according to latent classes. For each of the outcomes, the prevalence was the lowest among women in the low-stress class, and the highest among women in the multiple-stress class. Although 
the chi-square tests of independence were statistically significant for all the outcomes, the differences were most striking for severe nausea, vomiting or dehydration during pregnancy; preterm labor; and postpartum depression.

\section{Discussion}

Nearly $70 \%$ of respondents in the PRAMS 2009-11 survey reported having experienced at least one stressful life event during the year prior to their most recent childbirth (not shown in table), which is similar to previous findings (Herrick, 2000; Whitehead et al., 2002). As observed by Lu \& Chen (2004), we found that the mean number of events experienced during the 12 months before childbirth was significantly higher among non-Hispanic blacks (2.3) and American Indians/Alaska Natives (2.5), compared to non-Hispanic whites (1.7). In our study, the prevalence of the different antenatal stressful events ranged from $4 \%$ to $33 \%$, which is comparable with the prevalence reported in a study on 2007-2010 PRAMS data from the state of Massachusetts (Stone et al., 2015). However, there are also some interesting differences; for example, the proportion $(3.7 \%)$ of women who were involved in a physical fight in the nationwide PRAMS 2009-2011 sample was nearly twice that (2.0\%) of those in the Massachusetts PRAMS 2007-2010 (Stone et al., 2015). State-wise differences in the prevalence of specific SLEs might account for that; in the PRAMS 2009-2011 dataset, the proportion of respondents involved in a physical fight, ranged from around $2 \%$ in Massachusetts, Utah and Wyoming, to 5.5\% in Arkansas, and 7.2\% in Mississippi.

Principal component analyses performed by Ahluwalia et al. grouped the thirteen stressful events into partner-related (more than usual arguments with husband/partner; 
separation/divorce; partner not wanting the pregnancy), traumatic (involvement in a physical fight; the woman/partner going to jail; homelessness; drug/alcohol problem of someone very close), financial (moving to new address; having a lot of bills and unable to pay; loss of job of husband/partner; loss of job of the woman) and emotional (sickness of family member; death of someone close) stressors. Classification of antenatal SLEs into these four domains has been used in multiple studies (Burns et al., 2015; Brett et al., 2008; Stone et al., 2015). Instead of following this variable-centered approach, we used the latent class analysis method, which is respondent-centered (Muthén and Muthén, 2000). Although both of these approaches are data-driven, using LCA resulted in the classification of women into mutually exclusive categories, thereby enabling a comparison of the risk profiles between these categories and focus on the holistic experiences of the women. In contrast, one woman could have experienced more than one stress domain derived from the traditional approach. A comparison of the traditionally used stressor clusters with the stressors experienced by women in each latent class from our analyses (fig 1), revealed that women of the multiple-stress class had a high prevalence of stressors belonging to different categories. In other words, those who experience the so-called traumatic stressors, are not necessarily less vulnerable to the partner-related or financial ones. This suggests that any intervention that is directed towards prevention of or mitigation of the adverse consequences of one type of stressor might be insufficient. Rather, stressors need to be addressed as a whole.

Based on nationwide PRAMS data of the year 2010, the lowest prevalence of all SLE constructs (women experiencing at least one event of a particular category was defined as experiencing the construct) was among women who were married, were aged 
30 years or more, had 16 years of education or higher, and were Asians/Pacific Islanders (Burns et al., 2015). Somewhat similar trends were observed in our analysis. Seventy one percent to $79 \%$ of women in the above 25 -year age groups were classified in the lowstress group, compared with $56 \%$ to $61 \%$ of younger women. Eighty five percent of Asians/Pacific Islanders were classified in the low-stress category, compared with $71 \%$ of non-Hispanic whites, 59\% of non-Hispanic blacks and 55\% of American Indians/Alaska Natives. Among married women, $78 \%$ were grouped into the low-stress class, compared with $56 \%$ of unmarried. Previous research has shown a positive association between being married and having better health status, which has been hypothesized to be due to the protective effects of care and support and selection factors (i.e. individuals with good health have higher probability of getting married) (Schoenborn, 2004; Verbrugge, 1979; Hu and Goldman, 1990).

An analysis of nationwide PRAMS 2000 data (Lu and Chen, 2004), which adjusted for age, education and marital status, but not income, found that non-Hispanic blacks and Hispanics had a higher likelihood of experiencing different kinds of stress. In the current study, Asians/Pacific Islanders were less likely to be in the multiple-stress class both with and without adjusting for covariates. A greater degree of social and family support may account for this. A matter of concern, and something which future research should try to address, is whether the low likelihood of Asians/Pacific Islanders to be in the multiple-stress class is attributable to an under-reporting of SLEs, especially those that were partner-related, including having more than usual arguments, partner's non-intention towards the pregnancy, and physical fight, as suggested by some prior research. For example, an analysis of data collected from Asian American participants in 
the National Latino and Asian American Study (NLAAS) found that a higher proportion of men admitted perpetrating physical violence than women reporting to be a victim (Chang et al., 2009). It is interesting to note that while the unadjusted prevalence of being in the multiple-stress class was higher among Hispanics compared to non-Hispanic whites, the direction of association reversed after controlling for covariates, which might suggest that income disparities accounted for much of the unadjusted racial/ethnic disparities in women's membership into the multiple-stress class. This is supported by the finding that even after adjusting for other covariates, there is an increasing likelihood of membership in the multiple-stress class with increasing poverty. The role of income is not surprising because financial stressors, which were likely to be directly correlated with income, were highly prevalent in the mutiple-stress class. Our findings are similar to Whitehead et al. (2002) who reported that women of lower SES had a higher likelihood of experiencing life events just before or during pregnancy. The association of low SES with higher levels of different forms of stress has previously been noted (Dunkel Schetter et al., 2013). Our observation that the decrease in mean number of stressful events by FPL was greater and more uniform among the non-Hispanic whites, than among the nonHispanic blacks and Hispanics is comparable with that of Dunkel Schetter et al. (2013), who reported that higher income was more strongly associated with lower levels of major life events for non-Hispanic whites compared with non-Hispanic blacks and Hispanics .This suggests that additional unmeasured factors, such as discrimination, that affect the non-Hispanic whites to a lesser extent, can override the influence of income on SLEs among non-Hispanic blacks and Hispanics. Although we lacked information to account for experiences of discrimination or racism, it is interesting that women receiving health 
insurance through Medicaid were approximately 1.5 times as likely to be in the multiple-, and the illness/death related-stress classes, even after adjusting for other characteristics, including the poverty levels. Future research needs to explore whether this can be attributed to a higher degree of perceived or experienced racial discrimination among Medicaid recipients. Including a discrimination related question for all the participating PRAMS states will facilitate this research.

The limited research on the impact of maternal antenatal stressful events has mostly focused on the relationship between these events and postpartum depression (Stone et al., 2015; Liu et al., 2016), although none of these studies subdivided women into mutually exclusive groups based on their similar SLE experiences. Our results suggest that the prevalence of severe nausea, vomiting and dehydration; preterm labor, as well as, postpartum depression were the highest in the multiple-stress group. A retrospective cohort study in Israel reported that life-threatening stressful events, in the form of daily missile attacks continuing for a protracted period, was associated with preterm deliveries and premature rupture of membranes (Keren et al., 2015). Although the stressors examined in our study were different from that investigated by Keren et al., we observed that women in the multiple-, as well as the illness/death related-stress classes, were more likely to experience preterm labor and premature rupture of membranes, with the differences being particularly substantial for preterm labor. A U.S. study found that 15-19 year old women who had experienced pre-conception SLEs, had a four times risk of having preterm birth (Witt et al. 2014), and this effect diminished with increasing age. This, together with our finding, suggests that pre-conceptional and antepartum stressors are associated with preterm birth. While we were unable to find 
previous research that have focused specifically on the association between major life events and severe nausea/vomiting of pregnancy, it is not difficult to imagine that women experiencing various SLEs are more likely to be in psychological distress, which has been hypothesized to be in the causal pathway of hyperemesis gravidarum (Tan et al., 2014).

This study has a number of limitations. The questions on antenatal SLE ask about the 12 months before the birth of the new baby, so a woman might have reported an event that occurred during the year before childbirth, but within the 2-3 months before she got pregnant. Not all states participate in PRAMS, and even among the ones that do, data are released only for states meeting the $65 \%$ threshold response rate. We had data from 31 states and New York City. Hence, our results may not be generalizable to women in the entire U.S. Also, our results are not directly comparable with previous studies that have looked at antenatal SLE experiences, because our focus was on the groups of women experiencing similar SLEs, whereas in most studies the emphasis has been on the correlates of SLE clusters. The cross-sectional nature of our analysis precludes any causal inference. Lastly, it should be kept in mind that a stressful event, such as moving to a new address might not necessarily be a negative or an undesirable event for the woman.

This study used recent data from a nationwide representative sample of women. To our knowledge, this is the first study using an LCA approach to explore how women with similar SLE experiences are grouped together, and differentiated from other such groups. This study has important public health implications. The results of our study, as well as the traditionally used SLE clusters, provide valuable, complementary, and 
different insights into pregnant women's SLE experiences. While the commonly used principal component analysis focuses on the stressors, the latent class analysis used in this study shows the severity of the problem from the women's perspective. Our results suggest that women may be vulnerable to experiencing multiple types of SLEs, which need to be addressed as a whole. Being in the multiple-stress class appears to be common - with more than one out of every five women being in this class. Women who were unmarried, younger, and were in higher poverty, were particularly vulnerable. Even women with lower levels of risk factors for mutiple-stress can still be at a risk for illness/death related stress. A higher likelihood of being categorized in the multiple- and illness/death related-stress classes among the Medicaid insured, coupled with a race/ethnicity-based differential decrease in the average number of antenatal stressful events with decreasing poverty, points towards a potential role of perceived discrimination, overriding the benefits of health insurance and higher income, an aspect that caregivers need to be mindful of. The progressively increasing proportion of women experiencing severe nausea/vomiting; preterm labor; and postpartum depression from the low-, to the illness/death related-, to the multiple-stress classes suggest the importance of an antenatal care-giver being vigilant about the antenatal stressful life event experiences of their patients; and recommending the multiple-stress group for comprehensive psychological care and support if necessary, in order to mitigate the adverse outcomes. Our results also indicate that not only should these stressful events be explored during routine prenatal care, but the relative vulnerabilities of racial/ethnic groups should be taken into consideration. 


\section{Conclusions}

That 1 out of every 5 and 1 out of every 8 women were in the high- and emotional-stress classes suggest that SLEs are common among pregnant women. Together with a growing emphasis on the screening for perinatal mental health issues, knowledge of antenatal stressors and the relative vulnerabilities of different racial/ethnic groups might be highly effective in identifying women at-risk of experiencing perinatal stressors, and increase their chances of getting the necessary support and intervention, thereby preventing adverse maternal and infant health consequences, such as preterm birth, low birth weight and postpartum depression.

\section{References}

Ahluwalia, I., Merritt, R., Beck L, \& Rogers, M. (2001). Multiple lifestyle and psychosocial risks and delivery of small for gestational age infants. Obstetrics \& Gynecology, 97(5), 649-656.

Akaike, H. (1987). Factor analysis and AIC. Psychometrika, 52(3): 317-332.

Asparouhov, T., \& Muthén, B. (2015). Auxiliary Variables in Mixture Modeling: Using the BCH Method in Mplus to Estimate a Distal Outcome Model and an Arbitrary Secondary Model. Mplus Web Notes: No. 21 Version 2 Available: https://www.statmodel.com/examples/webnotes/webnote21.pdf. Accessed December 18, 2015.

Beydoun, H., \& Saftlas, A. F. (2008). Physical and mental health outcomes of prenatal maternal stress in human and animal studies: A review of recent evidence. Paediatric and Perinatal Epidemiology, 22(5), 438-466.

Brett, K., Barfield, W., \& Williams, C. (2008). Prevalence of self-reported postpartum depressive symptoms--17 states, 2004-2005. MMWR. Morbidity and Mortality Weekly Report, 57(14), 361. 
Burns, E.R., Farr, S.L., \& Howards, P.P. (2015). Stressful Life Events Experienced by Women in the Year Before Their Infants' Births — United States, 2000-2010. MMWR. Morbidity and Mortality Weekly Report, 64(9), 247-251.

Centers for Disease Control and Prevention. (2010). CDC PRAMS Guidelines For Proposals To Conducting Multi-State Analyses. Available http://www.cdc.gov/prams/pdf/pramsproposal_guidelines_2010.pdf. Accessed March 16, 2016.

Centers for Disease Control and Prevention. (2013). PRAMS Methodology. Available: http://www.cdc.gov/prams/methodology.htm. Accessed September 21, 2015.

Centers for Disease Control and Prevention. (2015) PRAMS questionnaires. Available: http://www.cdc.gov/prams/Questionnaire.htm. Accessed July 29, 2015.

Celeux, G., \& Soromenho, G. (1996). An entropy criterion for assessing the number of clusters in a mixture model. Journal of Classification, 13(2), 195-212.

Chang, D. F., Shen, B.-J., \& Takeuchi, D. T. (2009). Prevalence and demographic correlates of intimate partner violence in Asian Americans. International Journal of Law and Psychiatry, 32(3), 167-175.

Copper, R.L., Goldenberg, R.L., Das, A,, Elder, N,, Swain, M., Norman, G., ...\& Jones, P. (1996). The preterm prediction study: Maternal stress is associated with spontaneous preterm birth at less than thirty-five weeks' gestation. Obstetrics \& Gynecology, 175(5), 1286-1292.

Dunkel Schetter, C., Schafer, P., Lanzi, R.G., Clark-Kauffman, E., Raju, T.N., \& Hillemeier M.M. (2013). Shedding light on the mechanisms underlying health disparities through community participatory methods: The stress pathway. Perspectives on Psychological Science, 8(6), 613-633.

Dunkel Schetter, C., \& Tanner, L. (2012). Anxiety, depression and stress in pregnancy: Implications for mothers, children, research, and practice. Current Opinion in Psychiatry, 25(2), 141-148.

Hagenaars, J.A., \& McCutcheon, A.L. (Eds.). (2002). Applied Latent Class Analysis. New York, New York: Cambridge University Press.

Herrick, H.W.B. (2000). The effect of stressful life events on postpartum depression results from the 1997-1998 North Carolina Pregnancy Risk Assessment Monitoring System (PRAMS). SCHS Studies 121. Available: http://www.schs.state.nc.us/SCHS/pdf/SCHS121.pdf. Accessed December 18, 2015. 
Hu, Y., \& Goldman, N. (1990). Mortality differentials by marital status: An international comparison. Demography, 27(2), 233-250.

Huizink, A. C., Robles de Medina, P. G., Mulder, E. J., Visser, G. H., \& Buitelaar, J. K. (2003). Stress during pregnancy is associated with developmental outcome in infancy. Journal of Child Psychology and Psychiatry, 44(6), 810-818.

Kang, J., Ciecierski, C. C., Malin, E. L., Carroll, A. J., Gidea, M., Craft, L. L., ... \& Hitsman, B. (2014). A latent class analysis of cancer risk behaviors among US college students. Preventive Medicine, 64, 121-125.

Karsberg, S., Armour, C., \& Elklit, A. (2014). Patterns of victimization, suicide attempt, and posttraumatic stress disorder in Greenlandic adolescents: a latent class analysis. Social Psychiatry and Psychiatric Epidemiology, 49(9), 1389-1399.

Keren, M., Keren, N., Eden, A., Tsangen, S., Weizman, A., \& Zalsman, G. (2015). The complex impact of five years of stress related to life-threatening events on pregnancy outcomes: A preliminary retrospective study. European Psychiatry, 30(2), 317-321.

Kuo, S. H., Yang, Y. H., Wang, R. H., Chan, T. F., \& Chou, F. H. (2010). Relationships between leptin, HCG, cortisol, and psychosocial stress and nausea and vomiting throughout pregnancy. Biological Research for Nursing, 12(1), 20-27.

Landsbergis, P. A., \& Hatch, M. C. (1996). Psychosocial work stress and pregnancyinduced hypertension. Epidemiology, 7(4), 346-351.

Liu, C. H., Giallo, R., Doan, S. N., Seidman, L. J., \& Tronick, E. (2016). Racial and ethnic differences in prenatal life stress and postpartum depression symptoms. Archives of Psychiatric Nursing, 30 (2016), 7-12.

Lo, Y., Mendell, N. R., \& Rubin, D. B. (2001). Testing the number of components in a normal mixture. Biometrika, 88(3), 767-778.

Los Angeles County Department of Public Health, Maternal, Child and Adolescent Health Programs (MCAH), Los Angeles Mommy and Baby Project, 2012 Surveillance Report. Available: http://publichealth.lacounty.gov/mch/lamb/Results/2012Results/2012\%20LAMBSurveill ance.pdf. Accessed July 29, 2015.

Lu, M. C., \& Chen, B. (2004). Racial and ethnic disparities in preterm birth: the role of stressful life events. American Journal of Obstetrics and Gynecology, 191(3), 691-699.

March of Dimes Foundation (2012) Emotional and life changes [Internet]. Available: http://www.marchofdimes.com/pregnancy/stress-and-pregnancy.aspx. Accessed December 1, 2015. 
McChesney, G. C., Adamson, G., \& Shevlin, M. (2015). A latent class analysis of trauma based on a nationally representative sample of US adolescents. Social Psychiatry \& Psychiatric Epidemiology, 50(8), 1207-1217.

Muthén, L. K, \& Muthén, B. O. (1998-2012). Mplus User's Guide. (7th ed.). Los Angeles, CA: Muthén \& Muthén.

Muthén, B., \& Muthén, L. K. (2000). Integrating person-centered and variable-centered analyses: Growth mixture modeling with latent trajectory classes. Alcoholism: Clinical and Experimental Research, 24(6), 882-891.

Neugebauer, R., Kline, J., Stein, Z., Shrout, P., Warburton, D., \& Susser, M. (1996). Association of stressful life events with chromosomally normal spontaneous abortion. American Journal of Epidemiology, 143(6), 588-596.

Nkansah-Amankra, S., Luchok, K. J., Hussey, J. R., Watkins, K., \& Liu, X. (2010). Effects of maternal stress on low birth weight and preterm birth outcomes across neighborhoods of South Carolina, 2000-2003. Maternal and Child Health Journal, 14(2), 215-226.

O'hara, M. W., \& Swain, A. M. (1996). Rates and risk of postpartum depression-a metaanalysis. International Review of Psychiatry, 8(1), 37-54.

Petherick, E. S., Parslow, R., McKinney, P., Fairley, L., Tuffnell, D., Pickett, K. E., ...\& Wright, J. (2012). Health effect of multiple behaviours during pregnancy on birthweight: A latent class analysis of the born in Bradford cohort. The Lancet, 380, S64.

Schoenborn, C. A. (2004). Marital status and health, United States 1999-2002. Advance data from vital and health statistics; no 351. Hyattsville, Maryland: National Center for Health Statistics.

Schwarz, G. (1978). Estimating the dimension of a model. The Annals of Statistics, 6(2), 461-464.

Sclove, S. L. (1987). Application of model-selection criteria to some problems in multivariate analysis. Psychometrika, 52(3), 333-343.

Shevlin, M., Murphy, S., \& Murphy, J. (2014). Adolescent loneliness and psychiatric morbidity in the general population: Identifying "at risk" groups using latent class analysis. Nordic Journal of Psychiatry, 68(8), 633-639.

Stone, S. L., Diop, H., Declercq, E., Cabral, H. J., Fox, M. P., \& Wise, L. A. (2015). Stressful events during pregnancy and postpartum depressive symptoms. Journal of Women's Health, 24(5), 384-393. 
Tan, P. C., Zaidi, S. N., Azmi, N., Omar, S. Z., \& Khong, S. Y. (2014). Depression, anxiety, stress and hyperemesis gravidarum: temporal and case controlled correlates. PloS one, 9(3), e92036.

Van den Bergh, B. (1992). Maternal emotions during pregnancy and fetal and neonatal behaviour. In J.G. Nijhuis (Ed.), Fetal behaviour: Developmental and Perinatal Aspects (pp. 157-178). New York, New York: Oxford University Press.

Verbrugge, L. M. (1979). Marital status and health. Journal of Marriage and the Family, 41, 267-285.

Vermunt, J. K. (2010). Latent Class Modeling with Covariates: Two Improved ThreeStep Approaches. Political Analysis, 18, 450-469.

Whitehead, N., Hill, H. A., Brogan, D. J., \& Blackmore-Prince, C. (2002). Exploration of threshold analysis in the relation between stressful life events and preterm delivery.

American Journal of Epidemiology, 155(2), 117-124.

Zayas, L. H., Cunningham, M., McKee, M. D., \& Jankowski, K. R. (2002). Depression and negative life events among pregnant African-American and Hispanic women.

Women's Health Issues, 12(1), 16-22. 
Tables and Figures

Table 1 Descriptive statistics of the stressful life event (SLE) experiences during the 12 months prior to birth of new baby $\left(\mathrm{N}=115,704^{\mathrm{a}}\right.$ ) among women in the U.S. who have had a recent live birth (PRAMS, 2009-11)

\begin{tabular}{lcc}
\hline Stressful life event (SLE) item & $\begin{array}{c}\text { Experienced during the 12 months prior } \\
\text { to birth of new baby }\end{array}$ \\
\cline { 2 - 2 } & $\begin{array}{c}\text { Yes }(\%)^{\mathrm{b}} \\
\text { No }(\%)^{\mathrm{b}}\end{array}$ \\
\hline 1. She moved to a new address & $39,601(33.1)$ & $75,848(66.9)$ \\
2. She argued with her husband or partner more than usual & $28,530(24.0)$ & $86,660(76.0)$ \\
3. A close family member was very sick and had to go into the & $26,727(22.5)$ & $88,561(77.5)$ \\
hospital & & $88,740(78.1)$ \\
4. She had a lot of bills she couldn't pay & $26,456(21.9)$ & $94,732(83.1)$ \\
5. Someone very close to her died & $20,550(16.9)$ & $98,580(85.7)$ \\
6. Her husband or partner lost his job & $16,396(14.3)$ & $99,858(87.8)$ \\
7. Someone very close to her had a problem with drinking or drugs & $15,473(12.2)$ & $102,015(88.8)$ \\
8. She lost her job even though she wanted to go on working & $12,867(11.2)$ & $105,729(92.0)$ \\
9. Her husband or partner said he didn't want her to be pregnant & $9,488(8.0)$ & $105,694(92.1)$ \\
10. She got separated or divorced from her husband or partner & $9,640(7.9)$ & $109,845(95.9)$ \\
11. Her husband or partner or she went to jail & $5,420(4.1)$ & $110,610(96.1)$ \\
12. She was homeless & $4,524(3.9)$ & $110,477(96.3)$ \\
13. She was in a physical fight & $4,758(3.7)$ & \\
\hline
\end{tabular}

a: Missing values (\%) for the SLE items: 1: $255(0.2) ; 2: 514(0.4) ; 3: 416(0.4) ; 4: 373(0.3) ; 5: 422(0.4) ; 6: 728(0.6) ; 7: 373(0.3)$; 8: 822 (0.7); 9: $487(0.4) ; 10: 370(0.3) ; 11: 439(0.4) ; 12: 570(0.5) ; 13: 469(0.4)$

b: Weighted percentages out of the total number of women who responded to that particular item 
Table 2: Fit indices for latent class analysis of the antenatal stressful life event (SLE) items among women in the U.S. who have had a recent live birth (PRAMS, 2009-11)

\begin{tabular}{lllllll}
\hline & Log likelihood & AIC & BIC & ssaBIC & LRT & Entropy \\
\hline 2-class & $-524,092.711$ & $1,048,239.422$ & $1,048,500.209$ & $1,048,414.402$ & $75,667.874$ & 0.732 \\
$P$ & & & & & 0.3290 \\
3-class & $-518,376.855$ & $1,036,835.711$ & $1,037,231.721$ & $1,037,101.422$ & $\begin{array}{l}11,362.100 \\
<0.0001\end{array}$ & 0.711 \\
$P$ & & & & & $6,801.884$ & 0.657 \\
4-class & $-514,955.077$ & $1,030,020.155$ & $1,030,551.388$ & $1,030,376.596$ & 0.1234 \\
$P$ & & & & & $3,277.291$ & 0.672 \\
5-class & $-513,306.392$ & $1,026,750.785$ & $1,027,417.241$ & $1,027,197.957$ & 0.2645 & \\
$P$ & & & & & 0.727 .310 & 0.663 \\
6-class & $-512,437.446$ & $1,025,040.893$ & $1,025,842.572$ & $1,025,578.795$ & 0.5620 \\
$P$ & & & & & & \\
\hline
\end{tabular}

AIC: Akaike Information Criterion; BIC: Bayesian Information Criterion; ssaBIC: sample size adjusted Bayesian Information Criterion; LRT: Lo-Mendell-Rubin likelihood ratio test; BS-LRT: Bootstrap likelihood ratio test 
Table 3: Distribution of stressful life-events and the latent classes of stressful life-events among women in the U.S., who have had a recent live birth (PRAMS, 2009-11), by socio-demographic correlates $(\mathrm{N}=115,704)^{\mathrm{a}}$

\begin{tabular}{|c|c|c|c|c|c|c|}
\hline \multirow[t]{2}{*}{ Variables } & \multirow[b]{2}{*}{ Total $(\%)^{\mathrm{b}}$} & \multicolumn{5}{|c|}{ Antenatal stressful life-events (SLEs) } \\
\hline & & $\begin{array}{c}\text { Mean no. of } \\
\text { SLE (SE) }\end{array}$ & $\begin{array}{c}\geq 1 \mathrm{SLE} \\
\%(95 \% \mathrm{CI})^{\mathrm{c}}\end{array}$ & $\begin{array}{c}\text { Class 1 } \\
\text { Multiplestress } \\
\%(95 \% \mathrm{CI})^{\mathrm{d}}\end{array}$ & $\begin{array}{c}\text { Class } 2 \text { llness/death } \\
\text { related-stress } \\
\%(95 \% \mathrm{CI})^{\mathrm{d}}\end{array}$ & $\begin{array}{c}\text { Class } 3 \\
\text { Low-stress } \\
\%(95 \% \mathrm{CI})^{\mathrm{d}}\end{array}$ \\
\hline \multicolumn{7}{|l|}{ Age in years ${ }^{\mathrm{e}}$} \\
\hline Less than 17 & $3,262(2.9)$ & $2.05(0.08)$ & $78.6(75.8,81.4)$ & $28.0(25.0,30.9)$ & $11.2(9.1,13.3)$ & $60.9(57.6,64.1)$ \\
\hline 18-19 & $7,423(6.3)$ & $2.47(0.05)$ & $80.1(78.3,81.9)$ & $34.1(32.1,36.2)$ & $9.5(8.3,10.7)$ & $56.3(54.2,58.4)$ \\
\hline $20-24$ & $26,751(22.7)$ & $2.41(0.03)$ & $81.0(80.1,81.9)$ & $33.2(32.1,34.2)$ & $9.0(8.4,9.6)$ & $57.8(56.7,58.9)$ \\
\hline $25-29$ & $32,676(29.0)$ & $1.69(0.02)$ & $69.4(68.5,70.3)$ & $19.8(19.0,20.6)$ & $8.8(8.3,9.3)$ & $71.4(70.6,72.3)$ \\
\hline $30-34$ & $27,623(24.9)$ & $1.39(0.02)$ & $63.4(62.4,64.3)$ & $13.9(13.2,14.6)$ & $9.5(9.0,10.1)$ & $76.6(75.7,77.4)$ \\
\hline $35-39$ & $14,270(11.4)$ & $1.23(0.02)$ & $60.9(59.5,62.2)$ & $12.2(11.3,13.2)$ & $8.9(8.1,9.7)$ & $78.9(77.7,80.0)$ \\
\hline 40 and above & $3,693(2.8)$ & $1.33(0.06)$ & $61.3(58.4,64.2)$ & $14.0(12.0,15.9)$ & $8.8(7.0,10.5)$ & $77.2(74.8,79.7)$ \\
\hline \multicolumn{7}{|l|}{ Maternal race/ethnicity ${ }^{\mathrm{e}}$} \\
\hline Non-Hispanic white & $58,355(58.3)$ & $1.69(0.01)$ & $68.6(68.0,69.2)$ & $18.4(17.9,18.9)$ & $10.4(10.0,10.8)$ & $71.2(70.6,71.7)$ \\
\hline Non-Hispanic black & $17,351(13.5)$ & $2.29(0.03)$ & $76.9(75.7,78.0)$ & $31.9(30.7,33.1)$ & $8.8(8.1,9.5)$ & $59.3(58.1,60.6)$ \\
\hline Hispanic & $17,204(20.2)$ & $1.80(0.03)$ & $73.5(72.2,74.8)$ & $25.2(23.9,26.5)$ & $6.4(5.7,7.1)$ & $68.4(67.0,70.0)$ \\
\hline Asian/Pacific & $9,333(4.9)$ & $1.03(0.03)$ & $55.9(54.1,57.7)$ & $9.6(8.6,10.6)$ & $5.3(4.5,6.1)$ & $85.1(83.8,86.4)$ \\
\hline \multicolumn{7}{|l|}{ Islander } \\
\hline American-Indian or & $3,543(0.8)$ & $2.51(0.07)$ & $78.9(75.7,82.0)$ & $32.6(29.4,35.9)$ & $12.3(10.0,14.5)$ & $55.1(51.6,58.6)$ \\
\hline \multicolumn{7}{|l|}{ Alaska Native } \\
\hline Non-Hispanic other & $920(0.8)$ & $1.39(0.11)$ & $64.3(59.0,70.0)$ & $15.2(11.0,19.4)$ & $6.4(4.0,8.9)$ & $78.3(73.7,82.9)$ \\
\hline Non-Hispanic & $3,106(1.5)$ & $2.14(0.09)$ & $74.9(71.4,78.4)$ & $29.7(26.4,33.1)$ & $9.3(7.1,11.5)$ & $61.0(57.3,64.6)$ \\
\hline \multicolumn{7}{|l|}{ mixed race } \\
\hline \multicolumn{7}{|c|}{ Federal Poverty Level (FPL) } \\
\hline$\leq 100 \%$ & $37,858(34.6)$ & $2.50(0.02)$ & $80.4(79.6,81.1)$ & $36.3(35.3,37.2)$ & $7.9(7.4,8.4)$ & $55.8(54.9,56.7)$ \\
\hline $101-200 \%$ & $20,458(18.7)$ & $2.02(0.03)$ & $76.3(75.3,77.3)$ & $26.0(24.9,27.1)$ & $9.1(8.4,9.8)$ & $64.8(63.7,66.0)$ \\
\hline $201-300 \%$ & $12,598(11.2)$ & $1.73(0.03)$ & $72.5(71.2,73.8)$ & $18.7(17.5,18.9)$ & $10.6(9.7,11.5)$ & $70.7(69.3,72.0)$ \\
\hline $301-400 \%$ & $2,848(2.2)$ & $1.45(0.06)$ & $64.9(61.9,67.8)$ & $15.0(12.5,17.6)$ & $10.0(8.3,11.8)$ & $75.0(72.1,77.8)$ \\
\hline$\geq 401 \%$ & $32,433(33.2)$ & $1.00(0.01)$ & $56.7(55.9,57.5)$ & $5.5(5.0,5.9)$ & $10.3(9.8,10.8)$ & $84.3(83.6,84.9)$ \\
\hline
\end{tabular}




\begin{tabular}{|c|c|c|c|c|c|c|}
\hline \multicolumn{7}{|l|}{ Maternal education $^{\mathrm{e}}$} \\
\hline$<12$ yrs. (age: <18 & $2,254(2.0)$ & $1.91(0.07)$ & $77.2(73.9,80.6)$ & $26.0(22.7,29.3)$ & $11.9(9.3,14.6)$ & $62.1(58.3,65.9)$ \\
\hline \multicolumn{7}{|l|}{ yrs) } \\
\hline$<12$ yrs. (age: $\geq 18$ & $16,626(15.5)$ & $2.05(0.03)$ & $74.5(73.2,75.8)$ & $29.6(28.2,30.9)$ & $7.0(6.3,7.7)$ & $63.4(62.0,64.8)$ \\
\hline \multicolumn{7}{|l|}{ yrs) } \\
\hline 12-15 yrs. (age: < & $11,455(9.6)$ & $2.50(0.04)$ & $81.9(80.6,83.2)$ & $34.6(33.0,36.2)$ & $10.0(9.0,10.9)$ & $55.4(53.7,57.1)$ \\
\hline \multicolumn{7}{|l|}{$22 \mathrm{yrs})$} \\
\hline 12-15 yrs. (age: $\geq$ & $50,089(42.6)$ & $1.99(0.02)$ & $74.4(73.7,75.0)$ & $25.2(24.5,25.8)$ & $9.6(9.1,10.0)$ & $65.3(64.5,66.0)$ \\
\hline \multicolumn{7}{|l|}{$22 \mathrm{yrs})$} \\
\hline$\geq 16 \mathrm{yrs}$ & $33,923(30.3)$ & $1.09(0.01)$ & $58.3(57.5,59.1)$ & $7.7(7.2,8.2)$ & $9.3(8.9,9.8)$ & $82.9(82.3,83.6)$ \\
\hline \multicolumn{7}{|l|}{ Marital status $^{\mathrm{e}}$} \\
\hline Married at the time & $69,129(60.5)$ & $1.33(0.01)$ & $63.4(62.8,64.0)$ & $12.0(11.6,12.5)$ & $9.6(9.2,9.9)$ & $78.4(77.9,78.9)$ \\
\hline \multicolumn{7}{|l|}{ of survey } \\
\hline Unmarried & $46,487(39.5)$ & $2.46(0.02)$ & $80.8(80.1,81.5)$ & $35.9(35.1,36.7)$ & $8.5(8.1,9.0)$ & $55.5(54.7,56.4)$ \\
\hline \multicolumn{7}{|c|}{ Health insurance plan for prenatal care ${ }^{f}$} \\
\hline From job of herself & $55,138(49.1)$ & $1.30(0.01)$ & $62.8(62.2,63.5)$ & $11.2(10.8,11.7)$ & $10.2(9.8,10.6)$ & $78.5(78.0,79.1)$ \\
\hline \multicolumn{7}{|l|}{$\begin{array}{l}\text { or that of } \\
\text { husband/partner, or } \\
\text { parents }^{\mathrm{e}}\end{array}$} \\
\hline Paid by her or & $3,613(3.1)$ & $1.61(0.05)^{\mathrm{g}}$ & $68.0(65.4,70.5)$ & $17.4(15.2,19.5)^{\mathrm{h}}$ & $10.1(8.5,11.8)$ & $72.5(70.0,75.0)$ \\
\hline \multicolumn{7}{|l|}{$\begin{array}{l}\text { someone else (not } \\
\text { from a job) }\end{array}$} \\
\hline From Medicaid $^{\mathrm{e}}$ & $51,084(42.9)$ & $2.41(0.02)$ & $79.9(79.2,80.5)$ & $34.2(33.4,34.9)$ & $8.7(8.2,9.1)$ & $57.1(56.3,57.9)$ \\
\hline From Tricare or & $3,495(2.5)$ & $1.73(0.06)$ & $75.5(72.8,78.2)^{\mathrm{i}}$ & $17.5(14.9,20.1)^{\mathrm{h}}$ & $11.0(9.2,12.8)$ & $71.5(68.6,74.4)$ \\
\hline \multicolumn{7}{|l|}{$\begin{array}{l}\text { other military health } \\
\text { care }\end{array}$} \\
\hline $\begin{array}{l}\text { From any other } \\
\text { source }\end{array}$ & $4,027(4.9)$ & $1.88(0.06)$ & $74.3(71.7,77.0)^{\mathrm{j}}$ & $26.3(23.8,28.8)^{\mathrm{k}}$ & $6.2(5.0,7.3)$ & $67.5(64.9,70.2)$ \\
\hline
\end{tabular}

a: Missing values (\%) for the socio-demographic correlates: maternal age: 6 (0.0); maternal race/ethnicity: 5892 (5.1); FPL: 9,509 (8.2); maternal education: 1357; marital status: $88(0.1)$; insurance from job of herself, husband/partner, or parents: 1,130 (1.0); insurance paid by her or someone else (not from a job): 1,162 (1.0); insurance from Medicaid: 1,216 (1.1); insurance from Tricare or other military health care: $1,126(1.0)$; insurance from any other source: $1,107(1.0)$ 
${ }^{\mathrm{b}}$ : Among the total number of respondents with non-missing responses to the socio-demographic correlate, weighted percentage of the no. of respondents within that category

c: Among the total number of respondents in each category, proportion (weighted $\%$ and $95 \%$ confidence interval [CI]) experiencing $\geq 1$ antenatal SLE

d: Among the total number of respondents in each category, proportion (weighted $\%$ and $95 \%$ confidence interval [CI]) in each class

e: Chi-square $\mathrm{p}<0.0001$ for relationship of selected maternal demographic correlate with prevalence of the latent SLE classes; chi-square $\mathrm{p}<0.0001$ for relationship of selected maternal demographic correlate with prevalence with the prevalence of women with one or more SLE; $\mathrm{p}<0.0001$ for difference in mean by analysis of variance

f: Respondents may have checked more than one option, so the sum of the percentages may exceed 100.0; values and percentages are only for those who responded as "yes" to each type of insurance

g: $p<0.01$ for difference in mean between those who reported having the said health insurance plan, and those who did not

h: Chi-square $p<0.01$ for the relationship of having health insurance from this source with prevalence of the latent SLE classes

i: Chi-square $\mathrm{p}<0.001$ for the relationship of having insurance from this source with the prevalence of women with one or more SLE

j: Chi-square $p<0.01$ for the relationship of having insurance from this source with the prevalence of women with one or more SLE

k: Chi-square $p<0.0001$ for the relationship of having health insurance from this source with prevalence of the latent SLE classes 
Table 4: Multinomial logistic regression results of socio-demographic correlates within latent classes among women in the U.S. who have had a recent live birth (PRAMS, 2009-11) $(\mathrm{N}=98,567)$

\begin{tabular}{|c|c|c|c|c|}
\hline \multirow[t]{4}{*}{ Variables } & \multicolumn{4}{|c|}{ Antenatal stressful life events (SLEs) } \\
\hline & \multirow{2}{*}{\multicolumn{2}{|c|}{$\begin{array}{c}\text { Class } 1^{*} \\
\text { Multiple-stress }\end{array}$}} & \multirow{2}{*}{\multicolumn{2}{|c|}{$\begin{array}{c}\text { Class 2* } \\
\text { llness/death related-stress }\end{array}$}} \\
\hline & & & & \\
\hline & $\mathrm{aOR}(95 \% \mathrm{CI})^{\mathrm{a}}$ & $\mathrm{P}$ value & $\mathrm{aOR}(95 \% \mathrm{CI})^{\mathrm{a}}$ & $\mathrm{P}$ value \\
\hline \multicolumn{5}{|l|}{ Age in years } \\
\hline Less than 17 & Ref & & Ref & \\
\hline $18-19$ & $1.32(0.93,1.86)$ & 0.12 & $0.92(0.56,1.52)$ & 0.75 \\
\hline $20-24$ & $1.59(1.12,2.24)$ & 0.01 & $0.80(0.50,1.29)$ & 0.37 \\
\hline $25-29$ & $1.30(0.93,1.80)$ & 0.13 & $0.68(0.41,1.12)$ & 0.13 \\
\hline $30-34$ & $1.19(0.83,1.69)$ & 0.34 & $0.72(0.45,1.18)$ & 0.19 \\
\hline $35-39$ & $1.07(0.74,1.53)$ & 0.73 & $0.63(0.36,1.09)$ & 0.10 \\
\hline 40 and above & $1.13(0.75,1.70)$ & 0.57 & $0.63(0.35,1.13)$ & 0.12 \\
\hline \multicolumn{5}{|l|}{ Maternal race/ethnicity } \\
\hline Non-Hispanic white & Ref & & Ref & \\
\hline Non-Hispanic black & $0.94(0.80,1.11)$ & 0.48 & $0.92(0.77,1.10)$ & 0.38 \\
\hline Hispanic & $0.70(0.59,0.82)$ & $<0.001$ & $0.62(0.49,0.79)$ & $<0.001$ \\
\hline Asian/Pacific Islander & $0.40(0.31,0.52)$ & $<0.001$ & $0.39(0.32,0.48)$ & $<0.001$ \\
\hline American-Indian or Alaska Native & $1.12(0.88,1.43)$ & 0.36 & $1.57(1.20,2.07)$ & 0.001 \\
\hline Non-Hispanic other & $0.48(0.32,0.72)$ & $<0.001$ & $0.57(0.30,1.09)$ & 0.09 \\
\hline Non-Hispanic mixed race & $1.36(1.06,1.76)$ & 0.02 & $1.03(0.74,1.45)$ & 0.85 \\
\hline \multicolumn{5}{|l|}{ Federal Poverty Level (FPL) } \\
\hline$\leq 100 \%$ & Ref & & Ref & \\
\hline $101-200 \%$ & $0.73(0.66,0.80)$ & $<0.001$ & $1.05(0.91,1.21)$ & 0.52 \\
\hline $201-300 \%$ & $0.54(0.48,0.62)$ & $<0.001$ & $1.22(1.02,1.47)$ & 0.03 \\
\hline $301-400 \%$ & $0.55(0.39,0.78)$ & 0.001 & $1.17(0.84,1.62)$ & 0.36 \\
\hline$\geq 401 \%$ & $0.13(0.10,0.16)$ & $<0.001$ & $1.15(0.97,1.37)$ & 0.10 \\
\hline \multicolumn{5}{|l|}{ Maternal education } \\
\hline <12 yrs. (age: <18 yrs) & Ref & & Ref & \\
\hline$<12$ yrs. (age: $\geq 18$ yrs) & $1.10(0.77,1.57)$ & 0.59 & $0.61(0.30,1.24)$ & 0.17 \\
\hline $12-15$ yrs. (age: $<22$ yrs) & $1.34(0.93,1.94)$ & 0.12 & $0.89(0.46,1.73)$ & 0.73 \\
\hline $12-15$ yrs. (age: $\geq 22 \mathrm{yrs}$ ) & $1.48(1.03,2.13)$ & 0.04 & $0.80(0.42,1.50)$ & 0.48 \\
\hline
\end{tabular}




\begin{tabular}{|c|c|c|c|c|}
\hline$\geq 16$ yrs & $0.96(0.62,1.49)$ & 0.87 & $0.62(0.31,1.22)$ & 0.16 \\
\hline \multicolumn{5}{|l|}{ Marital status } \\
\hline Married at the time of survey & Ref & & Ref & \\
\hline Unmarried & $2.46(2.20,2.74)$ & $<0.001$ & $1.12(0.96,1.30)$ & 0.16 \\
\hline \multicolumn{5}{|l|}{ Health insurance plan for prenatal care } \\
\hline $\begin{array}{l}\text { From job of herself; that of } \\
\text { husband/partner, or parents (Ref: No) }\end{array}$ & $0.96(0.83,1.11)$ & 0.54 & $1.26(1.04,1.53)$ & 0.02 \\
\hline $\begin{array}{l}\text { Paid by her or someone else, but not } \\
\text { from a job (Ref: No) }\end{array}$ & $0.84(0.65,1.08)$ & 0.16 & $1.17(0.88,1.56)$ & 0.27 \\
\hline From Medicaid (Ref: No) & $1.72(1.44,2.04)$ & $<0.001$ & $1.36(1.11,1.66)$ & 0.003 \\
\hline $\begin{array}{l}\text { From Tricare or other military health } \\
\text { care (Ref: No) }\end{array}$ & $1.35(0.97,1.87)$ & 0.07 & $1.27(0.88,1.82)$ & 0.19 \\
\hline From any other source (Ref: No) & $1.06(0.90,1.24)$ & 0.48 & $0.68(0.47,0.99)$ & 0.04 \\
\hline
\end{tabular}

${ }^{*}$ : Class 3 was the reference category for other latent classes 
Table 5: Distribution of the mean (and standard error) of the number of stressful life events, by race/ethnicity and federal poverty level (FPL) categories, among women in the U.S. who have had a recent live birth (PRAMS, 2009-11) ${ }^{\text {a }}$

\begin{tabular}{|c|c|c|c|c|c|c|c|}
\hline $\begin{array}{l}\text { Federal Poverty } \\
\text { Level (FPL) }\end{array}$ & $\begin{array}{l}\text { Non-Hispanic } \\
\text { white } \\
(\mathrm{n}=55,483)\end{array}$ & $\begin{array}{l}\text { Non-Hispanic } \\
\text { black } \\
(\mathrm{n}=15,654)\end{array}$ & $\begin{array}{l}\text { Hispanic } \\
(n=14,912) \\
\end{array}$ & $\begin{array}{l}\text { Asian/Pacific } \\
\text { Islander } \\
(\mathrm{n}=7,825)\end{array}$ & $\begin{array}{l}\text { American-Indian } \\
\text { or Alaska Native } \\
(\mathrm{n}=3,251)\end{array}$ & $\begin{array}{l}\text { Non-Hispanic } \\
\text { other } \\
(\mathrm{n}=829)\end{array}$ & $\begin{array}{l}\text { Non-Hispanic } \\
\text { mixed race } \\
(n=2,948)\end{array}$ \\
\hline$\leq 100 \%$ & $2.83(0.04)$ & $2.59(0.05)$ & $1.93(0.05)$ & $1.33(0.10)$ & $2.75(0.13)$ & $1.74(0.24)$ & $3.06(0.13)$ \\
\hline $101-200 \%$ & $2.06(0.03)$ & $2.27(0.07)$ & $1.74(0.07)$ & $1.23(0.07)$ & $2.55(0.16)$ & $1.32(0.10)$ & $2.11(0.12)$ \\
\hline $201-300 \%$ & $1.66(0.03)$ & $2.07(0.09)$ & $1.84(0.11)$ & $1.25(0.10)$ & $2.15(0.16)$ & $1.65(0.15)$ & $1.49(0.15)$ \\
\hline $301-400 \%$ & $1.26(0.06)$ & $1.97(0.12)$ & $2.39(0.38)$ & $1.07(0.09)$ & $1.75(0.58)$ & $0.83(0.20)$ & $1.37(0.18)$ \\
\hline$\geq 401 \%$ & $0.97(0.01)$ & $1.38(0.06)$ & $1.14(0.06)$ & $0.71(0.04)$ & $1.19(0.08)$ & $0.79(0.08)$ & $1.20(0.10)$ \\
\hline
\end{tabular}

a: For each racial/ethnic group, the respondents with non-missing responses to FPL and those with valid response to at least one of the SLEs, were included in these analyses 


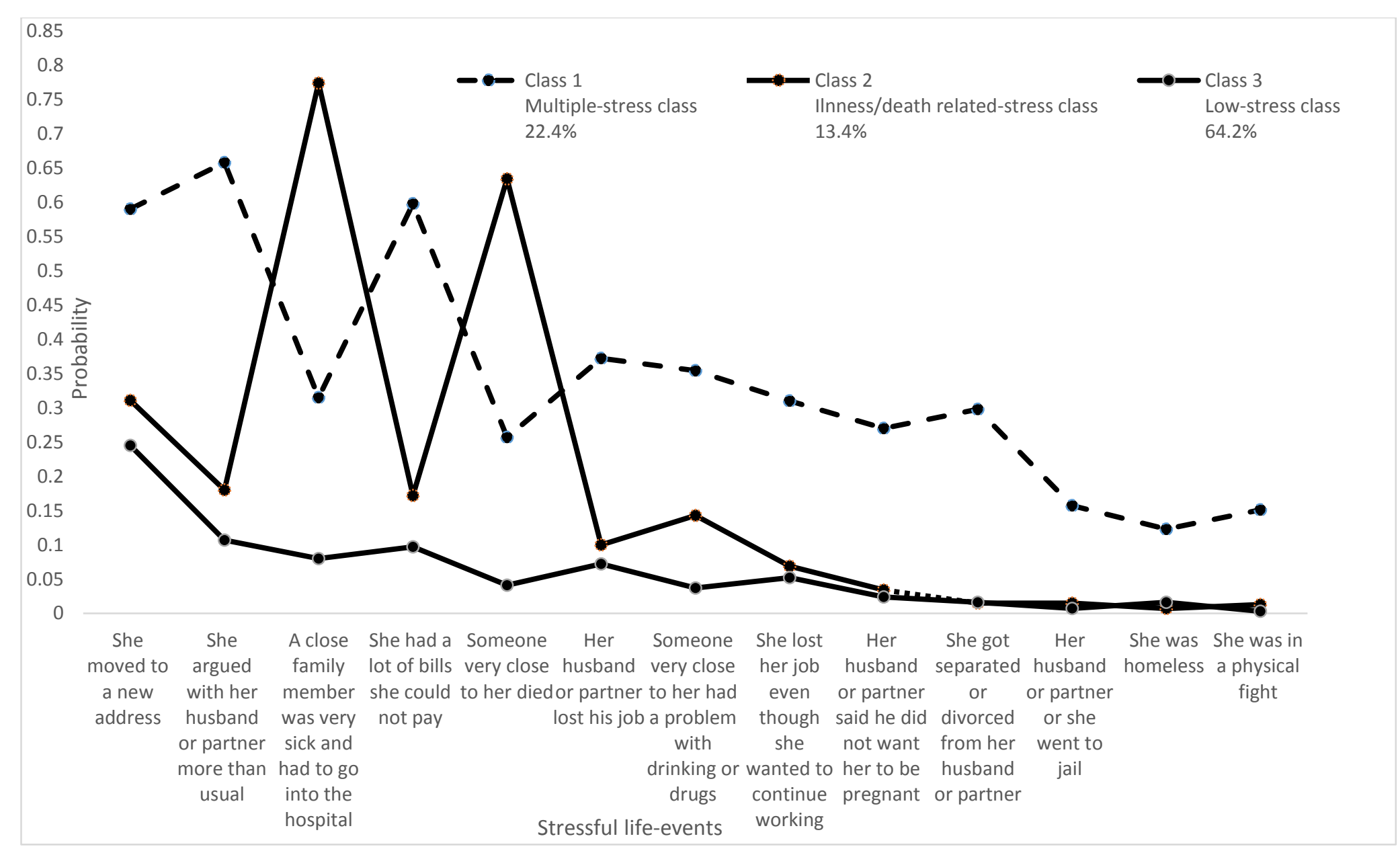

Figure 1: Latent class analysis profile plot; $\mathrm{X}$-axis represents the antenatal stressful life events experienced by women in the U.S. who have had a recent live birth (PRAMS, 2009-11); Y-axis represents the probabilities of these events 


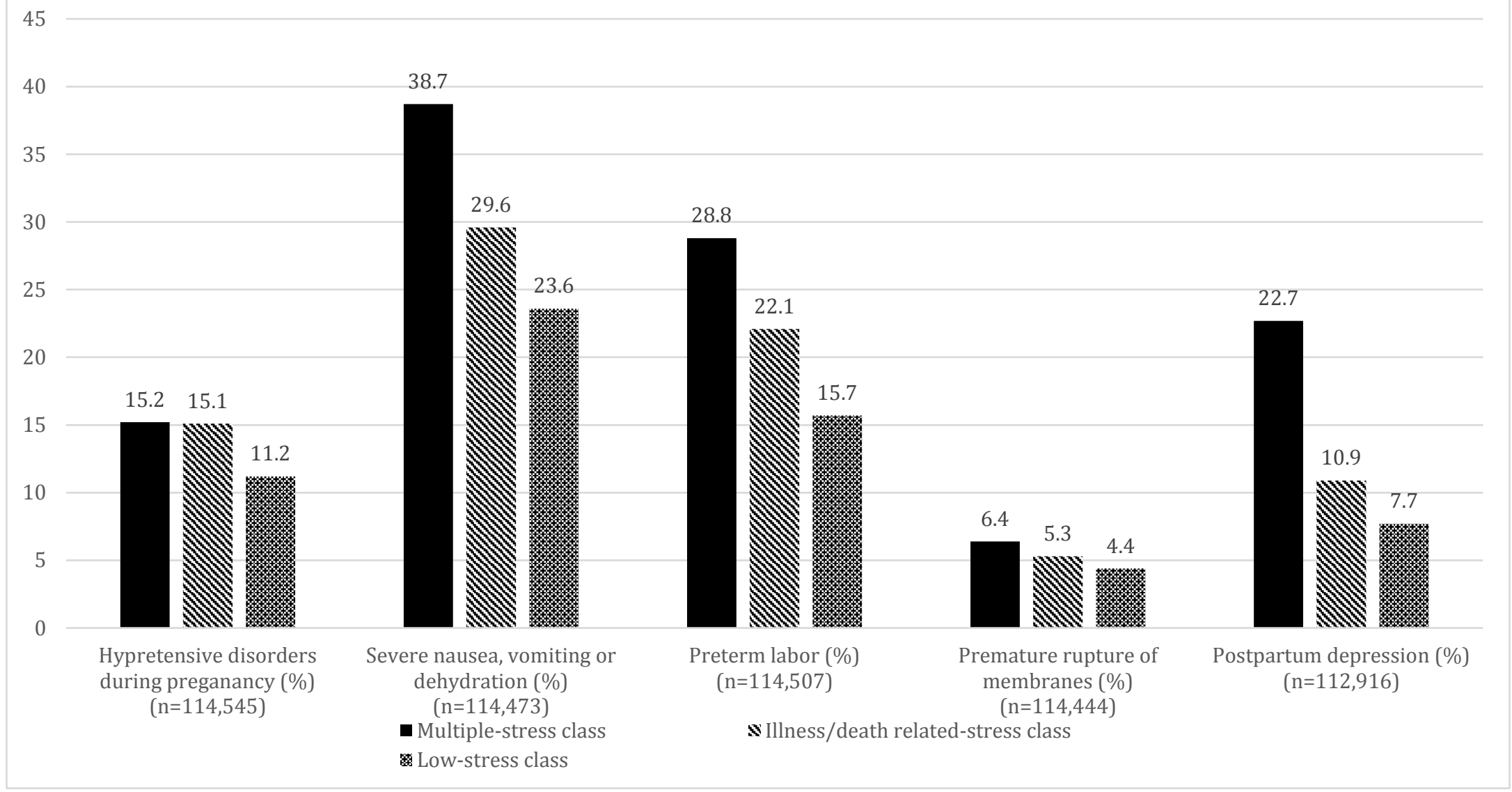

Figure 2: Distribution of maternal health outcomes according to the latent class of antenatal stressful life event, PRAMS 2009-11 


\section{MANUSCRIPT 2}

Antenatal stressful life events and postpartum depression in the United States: the role of women's socio-economic status indices at the state-level

Abstract

Objectives: Approximately 10-20\% of women suffer from postpartum depression (PPD); important predictors of which are antenatal stressful life event experiences (SLEs). The association between women's state-level socio-economic status (SES) and PPD has not been explored. This study aimed to examine whether the association between antenatal SLE and PPD was moderated by women's state-level SES. Methods: Data from the 2009-11 Pregnancy Risk Assessment Monitoring System (PRAMS) were used. Statelevel women's employment/earnings, and social/economic autonomy indices were computed from indicators published by the Institute of Women's Policy Research (IWPR). Multilevel multivariable logistic regression analyses were performed. Results: Among 91,253 women with valid responses, $11.3 \%$ had PPD symptoms; prevalence ranging from $7.1 \%$ in Illinois to $17.1 \%$ in Arkansas. Women who experienced all four stressor categories, including partner-related, traumatic, emotional, and financial, had the highest odds (adjusted odds ratio [aOR]: 5.43; 95\% confidence interval $[\mathrm{CI}]: 5.36,5.51$ ) of PPD. The risk of PPD decreased with an increase in the state-level social/economic autonomy index (aOR: 0.75; 95\% CI: 0.64, 0.88). There was significant cross-level interaction between number of stressor categories experienced and state-level index. Conclusions: Screening for antenatal SLEs can help identify women at risk for PPD. 
That the odds of PPD decreased with increasing state-level social/economic autonomy and that women residing in states with lower indices were more vulnerable to the impacts of antenatal stressors, could have policy implications related to improving the SES of women in these states.

\section{Introduction}

Postpartum depression (PPD) refers to feelings of severe sadness, anxiety, or despair leading to impairment in daily activities, which commonly begins about 1-3 weeks after childbirth and can occur up to one year after childbirth. PPD affects 10-20\% of postpartum women (O’Hara \& Swain, 1996; CDC, 2008) with implications on maternal and child wellbeing (Cooper \& Murray, 1998; Beck, 1998; Tse et al. 2010). Risk factors of PPD include antenatal depression and anxiety (O'Hara \& Swain, 1996; Robertson et al., 2004; Beck, 2001), unplanned pregnancy (Beck, 2001), history of previous depression (Robertson et al., 2004; Beck, 2001), complications during pregnancy and childbirth (Robertson et al., 2004), having operative or assisted delivery (Robertson et al., 2004), relationship problems (O’Hara \& Swain, 1996; Robertson et al., 2004), low social support (O’Hara \& Swain, 1996; Robertson et al., 2004), low socioeconomic status (SES) (O’Hara \& Swain, 1996; Robertson et al., 2004), and adverse neonatal outcomes such as preterm birth and low birthweight (Vigod et al., 2010). Experiencing stressful life-events (SLEs) during pregnancy is an important risk factor of PPD (O’Hara \& Swain, 1996; CDC, 2008; Robertson et al., 2004; Beck, 2001). Among women in New York City, those who experienced six or more stressful events during the 
12 months before delivery, had three times the odds of having a PPD diagnosis, compared with those who did not experience any stressful event (Liu \& Tronick, 2013). In Massachusetts, women reporting one or more antenatal stressors had a significantly higher prevalence of PPD symptoms (Stone et al., 2015).

In addition to the commonly explored individual risk-factors, contextual factors might play a role in PPD. A multiple determinants framework for perinatal health includes proximal risk factors, which are biomedical and behavioral responses to distal risk factors, such as the woman's physical, economic, social and political environment (Misra et al., 2003). As the state has increasingly become the unit to legislate, fund and implement policies and programs in the United States (U.S.), states with policies favoring gender equality in social-economic, political and reproductive rights can encourage an environment that is friendlier towards the women and their family (Daniels, 1997; Chen et al., 2005). The high status of women in the society can favorably influence their mental health by providing higher wages, better standard of living, health insurance, and state funding for reproductive and child health care (Chen et al., 2005). The importance of state-level women's status has been examined in the context of violence against married women (Yllö, 1984), global and cause-specific mortality rates among women and men (Kawachi et al., 1999), and low birthweight, teen pregnancy and infant and teen mortality (Koenen et al., 2006). Women's SES at the state-level has been significantly linked to depressive symptoms in general (Chen et al., 2005), with lower depression scores among women residing in higher-ranked states. 
Population-based multi-state studies focusing primarily on the relationship between maternal antenatal SLE and PPD are rare. Moreover, women's state-level SES, and its interaction with antenatal stress has not been considered in the context of PPD. The purpose of this study was to examine the association between antenatal SLEs and PPD, among women in the U.S. who have had a recent live birth and to explore whether state-level SES moderated the relationship between antenatal SLE and PPD.

\section{Methods}

Dataset and study subjects

This study used data for the years 2009-11, collected by the Pregnancy Risk Assessment Monitoring System (PRAMS), a surveillance project of the Centers for Disease Control and Prevention (CDC) and state health departments. A stratified systematic sample of 100 to 250 new mothers is drawn every month from a sampling frame of eligible birth certificates (CDC, 2015). Women from some groups, such as those having low weight births, are oversampled to ensure adequate data availability from smaller but higher-risk populations. Many states also stratify by maternal race/ethnicity. Sampling, nonresponse, and noncoverage weights are multiplied together to yield the analysis weight, which can be interpreted as the number of women like herself in the population that each respondent represents. The standardized data collection methodology enables between-state comparisons and optimal data use for single-state or multi-state analyses (CDC, 2015). The survey is conducted by mailed questionnaires with telephone follow-ups for the non-respondents, and the responses are linked to extracted 
birth certificate variables. Mailings start 2 to 4 months after delivery. Topics include barriers to and content of prenatal care, obstetric history, physical abuse, contraception, economic status, maternal stress, and early infant development and health status (CDC, 2009). Phase 6 PRAMS data were available for 31 states, including Alaska, Arkansas, Colorado, Delaware, Georgia, Hawaii, Illinois, Massachusetts, Maryland, Maine, Michigan, Minnesota, Missouri, Mississippi, Nebraska, New Jersey, New Mexico, New York, Ohio, Oklahoma, Oregon, Pennsylvania, Rhode Island, Tennessee, Texas, Utah, Vermont, Washington, Wisconsin, West Virginia, and Wyoming, and New York City. Race/ethnicity information were not available for the respondents from Vermont, which was therefore excluded from our analyses.

Variables

PPD, the outcome of interest, was assessed by a woman's responses to whether she felt the following since her new baby was born: 1 . down, depressed or sad; 2 . hopeless; or 3. slowed down. Depending on their responses ranging from "never" to "always" to each question, the total score ranged from 3-15. As recommended by the CDC, any woman with a score of 10 or higher was categorized as having PPD, and the rest were considered to not have PPD. When data was available for only two or one question(s), the cut-offs were 7 and 4 respectively (Guidelines for Analyzing Phase 6 Core Depression Question, unpublished report, 2012).

The exposure variable was antenatal SLE, assessed by whether (yes/no) each of the following events happened to a woman during the 12 months immediately prior to the birth of her new baby: 1 . A close family member was very sick and had to go to the 
hospital; 2. She got separated or divorced from her husband or partner; 3. She moved to a new address; 4. She was homeless; 5. Her husband/partner lost his job; 6. She lost her job although she wanted to continue working; 7 . She argued with her husband/partner more than usual; 8. Her husband/partner did not want her to be pregnant; 9. She had a lot of bills that she could not pay; 10. She was involved in a physical fight; 11 . Her husband/partner or she herself went to jail; 12 . Someone very close to her had a problem with drinking or drugs; 13 . Someone very close to her died (CDC, 2009). Based on previous research (Maryland, 2008; Ahluwalia et al., 2001), women were classified as whether or not they experienced each of the following categories ("yes" to at least one item of that category vs. "no" to all items of that category) of stressors: traumatic (question numbers 4,10,11, or 12); emotional (questions 1, or 13); financial (questions $3,5,6$, or 9); and partner-related (questions 2, 7, or 8). Women were grouped into those who experienced: 1 . No stressor; 2. Only partner-related stressor; 3. Only traumatic stressor; 4. Only financial stressor; 5. Only emotional stressor; 6. Traumatic and emotional stressors; 7. Traumatic and financial stressors; 8. Traumatic and partner-related stressors; 9. Partner-related and emotional stressors; 10. Partner-related and financial stressors; 11. Financial and emotional stressors; 12. Partner-related, traumatic, and financial stressors; 13. Partner-related, traumatic, and emotional stressors; 14. Traumatic, financial, and emotional stressors; 15. Partner-related, financial, and emotional stressors; and 16. All four stressor categories. The group of women with no stress was the reference group for all multivariable analyses.

Individual-level covariates included maternal age; race/ethnicity; income with respect to federal poverty level (FPL); education; marital status; pre-pregnancy check-up 
or treatment for depression; number of previous live births; pregnancy intention (when she got pregnant with her new baby); intimate partner physical violence (IPPV); adequacy of prenatal care; Medicaid for her prenatal care or delivery; enrolled/not enrolled in the Special Supplemental Nutrition Program for Women, Infants, and Children (WIC); any morbidity during her most recent pregnancy; mode of delivery; any adverse neonatal outcome; and gender of the new baby. Federal poverty levels were computed following the guidelines issued by the U.S. Department of Health \& Human Services (HHS) for the years 2009, 2010 and 2011, using annual household income and number of dependents including the woman herself. Income with respect to federal poverty level (FPL) was categorized as less than or equal to $100 \%$ of FPL; $101-200 \%$ of FPL; $201-300 \%$ of FPL; 301-400\% of FPL; and greater than 400\% of FPL. Marital status was classified as whether the respondent was married or not at the time of the survey. Adequacy of prenatal care was assessed by the Koltelchuck Index or the Adequacy of Antenatal Care Utilization Index, which takes into consideration both the timing of prenatal care initiation, as well as, the number of prenatal care visits after initiation (Kotelchuck, 1994). If a woman reported having experienced any antenatal morbidity, including gestational diabetes (diagnosed by a health care worker); vaginal bleeding; kidney or bladder infection; severe nausea, vomiting or dehydration; cervix having to be sewn shut; high blood pressure; placental problems; preterm or early labor; premature rupture of the membranes; having a blood transfusion; and being hurt in a car accident, she was considered to have had a medical/obstetric complication during her most recent pregnancy. A mother whose new baby had a birth defect, low birthweight, preterm birth, 
or had to be admitted to an intensive care unit, was considered to have experienced an adverse neonatal outcome. All the individual-level variables were categorical.

State-level indicators of women's SES, published by the Institute of Women's Policy Research (IWPR), were used to calculate composite employment and earnings, and social and economic autonomy indices (Cariazza \& Shaw, 2004; Institute for Women's Policy Research, 2009), which were the state-level variables used in our study. These indices, which have been used in previous research (Chen et al., 2005; McLaughlin et al., 2011), were computed following IWPR guidelines (Cariazza \& Shaw, 2004). Employment and earnings index comprised of median annual earnings of women working full-term, year-round; women-to-men ratio of median annual earnings; proportion (\%) of adult female population in the labor force; and proportion (\%) of employed women in managerial or professional occupations. The four indicators for each state were standardized by dividing with the comparable value for the entire U.S., and were added to create a composite score giving equal weight to each component (Cariazza $\&$ Shaw, 2004). The social and economic autonomy index comprised of the proportions (\%) of the following: 18-64 year old women with health insurance; women aged 25 and above with four or more years of college education; businesses owned by women; and women living above the poverty threshold. The four components were divided by the comparable value for the entire U.S. The standardized values were added to create a composite score, giving a weight of 4.0 to poverty and a weight of 1.0 to the rest (Cariazza \& Shaw, 2004). For each index, a higher composite score implied better state- 
level women's SES. The averages of the indices for the years 2009 to 2011 were used in our analyses.

Analysis

Chi-square tests of independence were done to examine the prevalence of PPD according to different levels of the individual-level variables. The prevalence of PPD was compared among the states. SAS procedures that account for survey design (Proc Survey) were employed to adjust for the analysis weights.

Multivariable analyses were performed using the generalized linear mixed model (GLMMs) with the logit link function (also called multilevel logistic regression) in order to take into account clustering at the state-level. Guidelines for multi-level analyses and approaches previously used were followed (Chen et al., 2005; Merlo et al., 2006; Heck \& Thomas, 2009; Hox, 2002). The state-level indices were centered using grand mean centering (CGM), by subtracting the grand mean from their respective scores. All categorical variables were dummy coded. In the beginning, a null model without any predictor at any level and with the intercept for PPD allowed to vary (random intercept model) was run to serve as a baseline for future comparisons. The intraclass correlation (ICC) was calculated to quantify the similarity of observations within the same cluster. The median odds ratio (MOR) was also calculated from the null model (Merlo et al., 2006). The individual and state-level variables were then introduced in a sequential manner. Each model was compared with the previous or less complicated model using the likelihood ratio test statistic, computed as the difference between the (-2) times log 
likelihood values with a chi-squared distribution equal to the difference in the number of parameters. The individual-level covariates that were statistically significant in bivariate analyses were included in a random intercept model (Model 1), and it was significantly better than the null model. Because of a high-level of correlation (0.90) between the two state-level indices, we decided to use only the social/economic autonomy index, which was more strongly associated with state-level PPD prevalence. Model 2, which was a random intercept model with state-level social and economic autonomy index, as well as, the individual-level variables, was significantly better than model 1. Adjusted odds ratios (ORs) and 95\% confidence intervals (CI s) were reported from model 2. A multilevel logistic regression model (model 3) was run, with PPD as the outcome; the independent variables being number of stressor categories experienced (none; 1, 2, 3, and all 4), all other individual-level variables used in model 2, state-level social and economic autonomy index, and an interaction term between the number of stressor categories and the state-level index.

SAS 9.4 (SAS Institute Inc., Cary, NC, US) was used for all analyses. SAS Proc GLIMMIX procedures with adaptive Gauss-Hermite quadrature method were used and analysis weights were adjusted for.

\section{Results}

Of 116,595 respondents to the PRAMS 2009-11 dataset, 91,253 (78.3\%) had valid responses to all variables of interest and were utilized for the bi- and multi-variate analyses. Sixty two percent of the respondents were non-Hispanic whites, $12.3 \%$ nonHispanic blacks, 18.3\% Hispanics, 0.8\% American Indians/Alaska Natives, $4.8 \%$ 
Asians/Pacific Islanders and the rest belonged to other/mixed races (table 1). Eleven percent $(11.3 \%)$ women met the criteria for PPD; the prevalence ranging from $7.1 \%$ in Illinois to $17.1 \%$ in Arkansas (prevalence by state not shown in table). Twenty nine percent of the respondents did not experience any antenatal stressful life event (table 1); $33.0 \%$ experienced only one stress construct; $22.0 \%$ experienced two stress constructs; 11.6\% experienced 3 stress constructs; and $4.3 \%$ experienced all four stress constructs.

In bivariate analyses (table 1), a lower proportion (8.1-11.0\%) of women in the age groups 25 years and above had PPD compared with younger women (14.1-14.8\%). The prevalence among non-Hispanic blacks (13.1\%) and American Indians/Alaska Natives (14.9\%) was higher than among non-Hispanic whites (11.2\%) and Hispanics (11.1\%), while Asians/Pacific Islanders had a lower prevalence (8.1\%). Women in the lower income and education categories had a higher prevalence than those in the highest income and education categories respectively. The prevalence was higher among women who experienced antenatal IPPV, those who did not intend to become pregnant, and those who went for a pre-pregnancy check-up or treatment for depression. Women who experienced all the four stressor categories had the highest prevalence (34.5\%) of PPD symptoms, while the prevalence was the lowest (5.4\%) among those who did not experience any stressor (table 1). The graphs in figure 1 and 2 suggest that in general, the state-level PPD prevalence decreased with increase in the average state-level SES measures.

From the null model, the ICC was computed as 0.016, suggesting that approximately $1.6 \%$ of the variability in PPD was accounted for by the states. The MOR 
of 1.25 suggested that a woman in a higher PPD prevalence state was 1.25 times likely to experience PPD compared to her counterpart in lower prevalence state (results not shown). The $\mathrm{P}$ value $(<0.0001)$ of the random effect of the intercept suggested a statistically significant amount of variability in the log odds of having PPD between the states (results not shown).

Experiencing all four stressor categories (aOR: 5.43 ; 95\% CI: 5.36, 5.51) was the strongest correlate of PPD (table 2). This was followed by experiencing partner-related, traumatic, and financial stressors (aOR: 3.69; 95\% CI: 3.64, 3.74); and partner-related, traumatic, and emotional stressors (aOR: 3.50; 95\% CI: 3.41, 3.60). Among those who experienced stressors of a single category, partner-related (aOR: 2.21; 95\% CI: 2.18 , 2.25 ) and traumatic (aOR: 1.62; 95\% CI: 1.57, 1.66) stressors were strongly associated with PPD. Pre-pregnancy treatment/checkup for depression (aOR: 2.14; 95\% CI: 2.13, 2.16) was an important predictor of PPD (table 2). Compared with non-Hispanic whites, the odds of experiencing PPD was lower for each racial/ethnic group. Higher income groups had significantly lower odds of experiencing PPD, compared with the lowest income group. Women never intending to be pregnant had a higher likelihood (aOR: $1.47 ; 95 \%$ CI: $1.45,1.48)$ than those who wanted to be pregnant sooner. Antenatal IPPV and morbidity were strong correlates of PPD, even after adjusting for all covariates. The risk of PPD decreased with an increase in the state-level social/economic autonomy index (aOR: 0.75, 95\% CI: 0.64, 0.88). Table 3 shows the effects of the interaction; aORs of having PPD in states with 1 SD below average, and 1 SD above average social and economic autonomy index were higher and lower respectively for women who 
experienced one to four stressor categories, compared with those who experienced none of those.

\section{Discussion}

The prevalence of PPD (11.3\%) in our analysis is comparable to the commonly observed prevalence of 10 to 20\% (O'Hara \& Swain, 1996; CDC, 2008). The prevalence ranged from $7 \%$ in Illinois to $17 \%$ in Arkansas. In an analysis of 2004-5 PRAMS data, Maine and New Mexico had the lowest (11.7\%) and highest prevalence (20.4\%) respectively (CDC, 2008). However, the 2004-05 PRAMS survey used a different instrument with two items to assess PPD and included data from 17 states, in contrast to the 30 states in our analysis (CDC, 2008). Our prevalence is lower than that found in studies looking at rural women from a single state or region (Baker \& Oswalt, 2008; Reighard \& Evans, 1995).

Despite having higher unadjusted prevalence, the adjusted odds of experiencing PPD was lower among non-Hispanic blacks and American Indians/Alaska Natives, compared with non-Hispanic whites. Similarly, women with lower levels of education had a higher prevalence of PPD compared to women with $\geq 16$ years education; but the direction of association was the opposite in the multivariable model. On further exploration (results not shown), it appeared that income differences were largely responsible for the unadjusted distribution of PPD prevalence by race/ethnicity. Once household income with respect to FPL categories was adjusted for, the associations reversed. In a study among preretirement adults, Hispanics, and non-Hispanic blacks had higher frequencies of depression than non-Hispanic whites, the difference being 
significant for the former. However, after adjusting for sociodemographic, health, and economic factors, depression was found to be significantly less frequent among nonHispanic blacks, and there was no significant difference between Hispanics and nonHispanic whites (Dunlop et al., 2003).

Experience of intimate partner physical violence during pregnancy and lack of pregnancy intention, known risk factors of PPD, were important correlates in our study (Beydoun et al., 2010; Mercier et al., 2013). Higher odds of PPD among women who had pre-pregnancy check-up or treatment for depression might be indicative that they had a history of depression, another predictor of PPD (Cooper \& Murray, 1998; Tse et al., 2010). Women in each stressor category had higher adjusted odds of PPD, even after adjusting for all individual-level and state-level correlates. Among those who experienced stressor of a single type, women experiencing antenatal partner-related stress had the highest adjusted odds, followed by traumatic stress. A previous analysis of Massachusetts PRAMS data (Stone et al., 2015) also revealed the highest vulnerability to partner stress. Furthermore, we observed that the odds was generally higher among women who experienced multiple types of stressors, with those reporting all the four types of stressors being more than five times likely to have PPD symptoms, compared with those who experienced none of the stressor types. This dose-response relationship is comparable to the findings of Stone et al. (2015), where the prevalence of PPD symptoms was more than 5 times higher among women who reported having experienced seven or more antenatal stressful life events, than those who experienced none. In addition to the number of stressor types, our results revealed that the stressor type was of paramount importance. Women experiencing multiple stressor types had particularly higher odds of 
PPD symptoms if they experienced partner-related and traumatic stressors, irrespective of whether any other type of stressor was present.

After adjusting for individual-level correlates, residents in states with higher women's social/economic autonomy index, were less likely to experience PPD compared with women in higher-scoring states. This is comparable to the findings of Chen et al. (2005) on depression among women, but different from the findings of McLaughlin et al. (2011), where no association was found between state-level women's status and 12month mood and anxiety disorders. McLaughlin et al. (2011) looked at DSM-IV psychiatric disorders, and not depressive symptoms, as the outcome. Associations have also been found between state-level SES and other health outcomes. Living in states with lower median household income or higher proportion of adults below the poverty line was associated with significantly higher odds of hypertension, compared to states with higher median household income or lower proportion of adults below poverty line respectively (Fan et al., 2015). State SES can influence residents' physical environment, as well as the quality and quantity of social services (Fan et al., 2015). Social/economic autonomy assesses women's economic security and access to opportunity (Hess et al., 2015). States with higher indices may be more likely to have policies and programs that provide better material and social resources, and better life opportunities for women, thereby contributing to their better postpartum mental health (Stone et al., 2015).

Our results suggest that the relationship between the number of antenatal stressor types experienced, and PPD is stronger in states scoring lower in women's social/economic autonomy index, and vice versa. It is possible that higher 
social/economic autonomy buffers some impact of the antenatal stressors, by providing better access to necessary resources to cope with the situation, and decreases the likelihood of depressive symptoms after childbirth. Social safety nets, including programs like Temporary Assistance for Needy Families (TANF), Supplemental Nutrition Assistance (SNAP), and Supplemental Security Income (SSI) provide support to those who earn very low wages or are unable to work, and thus reduce the proportion of women in poverty (Hess et al., 2015). Unfortunately, the benefits of such programs often fail to reach the women and families who have the highest needs (Hess et al., 2015). It is likely that states with a lower percentage of women in poverty, one of the indicators of social/economic autonomy, have better mechanisms to ensure that the benefits of social safety nets reach those who would benefit the most. It is worth noting that the aforementioned difference in adjusted odds of PPD symptoms between a state with lower social/economic autonomy index, and one with a higher index was the highest for those who experienced all the four stressor categories. Thus it appears that the higher the risk of PPD symptoms, the more likely is the state-level index to play a role; in other words, the most vulnerable women are the most likely to benefit through an improvement of the state ranking. Interactions between state-level SES in general, and individual risk factors have been previously observed. A study evaluating the role of state-level SES on the prevalence of hypertension, found that adults unable to work were most severely affected by low state SES; they had the highest odds of reporting hypertension out of all employment status categories (Fan et al., 2015). Low income women living in states with high income-inequality had a higher risk of experiencing depressive symptoms, compared with low income women in low-income-inequality states (Kahn et al., 2000). 


\section{Limitations}

There are a number of limitations to this study. First and foremost, according to the CDC guidelines, the 3 part PRAMS phase 6 PPD symptoms questionnaire, has a sensitivity of $57 \%$ and a specificity of $87 \%$ for PPD, when all the three questions were answered and the cut-off of 10 was used. When only two or one question(s) were/was answered and using the recommended cut-off of sevens and four, the sensitivity and specificity were $95 \%$ and $49 \%$, and $75 \%$ and $69 \%$ respectively. Moreover, the positive predictive value (PPV) of the instrument, given a PPD prevalence of 10-20\%, were 21$38 \%, 17-32 \%$, and $32-52 \%$, for cut-offs of 4,7 , and 10 respectively (Guidelines for Analyzing Phase 6 Core Depression Question, unpublished report, 2012). The distribution of responses to each of the three parts of the PPD symptom questionnaire is summarized in table 4 (table 4). We also looked at the distribution of women in our sample responding to one, two, and all three questions, which were respectively $0.8 \%$, $30.6 \%$, and $68.6 \%$ (results not shown in table). Thus, although the instrument was not particularly accurate in terms of assessing women at risk of PPD, it is somewhat reassuring that nearly $70 \%$ of the respondents answered all the 3 questions, and therefore the cut-off of 10, with by far the best PPV, could be used.

Another limitation is that potential correlates of PPD, including postpartum intimate partner violence and social support could not be included due to lack of information from most states. In addition, the questions on antenatal SLE in PRAMS asked about the 12 months prior to childbirth, so a woman might have reported an event that occurred during the year before childbirth, but within the 2-3 months before she got 
pregnant. Our analysis is based on data from 30 out of the 50 states; so findings may not be generalizable to the entire U.S. Moreover, we had to exclude $21 \%$ of all observations from our analyses, because of missing information on one or more variables of interest. The variables household income (7\%) and race/ethnicity (5\%) had the highest proportion missing values. The proportion of missing responses varied considerably between the states, which might have had an impact on our results. Data on other state-level women's status indices, such as political participation and reproductive rights, were not available for the years of interest. We did not have any information on more specific contextual factors that might depend on neighborhood or locality of residence. Women experiencing PPD could have been more likely to remember specific antenatal SLEs, leading to recall bias. Also, self-reported symptoms for PPD might be prone to subjective variation and social-desirability bias. Lastly, all the data are cross-sectional and temporal relationship cannot be established between the variables. This problem is partially obviated by the fact that an event during pregnancy must precede PPD.

\section{Conclusions}

Limitations notwithstanding, our study has examined the relationship between antenatal SLE and PPD using a large population-based dataset from multiple states, after adjusting for a number of covariates. Our results suggest that screening for antenatal SLEs might help identify women at risk for PPD. This, to our knowledge, is the first study exploring the role of state-level women's SES indices on PPD. The finding that the odds of PPD decrease with increasing social/economic autonomy could have policy implications and motivate efforts to improve these indices, particularly in the states that 
are below average. Moreover, the associations between traumatic, emotional and financial antenatal stressors, and state-level social/economic autonomy suggest that women residing in states with lower indices are more vulnerable to the impacts of antenatal stressors. It would be especially important to identify the at-risk women in these states so as to mitigate the impacts of antenatal stressors and decrease their probability of experiencing depressive symptoms after childbirth.

\section{References}

Ahluwalia, I. B., Merritt, R., Beck, L. F., \& Rogers, M. (2001). Multiple lifestyle and psychosocial risks and delivery of small for gestational age infants. Obstetrics \& Gynecology, 97(5), 649-656.

Baker, L., \& Oswalt, K. (2008). Screening for postpartum depression in a rural community. Community Mental Health Journal, 44(3), 171-180.

Beck, C. T. (1998). The effects of postpartum depression on child development: a metaanalysis. Archives of Psychiatric Nursing, 12(1), 12-20.

Beck, C. T. (2001). Predictors of postpartum depression: an update. Nursing Research, 50(5), 275-285.

Beydoun, H. A., Al-Sahab, B., Beydoun, M. A., \& Tamim, H. (2010). Intimate partner violence as a risk factor for postpartum depression among Canadian women in the Maternity Experience Survey. Annals of Epidemiology, 20(8), 575-583.

Caiazza, A.B., \& Shaw, A. (2004). The Status of Women in the States. Washington, DC: Institute for Women's Policy Research.

Centers for Disease Control and Prevention (CDC). (2008). Prevalence of self-reported postpartum depressive symptoms--17 states, 2004-2005. MMWR. Morbidity and Mortality Weekly Report, 57(14), 361.

Centers for Disease Control and Prevention (CDC). (2009). Pregnancy Risk Assessment Monitoring System Phase 6 Core Questionnaire. http://www.cdc.gov/prams/pdf/phase6_topicsreference.pdf. Accessed May 3, 2016.

Centers for Disease Control and Prevention (CDC). Guidelines for analyzing phase 6 core depression question (unpublished report). 
Centers for Disease Control and Prevention (CDC). (2015). PRAMS Methodology. http://www.cdc.gov/prams/methodology.htm. 2015; Accessed Sep 21, 2015.

Chen, Y. Y., Subramanian, S. V., Acevedo-Garcia, D., \& Kawachi, I. (2005). Women's Status and Depressive Symptoms: a multilevel analysis. Social Science \& Medicine, 60(1), 49-60.

Cooper, P. J., \& Murray, L. (1998). Fortnightly review: Postnatal depression. British Medical Journal, 316(7148), 1884.

Daniels, C. (1997). The Paradoxes of State Power. In C. Daniels \& R. Brooks (Eds.), Feminists Negotiate the State: The Politics of Domestic Violence (pp. 1-4). Lanham, Maryland: University Press of America.

Dunlop, D. D., Song, J., Lyons, J. S., Manheim, L. M., \& Chang, R. W. (2003). Racial/ethnic differences in rates of depression among preretirement adults. American Journal of Public Health, 93(11), 1945-1952.

Fan, A. Z., Strasser, S. M., Zhang, X., Fang, J., \& Crawford, C. G. (2015). State Socioeconomic Indicators and Self-Reported Hypertension Among US Adults, 2011 Behavioral Risk Factor Surveillance System. Preventing Chronic Disease, 12, 140353.

Heck, R. H., \& Thomas, S. L. (2015). An Introduction to Multilevel Modeling Techniques: MLM and SEM Approaches Using Mplus ( $3^{\text {rd }}$ ed.). New York, New York: Routledge.

Hess, C., Milli, J., Hayes, J., \& Hegewisch, A. (2015). The Status of Women in the States 2015. Washington, DC: Institute for Women's Policy Research.

Hox, J. J. (2010). Multilevel analysis: Techniques and applications ( $2^{\text {nd }}$ ed.). New York, New York: Routledge.

Institute for Women's Policy Research. (2009). Overview: State-by-state rankings and data on indicators of women's social and economic status, 2009. Institute for Women's Policy Research compilation based on U.S. Census Bureau 2007 Survey of Business Owners and U.S. Census Bureau 2009 American Community Survey. http://www.iwpr.org/initiatives/states/2009-state-by-state-overview. Accessed May 3, 2016.

Kahn, R. S., Wise, P. H., Kennedy, B. P., \& Kawachi, I. (2000). State income inequality, household income, and maternal mental and physical health: cross sectional national survey. BMJ, 321(7272), 1311-1315.

Kawachi, I., Kennedy, B. P., Gupta, V., \& Prothrow-Stith, D. (1999). Women's status and the health of women and men: a view from the States. Social Science \& Medicine, 48(1), 21-32.

Koenen, K. C., Lincoln, A., \& Appleton, A. (2006). Women's status and child well-being: A state-level analysis. Social Science \& Medicine, 63(12), 2999-3012. 
Liu, C. H., \& Tronick, E. (2013). Re-conceptualising Prenatal Life Stressors in Predicting Post-partum Depression: Cumulative-, Specific-, and Domain-specific Approaches to Calculating Risk. Paediatric and Perinatal Epidemiology, 27(5), 481-490.

McLaughlin, K. A., Xuan, Z., Subramanian, S. V., \& Koenen, K. C. (2011). State-level women's status and psychiatric disorders among US women. Social Psychiatry and Psychiatric Epidemiology, 46(11), 1161-1171.

Mercier, R. J., Garrett, J., Thorp, J., \& Siega-Riz, A. M. (2013). Pregnancy intention and postpartum depression: secondary data analysis from a prospective cohort. BJOG: An International Journal of Obstetrics \& Gynaecology, 120(9), 1116-1122.

Merlo, J., Chaix, B., Ohlsson, H., Beckman, A., Johnell, K., Hjerpe, P., ... \& Larsen, K. (2006). A brief conceptual tutorial of multilevel analysis in social epidemiology: using measures of clustering in multilevel logistic regression to investigate contextual phenomena. Journal of Epidemiology and Community Health, 60(4), 290-297.

Misra, D. P., Guyer, B., \& Allston, A. (2003). Integrated perinatal health framework: A multiple determinants model with a life span approach. American Journal of Preventive Medicine, 25(1), 65-75.

O'hara, M. W., \& Swain, A. M. (1996). Rates and risk of postpartum depression-a meta-analysis. International Review of Psychiatry, 8(1), 37-54.

Reighard, F. T., \& Evans, M. L. (1995). Use of the Edinburgh Postnatal Depression Scale in a southern, rural population in the United States. Progress in Neuro-

Psychopharmacology and Biological Psychiatry, 19(7), 1219-1224.

Robertson, E., Grace, S., Wallington, T., \& Stewart, D. E. (2004). Antenatal risk factors for postpartum depression: a synthesis of recent literature. General Hospital Psychiatry, 26(4), 289-295.

Stone, S. L., Diop, H., Declercq, E., Cabral, H. J., Fox, M. P., \& Wise, L. A. (2015). Stressful events during pregnancy and postpartum depressive symptoms. Journal of Women's Health, 24(5), 384-393.

Tse, A. C., Rich-Edwards, J. W., Rifas-Shiman, S. L., Gillman, M. W., \& Oken, E. (2010). Association of maternal prenatal depressive symptoms with child cognition at age 3 years. Paediatric and Perinatal Epidemiology, 24(3), 232-240.

Vigod, S. N., Villegas, L., Dennis, C. L., \& Ross, L. E. (2010). Prevalence and risk factors for postpartum depression among women with preterm and low-birth-weight infants: a systematic review. BJOG: An International Journal of Obstetrics \& Gynaecology, 117(5), 540-550.

Yllö, K. (1984). The status of women, marital equality, and violence against wives a contextual analysis. Journal of Family Issues, 5(3), 307-320. 


\section{Tables and figures}

Table 1: Distribution of postpartum depression among women who have had a recent live birth (PRAMS 2009-11), by individual-level correlates $(\mathrm{N}=91,253)^{\mathrm{a}}$

\begin{tabular}{|c|c|c|c|}
\hline & Total $(\%)^{\mathrm{b}}$ & $\begin{array}{c}\text { Postpartum } \\
\text { depression (PPD) } \\
\text { symptoms } \\
\%(95 \% \mathrm{CI})^{\mathrm{c}}\end{array}$ & $\begin{array}{c}\text { No postpartum } \\
\text { depression }(\mathrm{PPD}) \\
\text { symptoms } \\
\%(95 \% \mathrm{CI})^{\mathrm{d}}\end{array}$ \\
\hline Total $(\%)$ & $91,253(100.0)$ & $11,598(11.3)$ & $79,655(88.7)$ \\
\hline \multicolumn{4}{|l|}{ Socio-demographic characteristics } \\
\hline \multicolumn{4}{|l|}{ Age in years ${ }^{\mathrm{e}}$} \\
\hline Less than 17 & $1,724(1.6)$ & $14.2(11.4,17.1)$ & $85.8(82.9,88.6)$ \\
\hline $18-19$ & $5,229(5.6)$ & $14.8(13.1,16.6)$ & $85.2(83.4,86.9)$ \\
\hline $20-24$ & $21,323(22.8)$ & $14.1(13.2,14.9)$ & $85.9(85.1,86.8)$ \\
\hline $25-29$ & $26,644(29.9)$ & $11.0(10.4,11.7)$ & $89.0(88.3,89.6)$ \\
\hline $30-34$ & $22,344(25.8)$ & $9.5(8.8,10.1)$ & $90.5(89.9,91.2)$ \\
\hline $35-39$ & $11,234(11.6)$ & $8.5(7.7,9.4)$ & $91.5(90.6,92.3)$ \\
\hline 40 and above & $2,755(2.7)$ & $10.8(8.5,13.1)$ & $89.2(86.9,91.5)$ \\
\hline \multicolumn{4}{|l|}{ Maternal race/ethnicity ${ }^{\mathrm{e}}$} \\
\hline Non-Hispanic white & $51,206(61.6)$ & $11.2(10.7,11.6)$ & $88.9(88.4,89.3)$ \\
\hline Non-Hispanic black & $13,546(12.3)$ & $13.1(12.1,14.1)$ & $86.9(85.9,87.9)$ \\
\hline Hispanic & $12,725(18.3)$ & $11.1(10.0,12.2)$ & $88.9(87.8,90.0)$ \\
\hline Asian/Pacific Islander & $7,550(4.8)$ & $8.2(7.0,9.3)$ & $91.9(90.7,93.0)$ \\
\hline American-Indian/Alaska & $2,930(0.8)$ & $14.9(11.8,17.9)$ & $85.1(82.1,88.2)$ \\
\hline \multicolumn{4}{|l|}{ Native } \\
\hline Non-Hispanic other & $687(0.7)$ & $9.97(6.3,13.7)$ & $90.0(86.3,93.7)$ \\
\hline Non-Hispanic mixed race & $2,609(1.5)$ & $13.19(10.4,16.0)$ & $86.8(84.0,89.6)$ \\
\hline \multicolumn{4}{|l|}{ Maternal education ${ }^{\mathrm{e}}$} \\
\hline $0-8$ yrs & $2,551(3.5)$ & $10.0(7.8,12.2)$ & $90.0(87.8,92.2)$ \\
\hline $9-11$ yrs & $10,356(11.1)$ & $14.9(13.6,16.2)$ & $85.1(83.8,86.4)$ \\
\hline $12 \mathrm{yrs}$ & $24,064(25.4)$ & $13.4(12.6,14.2)$ & $86.6(85.8,87.4)$ \\
\hline $13-15$ yrs. & $25,689(27.5)$ & $12.0(11.3,12.6)$ & $88.0(87.4,88.7)$ \\
\hline$\geq 16 \mathrm{yrs}$ & $28,593(32.5)$ & $8.0(7.5,8.5)$ & $92.0(91.5,92.5)$ \\
\hline \multicolumn{4}{|c|}{ Income in relation to federal poverty level ${ }^{\mathrm{e}}$} \\
\hline$\leq 100 \%$ & $36,453(38.0)$ & $15.1(14.4,15.7)$ & $85.0(84.3,85.6)$ \\
\hline $101-200 \%$ & $19,387(20.9)$ & $11.6(10.8,12.4)$ & $88.4(87.6,89.2)$ \\
\hline $201-300 \%$ & $6,063(6.0)$ & $9.4(8.2,10.6)$ & $90.6(89.4,91.8)$ \\
\hline $301-400 \%$ & $3,466(3.2)$ & $7.4(6.2,8.6)$ & $92.6(91.4,93.8)$ \\
\hline$\geq 401 \%$ & $25,884(31.9)$ & $7.4(6.9,7.9)$ & $92.6(92.2,93.1)$ \\
\hline \multicolumn{4}{|l|}{ Marital status ${ }^{\mathrm{e}}$} \\
\hline Married at the time of survey & $56,423(63.0)$ & $9.2(8.8,9.6)$ & $90.8(90.4,91.2)$ \\
\hline Unmarried & $34,830(37.0)$ & $14.9(14.2,15.6)$ & $85.1(84.4,85.8)$ \\
\hline \multicolumn{4}{|c|}{ Pre-pregnancy and antenatal factors } \\
\hline \multicolumn{4}{|c|}{ Pre-pregnancy check-up/treatment for depression ${ }^{\mathrm{e}}$} \\
\hline Yes & $11,906(11.6)$ & $23.7(22.4,25.0)$ & $76.3(75.0,77.6)$ \\
\hline No & $79,347(88.4)$ & $9.7(9.3,10.0)$ & $90.3(9.0,90.7)$ \\
\hline \multicolumn{4}{|l|}{ Previous live births ${ }^{\mathrm{f}}$} \\
\hline 0 & $38,017(40.4)$ & $10.7(10.1,11.2)$ & $89.3(88.8,89.9)$ \\
\hline 1 & $28,496(32.7)$ & $11.4(10.7,12.0)$ & $88.6(88.0,89.3)$ \\
\hline 2 & $14,616(16.2)$ & $11.7(10.8,12.6)$ & $88.3(87.4,89.2)$ \\
\hline $3-5$ & $9,369(9.9)$ & $12.8(11.5,14.1)$ & $87.2(85.9,88.5)$ \\
\hline $6+$ & $755(0.8)$ & $13.8(8.8,18.8)$ & $86.2(81.2,91.2)$ \\
\hline
\end{tabular}


Table 1: Distribution of postpartum depression among women who have had a recent live birth (PRAMS 2009-11), by individual-level correlates $(\mathrm{N}=91,253)^{\mathrm{a}}$

\begin{tabular}{|c|c|c|c|}
\hline & Total $(\%)^{\mathrm{b}}$ & $\begin{array}{c}\text { Postpartum } \\
\text { depression }(\mathrm{PPD}) \\
\text { symptoms } \\
\%(95 \% \mathrm{CI})^{\mathrm{c}} \\
\end{array}$ & $\begin{array}{c}\text { No postpartum } \\
\text { depression }(\mathrm{PPD}) \\
\text { symptoms } \\
\%(95 \% \mathrm{CI})^{\mathrm{d}} \\
\end{array}$ \\
\hline \multicolumn{4}{|c|}{ Intention to get pregnant during most recent pregnancy ${ }^{\mathrm{e}}$} \\
\hline Sooner & $17,417(18.2)$ & $9.6(8.9,10.3)$ & $90.4(89.7,91.1)$ \\
\hline Later & $27,997(31.3)$ & $13.5(12.8,14.2)$ & $86.5(85.8,87.3)$ \\
\hline Then & $36,036(40.6)$ & $8.3(7.8,8.8)$ & $91.7(91.2,92.2)$ \\
\hline Did not want even in future & $9,803(9.9)$ & $19.9(18.4,21.3)$ & $80.1(78.7,81.6)$ \\
\hline \multicolumn{4}{|l|}{ Prenatal care $(\mathrm{PNC})^{\mathrm{e}}$} \\
\hline Inadequate & $10,431(12.2)$ & $13.8(12.6,15.0)$ & $86.2(85.0,87.4)$ \\
\hline Intermediate & $11,114(13.0)$ & $11.6(10.6,12.6)$ & $88.4(87.4,89.5)$ \\
\hline Adequate & $38,225(46.2)$ & $10.2(9.7,10.7)$ & $89.8(89.3,90.3)$ \\
\hline Adequate plus & $31,483(28.6)$ & $11.9(11.2,12.5)$ & $88.1(87.5,88.8)$ \\
\hline \multicolumn{4}{|c|}{ Used Special Supplemental Nutrition Program for Women, Infants, and Children (WIC) } \\
\hline Yes & $42,839(44.9)$ & $13.9(13.3,14.5)$ & $86.1(85.5,86.7)$ \\
\hline No & $48,414(55.1)$ & $9.2(8.7,9.6)$ & $90.9(90.4,91.3)$ \\
\hline \multicolumn{4}{|c|}{ Medicaid helped pay for prenatal care or delivery } \\
\hline Yes & $43,823(45.9)$ & $14.2(13.6,14.8)$ & $85.8(85.2,86.4)$ \\
\hline No & $47,430(54.1)$ & $8.8(8.4,9.2)$ & $91.2(90.8,91.6)$ \\
\hline \multicolumn{4}{|c|}{ Experienced intimate partner physical violence during pregnancy ${ }^{\mathrm{e}}$} \\
\hline Yes & $2,976(3.0)$ & $33.4(30.1,36.7)$ & $66.6(63.4,69.9)$ \\
\hline No & $88,277(97.0)$ & $10.6(10.3,11.0)$ & $89.4(89.0,89.7)$ \\
\hline \multicolumn{4}{|c|}{ Any medical/obstetric complication during the most recent pregnancy } \\
\hline Yes & $62,483(62.9)$ & $13.5(13.0,14.0)$ & $86.5(86.1,87.0)$ \\
\hline No & $28,770(37.1)$ & $7.6(7.1,8.1)$ & $92.4(91.9,92.9)$ \\
\hline \multicolumn{4}{|l|}{ Antenatal stressor category ${ }^{\mathrm{e}}$} \\
\hline Only partner-related & $3,866(4.3)$ & $12.7(10.8,14.6)$ & $87.3(85.4,89.2)$ \\
\hline Only traumatic & $1437(1.7)$ & $9.5(7.0,12.0)$ & $90.5(88.1,93.0)$ \\
\hline Only financial & $16,603(18.5)$ & $8.5(7.7,9.2)$ & $91.5(90.8,92.3)$ \\
\hline Only emotional & $7,566(8.5)$ & $6.8(5.9,7.8)$ & $93.2(92.2,94.1)$ \\
\hline Partner-related; traumatic & $905(0.9)$ & $22.1(16.7,27.6)$ & $77.9(72.4,83.3)$ \\
\hline Partner-related; financial & $7,377(8.0)$ & $17.7(16.1,19.2)$ & $82.3(80.8,83.9)$ \\
\hline Partner-related; emotional & $1,758(1.9)$ & $15.0(12.1,17.9)$ & $85.0(82.1,87.9)$ \\
\hline Traumatic; emotional & $959(0.9)$ & $6.9(4.6,9.2)$ & $93.1(90.8,95.5)$ \\
\hline Traumatic; financial & $2,540(2.7)$ & $11.7(9.5,13.8)$ & $88.4(86.2,90.5)$ \\
\hline Emotional; financial & $6,934(7.5)$ & $8.8(7.7,9.9)$ & $91.2(90.2,92.3)$ \\
\hline $\begin{array}{l}\text { Partner-related; traumatic; } \\
\text { emotional }\end{array}$ & $743(0.8)$ & $22.0(16.6,27.4)$ & $78.0(72.6,83.4)$ \\
\hline $\begin{array}{l}\text { Partner-related; traumatic; } \\
\text { financial }\end{array}$ & $4,445(4.5)$ & $25.1(22.7,27.7)$ & $75.0(72.6,77.3)$ \\
\hline $\begin{array}{l}\text { Financial; traumatic; } \\
\text { emotional }\end{array}$ & $2,141(2.0)$ & $14.0(11.6,16.4)$ & $86.0(83.6,88.4)$ \\
\hline $\begin{array}{l}\text { Partner-related; financial; } \\
\text { emotional }\end{array}$ & $3,995(4.3)$ & $20.1(17.9,22.4)$ & $79.9(77.6,82.1)$ \\
\hline All four types & $4,417(4.3)$ & $34.5(31.8,37.2)$ & $65.5(62.9,68.2)$ \\
\hline No stress & $25,567(29.1)$ & $5.4(4.9,5.8)$ & $94.6(94.2,95.1)$ \\
\hline \multicolumn{4}{|l|}{ Delivery and neonatal factors } \\
\hline \multicolumn{4}{|l|}{ Vaginal delivery } \\
\hline Yes & $58,280(66.8)$ & $10.6(10.2,11.1)$ & $89.4(88.9,89.8)$ \\
\hline
\end{tabular}


Table 1: Distribution of postpartum depression among women who have had a recent live birth (PRAMS 2009-11), by individual-level correlates $(\mathrm{N}=91,253)^{\mathrm{a}}$

\begin{tabular}{|c|c|c|c|}
\hline & Total $(\%)^{\mathrm{b}}$ & $\begin{array}{c}\text { Postpartum } \\
\text { depression }(\mathrm{PPD}) \\
\text { symptoms } \\
\%(95 \% \mathrm{CI})^{\mathrm{c}}\end{array}$ & $\begin{array}{c}\text { No postpartum } \\
\text { depression }(\mathrm{PPD}) \\
\text { symptoms } \\
\%(95 \% \mathrm{CI})^{\mathrm{d}}\end{array}$ \\
\hline No & $32,973(33.2)$ & $12.6(12.0,13.3)$ & $87.4(86.8,88.0)$ \\
\hline \multicolumn{4}{|c|}{ Any adverse outcomes of the new baby } \\
\hline Yes & $31,458(18.2)$ & $13.5(12.8,14.3)$ & $86.5(85.7,87.2)$ \\
\hline No & $59,795(81.8)$ & $10.8(10.4,11.2)$ & $89.2(88.8,89.6)$ \\
\hline \multicolumn{4}{|c|}{ Sex of new baby } \\
\hline Male & $46,011(51.1)$ & $11.5(11.0,12.0)$ & $88.5(88.0,89.0)$ \\
\hline Female & $45,242(48.9)$ & $11.1(10.6,11.6)$ & $89.0(88.5,89.5)$ \\
\hline
\end{tabular}

a: Individuals with valid responses to all the variables

b: Among the total number of respondents, weighted percentage of the no. of respondents in that category

c: Among the total number of respondents in each category, proportion (weighted \% and 95\% Confidence Interval [CI]) having PPD

d: Among the total number of respondents in each category, proportion (weighted \% and $95 \%$ Confidence Interval [CI]) having PPD

e: Chi-square $\mathrm{p}<0.0001$ for relationship of the selected correlate with prevalence of PPD

f: Chi-square $\mathrm{p}<0.05$ for relationship of the selected correlate with prevalence of PPD 
Table 2: Results of multilevel multivariable logistic regression analyses: adjusted odds ratios (aORs) and 95\% confidence intervals (CIs) for postpartum depression (PPD) symptoms ${ }^{\mathrm{a}}(\mathrm{N}=91,253)^{\mathrm{a}}$

\begin{tabular}{|c|c|}
\hline & $\begin{array}{c}\text { Postpartum Depression (PPD) } \\
\text { aOR }(95 \% \mathrm{CI})^{\mathrm{b}}\end{array}$ \\
\hline \multicolumn{2}{|l|}{ Individual level variables } \\
\hline \multicolumn{2}{|l|}{ Age in years } \\
\hline $25-29$ & 1.00 (Reference) \\
\hline Less than 17 & $0.91(0.89,0.94)$ \\
\hline $18-19$ & $0.93(0.92,0.94)$ \\
\hline $20-24$ & $0.99(0.98,1.00)$ \\
\hline $30-34$ & $0.97(0.97,0.98)$ \\
\hline $35-39$ & $0.89(0.88,0.90)$ \\
\hline 40 and above & $1.07(1.05,1.09)$ \\
\hline \multicolumn{2}{|l|}{ Maternal race/ethnicity } \\
\hline Non-Hispanic white & 1.00 (Reference) \\
\hline Non-Hispanic black & $0.83(0.82,0.84)$ \\
\hline Hispanic & $0.85(0.84,0.86)$ \\
\hline Asian/Pacific Islander & $0.93(0.91,0.94)$ \\
\hline American-Indian/Alaska Native & $0.93(0.90,0.96)$ \\
\hline Non-Hispanic other & $0.96(0.93,1.00)$ \\
\hline Non-Hispanic mixed race & $0.81(0.79,0.83)$ \\
\hline \multicolumn{2}{|l|}{ Maternal education } \\
\hline$\geq 16 \mathrm{yrs}$ & 1.00 (Reference) \\
\hline $0-8$ yrs & $0.87(0.85,0.89)$ \\
\hline $9-11 \mathrm{yrs}$ & $0.96(0.95,0.98)$ \\
\hline $12 \mathrm{yrs}$ & $0.96(0.95,0.97)$ \\
\hline $13-15 \mathrm{yrs}$ & $0.94(0.93,0.95)$ \\
\hline \multicolumn{2}{|c|}{ Income in relation to federal poverty level } \\
\hline$\leq 100 \%$ & 1.00 (Reference) \\
\hline $101-200 \%$ & $0.90(0.89,0.91)$ \\
\hline $201-300 \%$ & $0.79(0.77,0.80)$ \\
\hline $301-400 \%$ & $0.67(0.65,0.68)$ \\
\hline$\geq 401 \%$ & $0.74(0.73,0.75)$ \\
\hline \multicolumn{2}{|l|}{ Marital status } \\
\hline Married & 1.00 (Reference) \\
\hline Not married & $1.01(1.00,1.02)$ \\
\hline \multicolumn{2}{|c|}{ Pre-pregnancy check-up/treatment for depression } \\
\hline No & 1.00 (Reference) \\
\hline Yes & $2.14(2.13,2.16)$ \\
\hline \multicolumn{2}{|l|}{ Previous number of live births } \\
\hline 0 & 1.00 (Reference) \\
\hline 1 & $1.10(1.09,1.11)$ \\
\hline 2 & $1.01(1.00,1.02)$ \\
\hline $3-5$ & $1.00(0.99,1.01)$ \\
\hline $6+$ & $1.22(1.18,1.26)$ \\
\hline \multicolumn{2}{|c|}{ Intention to get pregnant before the most recent pregnancy } \\
\hline Sooner & 1.00 (Reference) \\
\hline Later & $1.05(1.04,1.06)$ \\
\hline Then & $0.85(0.85,0.86)$ \\
\hline Did not want even in future & $1.47(1.45,1.48)$ \\
\hline \multicolumn{2}{|l|}{ Prenatal care $(\mathrm{PNC})^{\mathrm{e}}$} \\
\hline Inadequate & 1.00 (Reference) \\
\hline
\end{tabular}




\begin{tabular}{|c|c|}
\hline & $\begin{array}{c}\text { Postpartum Depression (PPD) } \\
\text { aOR }(95 \% \mathrm{CI})^{\mathrm{b}}\end{array}$ \\
\hline Intermediate & $0.99(0.98,1.00)$ \\
\hline Adequate & $1.05(1.04,1.06)$ \\
\hline Adequate plus & $0.97(0.96,0.97)$ \\
\hline \multicolumn{2}{|c|}{ Used Special Supplemental Nutrition Program for Women, Infants, and Children (WIC) } \\
\hline No & 1.00 (Reference) \\
\hline Yes & $0.96(0.95,0.97)$ \\
\hline \multicolumn{2}{|c|}{ Medicaid helped pay for prenatal care or delivery } \\
\hline No & 1.00 (Reference) \\
\hline Yes & $0.95(0.94,0.96)$ \\
\hline \multicolumn{2}{|c|}{ Experienced intimate partner physical violence during pregnancy } \\
\hline No & 1.00 (Reference) \\
\hline Yes & $1.76(1.73,1.78)$ \\
\hline \multicolumn{2}{|c|}{ Any medical/obstetric complication during the most recent pregnancy } \\
\hline No & 1.00 (Reference) \\
\hline Yes & $1.40(1.39,1.41)$ \\
\hline \multicolumn{2}{|c|}{ Vaginal delivery during the most recent childbirth } \\
\hline No & 1.00 (Reference) \\
\hline Yes & $0.83(0.83,0.84)$ \\
\hline \multicolumn{2}{|l|}{ Any adverse outcome(s) of the new baby } \\
\hline No & 1.00 (Reference) \\
\hline Yes & $1.09(1.08,1.10)$ \\
\hline \multicolumn{2}{|l|}{ Antenatal stressor category ${ }^{\mathrm{e}}$} \\
\hline No stress & 1.00 (Reference) \\
\hline Only partner-related & $2.21(2.18,2.25)$ \\
\hline Only traumatic & $1.62(1.57,1.66)$ \\
\hline Only financial & $1.50(1.48,1.51)$ \\
\hline Only emotional & $1.27(1.25,1.29)$ \\
\hline Partner-related; traumatic & $3.49(3.41,3.58)$ \\
\hline Partner-related; financial & $2.94(2.90,2.97)$ \\
\hline Partner-related; emotional & $2.77(2.72,2.83)$ \\
\hline Traumatic; emotional & $1.06(1.02,1.10)$ \\
\hline Traumatic; financial & $1.85(1.81,1.88)$ \\
\hline Emotional; financial & $1.47(1.45,1.49)$ \\
\hline Partner-related; traumatic; emotional & $3.50(3.41,3.60)$ \\
\hline Partner-related; traumatic; financial & $3.69(3.64,3.74)$ \\
\hline Financial; traumatic; emotional & $2.10(2.05,2.14)$ \\
\hline Partner-related; financial; emotional & $3.33(3.28,3.37)$ \\
\hline All four types & $5.43(5.36,5.51)$ \\
\hline \multicolumn{2}{|l|}{ State-level variable } \\
\hline Social and economic autonomy index & $0.75(0.64,0.88)$ \\
\hline
\end{tabular}

a: Individuals with valid responses to all the variables

b: aORs and 95\% CIs are reported from the model 10 with all the individual-level correlates, random intercept for postpartum depression, and state-level women's social/economic autonomy index 
Table 3: Results of the interaction between number of stressor categories and stress-level social and economic autonomy index: adjusted odds ratios (aORs) and 95\% confidence intervals (CIs) for postpartum depression (PPD) symptoms ${ }^{\mathrm{a}}(\mathrm{N}=91,253)^{\mathrm{a}}$

\begin{tabular}{|c|c|c|c|}
\hline $\begin{array}{l}\text { No. of stressor } \\
\text { categories } \\
\text { experienced }\end{array}$ & $\begin{array}{c}\text { State with } \\
\text { social/economic } \\
\text { autonomy index 1 SD } \\
\text { below mean } \\
\text { aOR }(95 \% \mathrm{CI})\end{array}$ & $\begin{array}{l}\text { State with mean } \\
\text { social/economic } \\
\text { autonomy index } \\
\text { aOR }(95 \% \mathrm{CI})\end{array}$ & $\begin{array}{c}\text { State with } \\
\text { social/economic } \\
\text { autonomy index } 1 \mathrm{SD} \\
\text { above mean } \\
\text { aOR }(95 \% \mathrm{CI})\end{array}$ \\
\hline 0 & Reference & Reference & Reference \\
\hline 1 & $1.67(1.65,1.70)$ & $1.54(1.52,1.55)$ & $1.41(1.39,1.43)$ \\
\hline 2 & $2.26(2.22,2.29)$ & $2.19(2.17,2.21)$ & $2.12(2.09,2.15)$ \\
\hline 3 & $3.41(3.36,3.46)$ & $3.14(3.11,3.18)$ & $2.90(2.86,2.95)$ \\
\hline 4 & $5.63(5.53,5.74)$ & $5.18(5.11,5.25)$ & $4.76(4.66,4.85)$ \\
\hline
\end{tabular}

a: Individuals with valid responses to all the variables; Odds Ratios are adjusted for all other individuallevel variables specified in table 2

Table 4: Distribution of the responses to each of the questions on postpartum depression symptoms among women who have had a recent live birth (PRAMS 2009-11) $(\mathrm{N}=91,253)^{\mathrm{a}}$

\begin{tabular}{lccccc}
\hline $\begin{array}{l}\text { Feeling since the } \\
\text { new baby was born }\end{array}$ & Never $(\%)^{\mathrm{b}}$ & ${\text { Rarely }(\%)^{\mathrm{b}}}$ & ${\text { Sometimes }(\%)^{\mathrm{b}}}$ & ${\text { Often }(\%)^{\mathrm{b}}}$ & ${\text { Always }(\%)^{\mathrm{b}}}^{\mathrm{b}}$ \\
\hline $\begin{array}{l}\text { Down, depressed, } \\
\text { or sad }^{\mathrm{c}}\end{array}$ & $26,844(30.4)$ & $25,354(28.9)$ & $26,410(28.6)$ & $9,731(9.5)$ & $2,608(2.3)$ \\
Hopeless $^{\mathrm{d}}$ & $57,820(65.3)$ & $16,106(17.5)$ & $10,800(10.8)$ & $4,159(4.0)$ & $1,561(1.4)$ \\
Slow $^{\mathrm{e}}$ & $27,281(30.3)$ & $18,589(20.7)$ & $27,258(29.9)$ & $13,227(14.2)$ & $4,187(4.1)$ \\
\hline
\end{tabular}

a: Individuals with valid responses to all the variables

b: Among the 91,235 respondents, weighted $\%$ of those who endorsed each of the responses

c: Missing responses: $306(0.3 \%)$

d: Missing responses: $807(0.9 \%)$

e. Missing responses: $711(0.8 \%)$ 


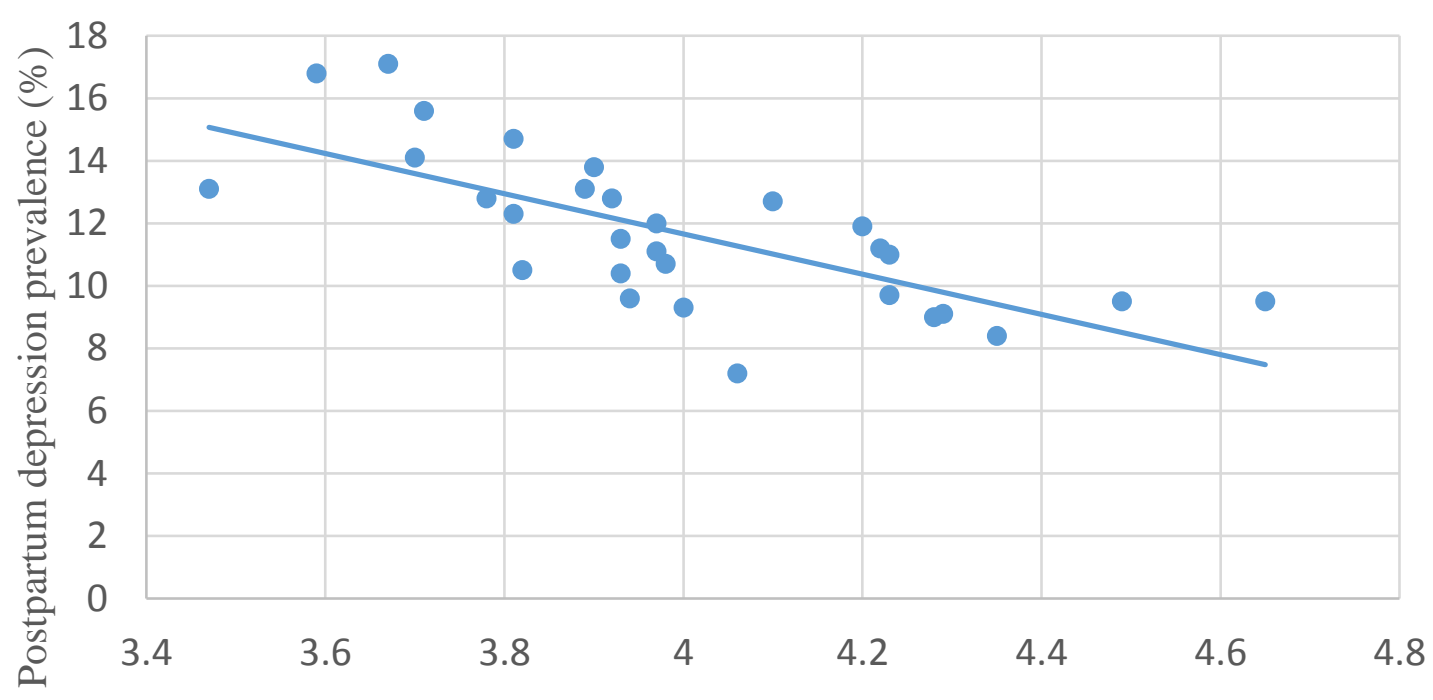

Women's state-level employment and earnings index in the U.S., PRAMS 2009-11

Fig 1: Distribution of state-wise postpartum depression prevalence (PRAMS 2009-11) with state-level women's employment and earnings index

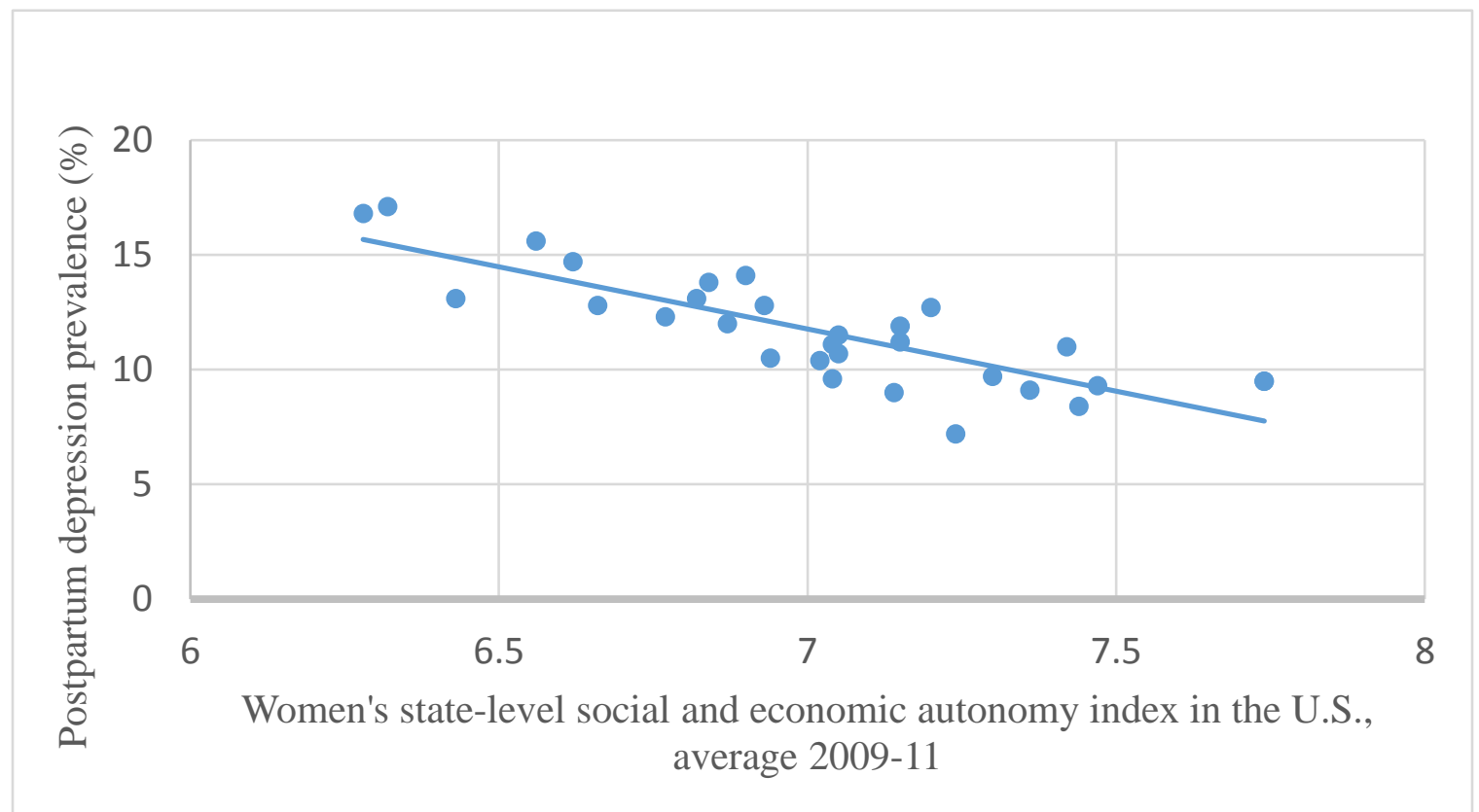

Fig 2: Distribution of state-wise postpartum depression prevalence (PRAMS 2009-11) with state-level women's social and economic autonomy index 


\section{MANUCSRIPT 3}

Racial and ethnic differences in the relationship between antenatal stressful life events and postpartum depression among women in the United States: Does provider communication on perinatal depression minimize the risk?

Abstract

Objectives: Multistate population-based studies exploring the racial/ethnic differences in the prevalence and correlates of postpartum depression (PPD), which affects 10-20\% of women giving birth in the United States (U.S.), are rare. The aim of this study was to examine the racial/ethnic disparities in the relationship between antenatal stressful life events and PPD among U.S. women, and to further explore whether antenatal health care provider communication on perinatal depression was associated with a lower risk.

Methods: Data from the 2009-11 Pregnancy Risk Assessment Monitoring System (PRAMS) were used. For each racial/ethnic group, the distribution of PPD was compared according to different levels of the stressors, and socio-demographic, pre-pregnancy, antenatal, delivery and neonatal characteristics. Multivariable logistic regression analyses were performed, with postpartum depression as outcome and all variables that were significant in bivariate analyses as predictors. Results: Eleven percent of 87,565 women met the criteria for PPD; prevalence ranging from 7.9\% among Asians/Pacific Islanders to $14 \%$ among American Indians/Alaska Natives. Irrespective of race/ethnicity, having a lot of bills to pay, and having more than usual arguments with husband/partner were risk factors for PPD. Among non-Hispanic blacks, having a husband/partner who did not want 
the pregnancy was a correlate of PPD (adjusted odds ratio [aOR]: 1.47; 95\% confidence interval $[\mathrm{CI}]: 1.14,1.90)$, and among non-Hispanic whites, drug/drinking problems of someone close was associated with PPD (aOR: 1.37; 95\% CI: 1.21, 1.55). Provider communication was inversely associated with PPD among non-Hispanic whites (aOR: 0.77; 95\% CI: 0.69, 0.85) and non-Hispanic blacks (aOR: 0.74; 95\% CI: 0.60, 0.93). Conclusions. The protective effect of provider communication on PPD suggests the benefit of a conversation about perinatal depression during antenatal care. Furthermore, risk factors for PPD varied by race/ethnicity suggesting that these vulnerabilities should be taken into consideration in identifying women at-risk for postpartum depression.

\section{Introduction}

Postpartum depression includes feelings of severe sadness, anxiety or despair, which leads to impairment in daily activities. Postpartum depression can occur 1-3 weeks to one year after childbirth with implications on maternal and child health (Cooper \& Murray, 1998; Beck, 1998; Tse et al., 2010). Nearly 10 to $20 \%$ of women in the United States (U.S.) experience depressive symptoms postpartum (CDC, 2008). Racial and ethnic differences in the prevalence of postpartum depression have been noted among women in Massachusetts (Liu \& Tronick 2014) and New York City (Liu et al., 2013). However, multistate population-based studies exploring the racial/ethnic disparities in the prevalence of postpartum depression and the relationship between antenatal stressful life events and postpartum depression are difficult to find. One of the U.S. Department of Health and Human Services Healthy People 2020 objectives is to decrease the proportion of women with a live birth, experiencing postpartum depressive symptoms. Depression 
and anxiety during pregnancy (O’Hara \& Swain 1996; Robertson et al., 2004; Beck, 2001), unplanned pregnancy (Beck, 2001), history of previous depression (Robertson et al., 2004; Beck, 2001), physical or sexual abuse experiences (Silverman \& Loudon, 2010), perinatal complications (Robertson et al., 2004), operative or assisted delivery (Robertson et al., 2004), relationship problems (O'Hara \& Swain, 1996; Robertson et al., 2004), low social support (O’Hara \& Swain, 1996; Robertson et al., 2004), low socioeconomic status (SES) (O’Hara \& Swain, 1996; Robertson et al., 2004), adverse neonatal outcomes including preterm birth and low birthweight (Vigod et al., 2010), and inadequate coping strategies (Faisal-Cury et al., 2004) are some of the correlates of postpartum depression. Having experienced stressful life-events during pregnancy places a woman at high risk of postpartum depression (O’Hara \& Swain, 1996; CDC, 2008; Robertson et al., 2004; Beck, 2001). In New York City, women who experienced six or more stressful life events, during the 12 months before delivery, were at a higher odds of having a postpartum depression diagnosis, compared with those who did not experience any such event (Liu et al., 2013). Women in Massachusetts reporting one or more antenatal stressors had a significantly higher prevalence of postpartum depression symptoms (Stone et al., 2015). A different study conducted in Massachusetts revealed that antenatal stress did not predict postpartum loss of interest among non-Hispanic whites, but high relational stress and high financial stress were respectively associated with loss of interest among non-Hispanic blacks; and Hispanics and Asians/Pacific Islanders (Liu et al., 2016).

Previous research suggests that interventions delivered during pregnancy can be effective in preventing postpartum depression, especially among those with antenatal 
depression symptoms (Clatworthy, 2012; Sockol et al., 2013). The US Preventive Services Task Force (USPSTF) has recently concluded that in addition to screening for depression in pregnant and postpartum women, a variety of treatment options, including antidepressants and behavioral therapy, should be available (Siu \& the US Preventive Services Task Force [USPSTF], 2016). Providing pregnant women with information about perinatal depression can be empowering, and contribute to an increased awareness on this health issue and its symptoms, so that they can seek necessary care and support early enough (Youash et al., 2013). An analysis of data from the 2011 Pregnancy Risk Assessment Monitoring System (PRAMS) revealed that nearly $72 \%$ women reported a discussion on perinatal depression with their health care provider during antenatal care (Farr et al., 2016). There has been little, if any, research on the impact of provider communication on the occurrence of postpartum depression, after taking other sociodemographic factors into account.

The purpose of this study was to examine racial/ethnic disparities in the relationship between different antenatal stressful life events and postpartum depression, among women in the U.S. who have had a recent live birth. Secondly, we aimed to explore whether provider communication on perinatal depression was associated with a lower risk of postpartum depression and whether the effect (if any) varied according to maternal race/ethnicity. 
Methods

Dataset and study subjects

This study used data for the years 2009-11, collected by the PRAMS, a surveillance project of the Centers for Disease Control and Prevention (CDC) and state health departments. Every month, a stratified systematic sample of 100 to 250 new mothers is drawn from a sampling frame of eligible birth certificates. Some women, such as those having babies with low birth weight, are oversampled so that adequate data are available from smaller but higher-risk populations. Many states also stratify by maternal race/ethnicity. The analysis weight, which can be interpreted as the number of women like herself in the population that each respondent represents, is obtained by multiplying the sampling, nonresponse, and noncoverage weights. The standardized data collection methodology ensures that between-state comparisons can be made and the data can be used for single-state or multi-state analyses. Questionnaires are mailed starting 2 to 4 months after delivery, with telephone follow-ups for the non-respondents. The responses are linked to extracted birth certificate variables. Barriers to and content of prenatal care, obstetric and medical history, intimate partner physical violence, contraceptive practices, economic status, maternal antenatal stress, topics discussed during antenatal care, and early infant development and health status are some of the contents of the PRAMS questionnaire.

Variables

Postpartum depression, the outcome of interest, was assessed by whether a women felt down, depressed or helpless; hopeless; or slowed down, since the birth of her 
new baby. For each of the three questions, respondents were required to choose between the following options: never, rarely, sometimes, often, and always, with corresponding scores of 1 to 5 respectively. So, the total score ranged from 3-15. Based on CDC recommendations, any woman with a score of 10 or higher was considered to have postpartum depression. When only two or one question(s) were/was answered, the cutoffs were 7 and 4 respectively (Guidelines for Analyzing Phase 6 Core Depression Question, unpublished report, 2012).

The exposure variables were the antenatal stressful life events, assessed by whether the following events happened to a woman during the 12 months immediately before the birth of her new baby: 1 . A close family member was very sick and had to go to the hospital; 2. She had a separation or divorce from her husband or partner; 3. She moved to a new address; 4. She was homeless; 5 . Her husband/partner lost his job; 6. She wanted to continue working, but lost her job; 7. She had more than usual arguments with her husband/partner; 8 . Her husband/partner revealed that he did not want her to be pregnant; 9. She had a lot of bills, but was unable to pay; 10. She was involved in a physical fight; 11 . She or her husband/partner went to jail; 12 . Someone very close to her had a problem with drinking or drugs; 13 . Someone very close to her died (CDC, 2009).

The main covariate of interest was provider communication on perinatal depression, which was assessed by a woman's response (yes or no) to whether a doctor, nurse, or other health care worker talked with her, during any of her prenatal cate visits, regarding what to do if she felt depressed during her pregnancy or after the birth of her baby (CDC, 2009). Other covariates were maternal age; federal poverty level; education; 
marital status; pre-pregnancy visit to a health care worker to have a check-up or treatment for depression; number of previous live births; pregnancy intention at the time of conception; antenatal intimate partner physical violence ; provider communication on IPPV; adequacy of prenatal care utilization; health insurance for her prenatal care and delivery; antenatal morbidity; mode of delivery, any adverse neonatal outcome; and gender of the new baby. Race/ethnicity was classified as non-Hispanic white, nonHispanic black, Hispanic, American Indian/Alaska Native, Asian/Pacific Islander, and non-Hispanic other or mixed race. Antenatal maternal morbidity was assessed by whether a respondent reported having experienced none, 1,2,3, or, more than 3 of the following problems during her most recent pregnancy: gestational diabetes (diagnosed by a health care worker); vaginal bleeding; kidney or bladder infection; severe nausea, vomiting or dehydration; cervix had to be sewn shut; high blood pressure; placental problems; preterm or early labor; premature rupture of the membranes; having a blood transfusion; and being hurt in a car accident. A mother whose new baby had a birth defect, low birthweight, preterm birth, or had to be admitted to an intensive care unit, was considered to have experienced an adverse neonatal outcome. Following the guidelines issued by the U.S. Department of Health \& Human Services (HHS) for the years 2009, 2010 and 2011, income relative to the federal poverty level was calculated using annual household income and the number of dependents including the woman and her new child. Race/ethnicity was used to stratify all the analyses (described in the next section). All the variables included in the analyses were categorical. 
Analysis

Chi-square tests of independence were done to compare the distribution of each variable with maternal race/ethnicity. The prevalence of postpartum depression was compared between those who did and did not experience each stressful life event. This comparison was done separately for each racial/ethnic group. Postpartum depression prevalence was also examined according to the different levels of all covariates.

The independent variables and postpartum depression were dummy coded. For each racial/ethnic group, the variables that were statistically significant in bivariate analyses were introduced in a multivariable logistic regression model with postpartum depression as the outcome, and the adjusted odds ratios (aORs) and 95\% confidence intervals (CIs) were reported. SAS 9.4 (SAS Institute Inc., Cary, NC, US) was used for all analyses. SAS procedures that account for survey design (Proc Survey) were employed to adjust for the analysis weights.

Results

Of 116,595 respondents in the PRAMS 2009-11 dataset, 87,565 (75\%) had valid responses to all variables of interest and were utilized in the bivariate and multivariable analyses. Sixty-three percent were non-Hispanic whites, $12.0 \%$ non-Hispanic blacks, 17.7\% Hispanics, 0.8\% American Indians/Alaska Natives, 4.7\% Asians/Pacific Islanders, and the rest belonged to other/mixed races (results not shown in table). The distribution of most of the variables, differed significantly $(\mathrm{P}<0.05)$ between the racial/ethnic groups, 
but the disparities were striking for some factors (table 1). Sixty-three percent of the Hispanics were in the $\leq 100 \%$ FPL category, compared with $23.2 \%$ of Asians/Pacific Islanders, and $25.8 \%$ of non-Hispanic whites. The proportion of women in the highest education category was the highest among Asians/Pacific Islanders and the lowest among American Indians/Alaska Natives. Less than $9 \%$ of non-Hispanic whites had inadequate prenatal care utilization, compared with $19 \%$ of American Indians/Alaska Natives. The proportion of women reporting provider communication on perinatal depression was higher than $70 \%$ for the entire sample, ranging from $60.2 \%$ among Asians/Pacific Islanders to $76.2 \%$ among non-Hispanic blacks. For each racial/ethnic group, the most common antenatal stressful life event was moving to a new address, which was reported by $29 \%$ to $42 \%$ of the respondents. American Indians/Alaska Natives reported the highest prevalence for six antenatal stressful life events, including sickness and hospitalization of a close family member, separation/divorce, moving to a new address, incarceration of herself or husband/partner, drug/alcohol problems of someone very close, and death of someone very close. The highest proportions of loss of job, having more than usual arguments with husband/partner, husband/partner not wanting the pregnancy, having a lot of bills that she could not pay, and being in a physical fight, were noted amongst nonHispanic blacks. For homelessness and loss of job of husband/partner, Hispanics had the highest prevalence. Eleven percent women met the criteria for postpartum depression; the prevalence ranged from 7.9\% among Asians/Pacific Islanders to 14.0\% among American Indians/Alaska Natives (table 1).

Women in the lower income and education categories generally had a higher prevalence of postpartum depression than those in the highest categories respectively 
(table 2). Having a pre-pregnancy check-up or treatment for depression; lack of intention to become pregnant at the time (or before) her last pregnancy; experiencing intimate partner physical violence; and experiencing a higher number of maternal morbidities significantly associated with postpartum depression symptoms, irrespective of race/ethnicity. Those who experienced a stressful life event had a 2 to 3 times unadjusted prevalence of postpartum depression than those who did not experience it. The proportion of women experiencing postpartum depression symptoms was lower among those who reported provider communication on perinatal depression compared with those who did not have this communication for non-Hispanic whites, non-Hispanic blacks, Hispanics, and Asians/Pacific Islanders. The difference in postpartum depression prevalence between those with and without a provider communication was statistically significant for non-Hispanic whites, non-Hispanic blacks and the Hispanics (table 2).

In multivariable analyses (table 3 ), belonging to the $\geq 401 \%$ FPL category, compared with the $100 \%$ or less FPL bracket, was a protective factor for non-Hispanic whites (aOR: 0.83; 95\% CI: 0.70, 0.97) and non-Hispanic blacks (aOR: 0.46; 95\% CI: 0.31, 0.69) (table 3). All, but Asians/Pacific Islanders, with pre-pregnancy depression check-up or treatment had a significantly higher odds of postpartum depression compared with those who did not have this check-up. Non-Hispanic whites, Hispanics, and Asians/Pacific Islanders without any intention to be pregnant even in the future had more than 1.5 times the odds of experiencing postpartum depression, compared with those who wanted to be pregnant then or sooner. Having experienced IPPV was a significant correlate of postpartum depression for most women, but the adjusted odds were notably high (nearly 2.5) among Hispanics and American Indians/Alaska Natives. Among 
women of all the racial/ethnic groups, with the exception of those of other or mixed race, having more than usual arguments with husband or partner increased the adjusted odds of postpartum depression. Especially, Hispanics experiencing this stressful life event were nearly four times as likely to have postpartum depression, compared with those who did not have more than usual arguments with partner. Non-Hispanic blacks, whose husband or partner did not want the pregnancy, were more likely (aOR: 1.47; 95\% CI: 1.14, 1.90) to experience postpartum depression. Irrespective of race/ethnicity, having a lot of bills that they were unable to pay was a significant risk factor, whereas drug or drinking problems of someone very close was significant (aOR: 1.37 ; $95 \%$ CI: $1.21,1.55)$ for nonHispanic whites (table 3). Provider communication was inversely associated with postpartum depression for the non-Hispanic whites (aOR: 0.77 ; 95\% CI: $0.69,0.85)$ and non-Hispanic blacks (aOR: 0.74; 95\% CI: 0.60, 0.93) (table 3).

\section{Discussion}

Approximately $11 \%$ of all the respondents in our study reported postpartum depression symptoms. American Indians/Alaska Natives had the highest prevalence, followed by non-Hispanic blacks, non-Hispanic whites, Hispanics and Asians/Pacific Islanders in that order. More than $70 \%$ reported that their antenatal care provider discussed perinatal depression; the proportion ranging from 60\% among Asians/Pacific Islanders to $76 \%$ among Hispanics. Among the antenatal stressful life events, having more than usual arguments with husband/partner, husband/partner not wanting the woman to be pregnant, and having a lot of bills that she was unable to pay, were common risk factors of postpartum depression, even after taking into account maternal socio- 
demographic characteristics, and other pre-pregnancy, antepartum, intrapartum, postpartum and neonatal factors. Provider communication about perinatal depression significantly reduced the adjusted odds of postpartum depression among non-Hispanic blacks and non-Hispanic whites.

The prevalence of postpartum depression symptoms in all the racial/ethnic groups, barring Asians/Pacific Islanders, was $\geq 11 \%$, with American Indians/Alaska Natives having the highest proportion. The prevalence of postpartum depression symptoms in 2004-2005 was the highest among non-Hispanic blacks and/or Hispanics in most of the states (CDC, 2008). Most of the other studies that have looked at racial/ethnic distribution of postpartum depression (Liu \& Tronick, 2013, 2014) have focused on single states. In addition, none of these studies were able to examine the proportion of women with postpartum depression symptoms among the American Indians/Alaska Natives. Our finding regarding the highest prevalence of postpartum depression symptoms among American Indians/Alaska Natives might be a reflection of the fact that in general, American Indians/Alaska Natives adults have a higher prevalence of any mental illness, as reported in the Substance Abuse and Mental Health Services Administration (SAMHSA). This is also corroborated by our observation that the proportion of women reporting a pre-pregnancy check-up or treatment for depression was the highest among American Indians/Alaska Natives. Factors leading to negative mental health consequences among American Indians/Alaska Natives might include adverse life situations, lower SES, and historical aspects, such as being removed from their lands, and attempts to eradicate the native culture (Office of the Surgeon General [US] and the Center for Mental Health Services [US], 2001). Discrimination, which has been linked 
with postpartum depression (Canady et al. 2008) and is more likely to be experienced by the minorities, could also explain the racial/ethnic disparities. Although it is difficult to explain the low prevalence of postpartum depression symptoms among Asians/Pacific Islanders, ethnic group density (Pickett \& Wilkinson, 2008) and nativity might have played a role. An analysis of 2002-03 National Latino and Asian American Study data revealed that immigrants, compared with U.S. born Asians, were less likely to have anxiety or depression (John et al., 2012).

Similar to the results of an analysis of New York City PRAMS data of 2004-2007 (Liu et al., 2013), we observed that the prevalence of provider-patient conversation on perinatal depression was the lowest among Asians/Pacific Islanders in each of the 30 states and in NYC. A qualitative study among Asian Indian mothers living in Northern California suggested that this group of women might prefer family or social support, rather than the help of a mental health care provider (Goyal et al., 2015). They also shared that depression was usually not taken seriously; mental health help-seeking was often viewed in the family as a weakness, and as an attempt at attention-seeking (Goyal et al., 2015). It will be interesting to examine whether these factors apply to Asians/Pacific Islanders from other countries as well, thereby making them uncomfortable or reluctant to engage in any discussion regarding potential future depressive symptoms with their antenatal care providers. Language barriers, especially among first generation immigrants, might also have contributed to this lack of communication.

In the context of postpartum depression, studies conducted in diverse settings, including Mexico, USA, Korea, and Australia have reported the beneficial roles of 
antenatal interventions, such as psychotherapy, psychoeducation, interpersonal therapy and cognitive behavioral therapy (Clatworthy, 2012). Our findings highlight the importance of provider communication on perinatal depression, which can be a component of routine antenatal care, without requiring any additional intervention. The absence of significant unadjusted and adjusted provider communication-postpartum depression associations, respectively, among Asians/Pacific Islanders and Hispanics, might be due to cultural and/or language barriers. Contrary to the other groups, American Indians/Alaska Natives with provider-patient communication actually had a higher $(14.5 \%)$ unadjusted prevalence of postpartum depression than those without the communication (13.0\%). This could be attributed to the extremely low likelihood of an American Indians/Alaska Natives pregnant woman to have someone of her own race, as her health care provider, which is likely among all minority groups, but more so among American Indians/Alaska Natives, who constitute a negligible proportion of the U.S. health care workforce; in $2010-12$ only $0.2 \%$ of the physicians and $0.4 \%$ of the registered nurses were American Indians/Alaskan Natives (U.S. Department of Health and Human Services, Health Resources and Services Administration, and National Center for Health Workforce Analysis, 2014). Although the evidence is inconclusive (Meghani et al., 2009), provider-patient concordance in race, ethnicity and language has been hypothesized to result in improved communication, understanding, trust and decisionmaking (U.S. Department of Health and Human Services, Health Resources and Services Administration, and Bureau of Health Professions, 2006). It is possible that a race/ethnicity discordant provider-patient conversation, especially on a sensitive topic such as mental health, results in more harms than benefits, among American 
Indians/Alaska Natives. However, this needs to be cautiously interpreted in the absence of any data on providers' race/ethnicity in our study.

Our observation that being told by the husband/partner that he did not want the pregnancy was a significant risk factor for postpartum depression only for non-Hispanic blacks, even after controlling for covariates, coupled with the fact that this particular stressful life event also had the highest prevalence among non-Hispanic blacks, may be related to inadequate partner support, which has been found to disproportionately affect the perinatal mental health of non-Hispanic blacks, compared with non-Hispanic whites (Cheng et al., 2016). High partner-related or relational stress has previously been noted to be a risk factor for the minorities, but not for the non-Hispanic whites (Liu et al., 2016). Although drug/alcohol problems of someone very close had a strong association with the unadjusted postpartum depression prevalence for all race/ethnicities, in the multivariable model, this stressful life event was a significant predictor only for the non-Hispanic whites. This suggests that for the non- non-Hispanic whites, covariates, such as, belonging to a lower income category, experiencing IPPV, and having a lot of bills, were more important postpartum depression correlates. It is possible that provider communication buffers some of the impact of the antenatal stressor by making the women better prepared to cope with pregnancy and postpartum, and thereby reduces the odds of postpartum depression.

\section{Limitations}

There are a number of limitations to this study. Potential correlates of postpartum depression, such as intimate partner violence experienced after childbirth, and social 
support could not be included because the information was unavailable or available from very few states. Because the questions on antenatal stressful life events in PRAMS asked about the 12 months prior to childbirth, a woman reporting an event may have experienced it during the year before childbirth, but within the 2-3 months before she got pregnant. Based on data from 30 out of the 50 states, this analysis may not be generalizable to the entire U.S. Furthermore, $25 \%$ of the observations had to be excluded from our analyses because of missing information on one or more variables of interest. There were some striking differences between women with all valid responses and those with missing response(s) to at least one variable of interest. Forty one percent, $20 \%$ and $29 \%$ of the 23,101 women with missing responses to one or more variables of interest were non-Hispanic whites, non-Hispanic blacks, and Hispanics respectively, as opposed to $63 \%, 12 \%$ and $18 \%$ among those without any missing response (results not shown in table). Nevertheless, it is somewhat reassuring that the racial/ethnic distribution of the sample included in our analyses was not strikingly different that of the national population of 2010. The antenatal stressful life event with the most notable difference in prevalence between women with missing (6\%) and non-missing responses (3.2\%) was homelessness. However, among women with one or more missing responses, the proportion with provider communication on perinatal depression (73.3\%) and postpartum depression (11.1\%) was fairly close to the respective proportions ( $70.4 \%$ and $11.7 \%)$ among women with valid responses. Another limitation in our study was that women experiencing postpartum depression could have been more likely to remember specific stressful life events, and whether they had a provider communication on perinatal depression, leading to recall bias. However, this bias was more likely to bring the OR 
towards the null; the fact that the OR is significantly lower than null despite that suggests that recall bias may not have been a major issue as far as investigating the effect of provider communication is concerned. Self-reported postpartum depression symptoms are likely to have subjective variation and social-desirability bias. Lastly, with crosssectional data, temporal relationship cannot be established between the variables. This problem is partially obviated by the fact that an event during pregnancy must have preceded postpartum depression. We also did not have any information on the women's experiences of perceived discrimination during the peripartum.

\section{Conclusions}

Despite the limitations, our study has examined the racial/ethnic disparities in the relationship between antenatal stressful life events and postpartum depression using a multi-state population-based dataset, after taking into consideration a number of covariates. This information can help antenatal health care providers identify women at risk for postpartum depression, after taking into consideration the race/ethnicity-specific vulnerabilities of different racial/ethnic groups to specific antenatal stressful life events. In addition, this study points out the benefits of health care provider communication on perinatal depression during antenatal check-ups. With a growing recognition of the importance of peripartum mental health issues, considering the recent USPSTF recommendations, and in light of our findings, the importance of provider communication to reduce postpartum depression, cannot be overemphasized. This conversation seems especially important to mitigate the adverse consequences of specific stressful life events and to decrease the probability of postpartum depression. Despite the 
general benefits, the potential reasons as to why American Indians/Alaska Natives and Asians/Pacific Islanders women have not been benefitted by this communication, merit in-depth investigation. Our findings can help guide policy changes on provider communication on perinatal depression, as well as to make this communication culturally appropriate.

\section{References}

Beck, C. T. (1998). The effects of postpartum depression on child development: a metaanalysis. Archives of Psychiatric Nursing, 12(1), 12-20.

Beck, C. T. (2001). Predictors of postpartum depression: an update. Nursing Research, 50(5), 275-285.

Canady, R. B., Bullen, B. L., Holzman, C., Broman, C., \& Tian, Y. (2008).

Discrimination and symptoms of depression in pregnancy among African American and White women. Women's Health Issues, 18(4), 292-300.

Centers for Disease Control and Prevention (CDC). (2008). Prevalence of self-reported postpartum depressive symptoms--17 states, 2004-2005. MMWR. Morbidity and Mortality Weekly Report, 57(14), 361.

Centers for Disease Control and Prevention (CDC). (2009). Pregnancy Risk Assessment Monitoring System Phase 6 Core Questionnaire. http://www.cdc.gov/prams/pdf/phase6_topicsreference.pdf. Accessed May 3, 2016.

Cheng, E. R., Rifas-Shiman, S. L., Perkins, M. E., Rich-Edwards, J. W., Gillman, M. W., Wright, R., \& Taveras, E. M. (2016). The influence of antenatal partner support on pregnancy outcomes. Journal of Women's Health. February 2016, ahead of print. doi:10.1089/jwh.2015.5462.

Clatworthy, J. (2012). The effectiveness of antenatal interventions to prevent postnatal depression in high-risk women. Journal of Affective Disorders, 137(1), 25-34.

Cooper, P. J., \& Murray, L. (1998). Fortnightly review: Postnatal depression. British Medical Journal, 316(7148), 1884. 
Faisal-Cury, A., Tedesco, J. J. A., Kahhale, S., Menezes, P. R., \& Zugaib, M. (2004). Postpartum depression: in relation to life events and patterns of coping. Archives of Women's Mental Health, 7(2), 123-131.

Farr, S. L., Ko, J. Y., Burley, K., \& Gupta, S. (2016). Provider communication on perinatal depression: a population-based study. Archives of Women's Mental Health, 19, $35-40$.

Goyal, D., Park, V. T., \& McNiesh, S. (2015). Postpartum depression among Asian Indian mothers. MCN: The American Journal of Maternal/Child Nursing, 40(4), 256-261.

John, D. A., De Castro, A. B., Martin, D. P., Duran, B., \& Takeuchi, D. T. (2012). Does an immigrant health paradox exist among Asian Americans? Associations of nativity and occupational class with self-rated health and mental disorders. Social Science \& Medicine, 75(12), 2085-2098.

Liu, C. H., \& Tronick, E. (2013). Re-conceptualising Prenatal life stressors in predicting post-partum depression: Cumulative-, specific-, and domain-specific Approaches to Calculating Risk. Paediatric and Perinatal Epidemiology, 27(5), 481-490.

Liu, C. H., \& Tronick, E. (2013). Rates and predictors of postpartum depression by race and ethnicity: results from the 2004 to 2007 New York City PRAMS survey (Pregnancy Risk Assessment Monitoring System). Maternal and Child Health Journal, 17(9), 15991610.

Liu, C. H., \& Tronick, E. (2014). Prevalence and predictors of maternal postpartum depressed mood and anhedonia by race and ethnicity. Epidemiology and Psychiatric Sciences, 23(02), 201-209.

Liu, C. H., Giallo, R., Doan, S. N., Seidman, L. J., \& Tronick, E. (2016). Racial and ethnic differences in prenatal life stress and postpartum depression symptoms. Archives of Psychiatric Nursing, 30(1):7-12.

Meghani, S. H., Brooks, J. M., Gipson-Jones, T., Waite, R., Whitfield-Harris, L., \& Deatrick, J. A. (2009). Patient-provider race-concordance: does it matter in improving minority patients' health outcomes?. Ethnicity \& Health, 14(1), 107-130.

Office of the Surgeon General (US), Center for Mental Health Services (US), \& National Institute of Mental Health (U.S.) (2001). Mental health: Culture, race, and ethnicity: A supplement to mental health: A report of the surgeon general. Rockville, Maryland: Substance Abuse and Mental Health Services Administration (U.S.).

O'Hara, M. W., \& Swain, A. M. (1996). Rates and risk of postpartum depression-a meta-analysis. International Review of Psychiatry, 8(1), 37-54.

Pickett, K. E., \& Wilkinson, R. G. (2008). People like us: ethnic group density effects on health. Ethnicity \& Health, 13(4), 321-334. 
Robertson, E., Grace, S., Wallington, T., \& Stewart, D. E. (2004). Antenatal risk factors for postpartum depression: a synthesis of recent literature. General Hospital Psychiatry, 26(4), 289-295.

Silverman, M. E., \& Loudon, H. (2010). Antenatal reports of pre-pregnancy abuse is associated with symptoms of depression in the postpartum period. Archives of Women's Mental Health, 13(5), 411-415.

Siu, A.L., \& the US Preventive Services Task Force. (2016). Screening for depression in adults: US preventive services task force recommendation statement. JAMA 315 (4): 380387.

Sockol, L. E., Epperson, C. N., \& Barber, J. P. (2013). Preventing postpartum depression: a meta-analytic review. Clinical Psychology Review, 33(8), 1205-1217.

Stone, S. L., Diop, H., Declercq, E., Cabral, H. J., Fox, M. P., \& Wise, L. A. (2015). Stressful events during pregnancy and postpartum depressive symptoms. Journal of Women's Health, 24(5), 384-393.

Tse, A. C., Rich-Edwards, J. W., Rifas-Shiman, S. L., Gillman, M. W., \& Oken, E. (2010). Association of maternal prenatal depressive symptoms with child cognition at age 3 years. Paediatric and Perinatal Epidemiology, 24(3), 232-240.

U.S. Department of Health and Human Services, Health Resources and Services Administration, Bureau of Health Professions. (2006). The Rationale for Diversity in the Health Professions: A Review of the Evidence. Rockville, Maryland.

U.S. Department of Health and Human Services, Health Resources and Services Administration, National Center for Health Workforce Analysis. (2014). Sex, Race, and Ethnic Diversity of U.S. Health Occupations (2010-2012). Rockville, Maryland.

Vigod, S. N., Villegas, L., Dennis, C. L., \& Ross, L. E. (2010). Prevalence and risk factors for postpartum depression among women with preterm and low-birth-weight infants: a systematic review. BJOG: An International Journal of Obstetrics \& Gynaecology, 117(5), 540-550.

Youash, S., Campbell, K., Avison, W., Peneva, D., Sharma, V., \& Xie, B. (2013). Influence of health information levels on postpartum depression. Archives of Women's Mental Health, 16(6), 489-498. 
Tables and figures

Table 1: Racial and ethnic distribution of antenatal stressful life events (SLEs), postpartum depression (PPD), socio-demographic characteristics and pre-pregnancy and antenatal factors and all covariates among women in the United States, who have had a recent live birth (PRAMS, 2009-11)

\begin{tabular}{|c|c|c|c|c|c|c|}
\hline & $\begin{array}{l}\begin{array}{l}\text { Non-Hispanic } \\
\text { white }\end{array} \\
\%(95 \% \mathrm{CI})^{\mathrm{a}} \\
\mathrm{N}=49,949\end{array}$ & $\begin{array}{l}\text { Non-Hispanic } \\
\text { black }\end{array}$ & $\begin{array}{l}\%(95 \% \text { CI })^{a} \\
N=11,874\end{array}$ & $\begin{array}{l}\text { American } \\
\text { Indian/Alaska } \\
\text { Native } \\
\%(95 \% \mathrm{CI})^{\mathrm{a}} \\
\mathrm{N}=2,757\end{array}$ & $\begin{array}{l}\text { Asian/Pacific } \\
\text { Islander }\end{array}$ & $\begin{array}{l}\text { Non-Hispanic other, } \\
\text { or mixed race }\end{array}$ \\
\hline \multicolumn{7}{|c|}{ Socio-demographic characteristics } \\
\hline \multicolumn{7}{|c|}{ Age in years ${ }^{* * * *}$} \\
\hline $25-29$ & $31.2(30.5,31.8)$ & $27.3(25.9,28.7)$ & $28.2(26.6,29.8)$ & $30.3(26.8,33.8)$ & $28.9(27.0,30.8)$ & $27.8(24.7,30.9)$ \\
\hline Less than 20 & $5.5(5.2,5.8)$ & $10.8(9.8,11.7)$ & $10.3(9.3,11.4)$ & $14.1(11.2,17.0)$ & $2.3(1.7,2.9)$ & $10.6(8.3,12.9)$ \\
\hline $20-24$ & $20.4(19.9,21.0)$ & $30.7(29.3,32.2)$ & $27.2(25.6,28.8)$ & $33.6(30.0,37.2)$ & $10.2(9.0,11.4)$ & $24.8(21.8,27.8)$ \\
\hline $30-34$ & $28.2(27.6,28.8)$ & $19.2(18.0,20.4)$ & $21.4(19.9,22.8)$ & $16.6(13.4,19.8)$ & $35.3(33.3,37.4)$ & $23.1(20.1,26.2)$ \\
\hline 35 and above & $14.7(14.3,15.2)$ & $12.0(11.1,12.9)$ & $12.9(11.7,14.0)$ & $5.4(4.2,6.5)$ & $23.2(21.4,25.0)$ & $13.7(11.1,16.3)$ \\
\hline \multicolumn{7}{|c|}{ Maternal education ${ }^{* * * *}$} \\
\hline$\geq 16$ yrs & $40.8(40.2,41.5)$ & $16.9(15.8,18.0)$ & $10.8(9.8,11.9)$ & $9.9(7.3,12.6)$ & $61.8(59.8,63.8)$ & $28.0(24.9,31.1)$ \\
\hline $0-8$ yrs & $1.0(0.8,1.2)$ & $1.1(0.8,1.4)$ & $13.4(12.2,14.6)$ & $1.1(0.4,1.8)$ & $1.2(0.7,1.7)$ & $1.8(0.5,3.0)$ \\
\hline $9-11$ yrs & $7.0(6.6,7.4)$ & $14.3(13.2,15.4)$ & $22.2(20.8,23.7)$ & $23.3(19.8,26.7)$ & $4.2(3.4,5.0)$ & $13.0(10.5,15.5)$ \\
\hline 12 yrs & $22.4(21.8,23.0)$ & $32.7(31.3,34.1)$ & $32.0(30.3,33.7)$ & $36.4(32.8,40.0)$ & $14.9(13.6,16.2)$ & $24.9(21.9,28.0)$ \\
\hline $13-15$ yrs & $28.8(28.2,29.4)$ & $35.0(33.5,36.4)$ & $21.5(20.1,23.0)$ & $29.3(25.8,32.7)$ & $18.0(16.4,19.6)$ & $32.3(29.0,35.6)$ \\
\hline \multicolumn{7}{|c|}{ Income in relation to federal poverty level ${ }^{* * * *}$} \\
\hline$\leq 100 \%$ & $25.8(25.2,26.4)$ & $59.1(57.6,60.6)$ & $62.5(60.8,64.2)$ & $61.3(57.5,65.1)$ & $23.2(21.4,24.9)$ & $43.0(39.5,46.5)$ \\
\hline $101-200 \%$ & $21.0(20.5,21.6)$ & $21.9(20.7,23.2)$ & $21.5(20.0,22.9)$ & $22.4(19.3,25.5)$ & $17.5(16.0,18.9)$ & $23.5(20.5,26.6)$ \\
\hline $201-300 \%$ & $7.0(6.7,7.3)$ & $4.6(4.0,5.2)$ & $3.5(2.9,4.0)$ & $3.7(2.5,4.9)$ & $7.1(6.1,8.1)$ & $6.1(4.5,7.6)$ \\
\hline $301-400 \%$ & $4.1(3.9,4.4)$ & $1.3(1.1,1.6)$ & $1.6(1.1,2.1)$ & $2.0(1.1,3.0)$ & $3.6(2.9,4.4)$ & $2.8(1.6,3.9)$ \\
\hline$\geq 401 \%$ & $42.0(41.3,42.7)$ & $13.0(12.0,14.1)$ & $10.9(9.8,12.0)$ & $10.6(7.9,13.3)$ & $48.7(46.6,50.8)$ & $24.6(21.6,27.6)$ \\
\hline \multicolumn{7}{|l|}{ Marital status ${ }^{* * * *}$} \\
\hline Married & $73.1(72.5,73.8)$ & $28.8(27.5,30.2)$ & $50.6(48.8,52.3)$ & $41.2(37.4,45.0)$ & $84.5(83.1,85.8)$ & $56.1(52.6,59.7)$ \\
\hline Not married & $26.9(26.2,27.5)$ & $71.2(69.8,72.5)$ & $49.4(47.7,51.2)$ & $58.8(55.0,62.6)$ & $15.5(14.2,16.9)$ & $43.9(40.3,47.4)$ \\
\hline
\end{tabular}


Table 1: Racial and ethnic distribution of antenatal stressful life events (SLEs), postpartum depression (PPD), socio-demographic characteristics and pre-pregnancy and antenatal factors and all covariates among women in the United States, who have had a recent live birth (PRAMS, 2009-11)

\begin{tabular}{|c|c|c|c|c|c|c|}
\hline & $\begin{array}{l}\%(95 \% \mathrm{CI})^{\mathrm{a}} \\
\mathrm{N}=49,949\end{array}$ & $\begin{array}{l}\text { Non-Hispanic } \\
\text { black }\end{array}$ & $\begin{array}{l}\%(95 \% \mathrm{CI})^{\mathrm{a}} \\
\mathrm{N}=11,874\end{array}$ & $\begin{array}{l}\text { American } \\
\text { Indian/Alaska } \\
\text { Native } \\
\%(95 \% \mathrm{CI})^{\mathrm{a}} \\
\mathrm{N}=2,757\end{array}$ & $\begin{array}{l}\text { Asian/Pacific } \\
\text { Islander }\end{array}$ & $\begin{array}{l}\text { Non-Hispanic other, } \\
\text { or mixed race }\end{array}$ \\
\hline \multicolumn{7}{|c|}{ Pre-pregnancy and antenatal factors } \\
\hline $\begin{array}{l}\text { No } \\
\text { Yes }\end{array}$ & $\begin{array}{l}86.8(86.4,87.3) \\
13.1(12.7,13.6)\end{array}$ & $\begin{array}{l}90.1(89.3,91.0) \\
9.9(9.0,10.7)\end{array}$ & $\begin{array}{l}91.7(90.8,92.6) \\
8.3(7.4,9.2)\end{array}$ & $\begin{array}{l}84.7(81.6,87.8) \\
15.3(12.2,18.4)\end{array}$ & $\begin{array}{l}94.7(93.9,95.6) \\
5.3(4.4,6.1)\end{array}$ & $\begin{array}{l}86.3(84.0,88.5) \\
13.7(11.5,16.0)\end{array}$ \\
\hline $\begin{array}{l}\text { Previous number } \\
\quad 0 \\
1 \\
2 \\
3+\end{array}$ & $\begin{array}{l}\text { ve births } \\
42.6(41.9,43.3) \\
33.8(33.1,34.4) \\
15.0(14.6,15.5) \\
8.6(8.2,9.0)\end{array}$ & $\begin{array}{l}37.9(36.4,39.4) \\
29.5(28.1,30.8) \\
18.2(17.0,19.4) \\
14.4(13.3,15.5)\end{array}$ & $\begin{array}{l}32.5(30.9,34.1) \\
31.0(29.3,32.6) \\
20.5(19.0,21.9) \\
16.0(14.7,17.4)\end{array}$ & $\begin{array}{l}37.8(33.9,41.7) \\
27.4(24.1,30.7) \\
17.6(14.5,20.6) \\
17.2(14.5,19.9)\end{array}$ & $\begin{array}{l}47.2(45.1,49.3) \\
34.7(32.7,36.7) \\
12.4(11.0,13.8) \\
5.7(4.8,6.5)\end{array}$ & $\begin{array}{l}43.0(39.5,46.5) \\
30.5(27.2,33.7) \\
17.0(14.2,19.9) \\
9.5(7.4,11.7)\end{array}$ \\
\hline $\begin{array}{l}\text { Intention to get p } \\
\text { Then/sooner } \\
\text { Later } \\
\text { Never }\end{array}$ & $\begin{array}{l}\text { ant before the mos } \\
64.9(64.2,65.3) \\
27.3(26.7,27.9) \\
7.8(7.4,8.2)\end{array}$ & $\begin{array}{l}\text { recent pregnancy } \\
36.3(34.8,37.7) \\
43.3(41.8,44.8) \\
20.4(19.2,21.7)\end{array}$ & $\begin{array}{l}\text { en did she intend to } \\
53.1(51.3,54.9) \\
37.4(35.7,39.1) \\
9.5(8.5,10.6)\end{array}$ & $\begin{array}{l}\text { pregnant) } \\
47.6(43.7,51.5) \\
39.1(35.3,42.9) \\
13.3(10.8,15.8)\end{array}$ & $\begin{array}{l}69.7(67.9,71.6) \\
23.0(21.4,24.7) \\
7.2(6.2,8.3)\end{array}$ & $\begin{array}{l}55.4(51.9,58.9) \\
32.4(29.2,35.7) \\
12.1(9.6,14.7)\end{array}$ \\
\hline $\begin{array}{l}\text { Prenatal care utili } \\
\text { Adequate } \\
\text { Inadequate } \\
\text { Intermediate } \\
\text { Adequate plus }\end{array}$ & $\begin{array}{l}\text { on }{ }^{* * * *} \\
49.2(48.5,49.9) \\
8.5(8.1,8.9) \\
12.4(12.0,12.9) \\
29.9(29.3,30.5)\end{array}$ & $\begin{array}{l}39.3(37.8,40.8) \\
18.6(17.4,19.8) \\
13.8(12.7,14.8) \\
28.3(27.0,29.7)\end{array}$ & $\begin{array}{l}42.6(40.9,44.4) \\
18.0(16.6,19.4) \\
14.1(12.9,15.4) \\
25.3(23.8,26.8)\end{array}$ & $\begin{array}{l}37.7(33.8,41.6) \\
18.9(16.1,21.8) \\
16.6(13.9,19.2) \\
26.8(23.4,30.2)\end{array}$ & $\begin{array}{l}49.1(47.0,51.2) \\
10.2(8.8,11.5) \\
14.6(13.1,16.0) \\
26.2(24.4,28.0)\end{array}$ & $\begin{array}{l}40.9(37.4,44.4) \\
14.1(11.5,16.7) \\
12.9(10.7,15.1) \\
32.1(28.7,35.4)\end{array}$ \\
\hline $\begin{array}{l}\text { Health care provi } \\
\text { No } \\
\text { Yes }\end{array}$ & $\begin{array}{c}\text { communication on } \\
30.4(29.7,31.0) \\
69.6(69.0,70.3)\end{array}$ & $\begin{array}{l}\text { erinatal depression } \\
23.8(22.5,25.1) \\
76.2(74.9,77.5)\end{array}$ & $\begin{array}{l}28.2(26.6,29.8) \\
71.8(70.2,73.4)\end{array}$ & $\begin{array}{l}27.4(23.7,31.1) \\
72.6(68.9,76.3)\end{array}$ & $\begin{array}{l}39.8(37.7,41.9) \\
60.2(58.1,62.3)\end{array}$ & $\begin{array}{l}28.2(28.6,29.8) \\
69.9(66.6,73.2)\end{array}$ \\
\hline $\begin{array}{l}\text { Experienced intin } \\
\text { No } \\
\text { Yes }\end{array}$ & $\begin{array}{l}\text { partner physical v } \\
97.9(97.7,98.1) \\
2.1(1.9,2.3)\end{array}$ & $\begin{array}{l}\text { lence during pregn } \\
94.5(93.9,95.2) \\
5.5(4.8,6.1)\end{array}$ & $\begin{array}{l}\text { cy } \\
96.5(95.8,97.1) \\
3.5(2.9,4.2)\end{array}$ & $\begin{array}{l}95.0(93.5,96.6) \\
5.0(3.4,6.5)\end{array}$ & $\begin{array}{l}97.9(97.4,98.5) \\
2.1(1.5,2.6)\end{array}$ & $\begin{array}{l}95.6(94.1,97.2) \\
4.4(2.8,5.9)\end{array}$ \\
\hline $\begin{array}{l}\text { Health care provi } \\
\text { No } \\
\text { Yes }\end{array}$ & $\begin{array}{c}\text { communication on } \\
56.0(55.4,56.7) \\
44.0(43.3,44.6)\end{array}$ & $\begin{array}{l}36.8(35.4,38.3) \\
63.2(61.7,64.6)\end{array}$ & $\begin{array}{l}\text { al violence } \\
40.1(38.3,41.8) \\
59.9(58.2,61.7)\end{array}$ & $\begin{array}{l}40.0(36.0,43.9) \\
60.0(56.1,64.0)\end{array}$ & $\begin{array}{l}59.2(57.1,61.2) \\
40.8(38.8,42.9)\end{array}$ & $\begin{array}{l}46.8(43.3,50.4) \\
53.2(49.6,56.7)\end{array}$ \\
\hline
\end{tabular}


Table 1: Racial and ethnic distribution of antenatal stressful life events (SLEs), postpartum depression (PPD), socio-demographic characteristics and pre-pregnancy and antenatal factors and all covariates among women in the United States, who have had a recent live birth (PRAMS, 2009-11)

\begin{tabular}{|c|c|c|c|c|c|c|}
\hline & $\begin{array}{l}\text { Non-Hispanic } \\
\text { white }\end{array}$ & $\begin{array}{l}\text { Non-Hispanic } \\
\text { black }\end{array}$ & $\begin{array}{l}\%(95 \% \mathrm{CI})^{\mathrm{a}} \\
\mathrm{N}=11,874\end{array}$ & $\begin{array}{l}\text { American } \\
\text { Indian/Alaska } \\
\text { Native } \\
\%(95 \% \mathrm{CI})^{\mathrm{a}} \\
\mathrm{N}=2,757\end{array}$ & $\begin{array}{l}\text { Asian/Pacific } \\
\text { Islander }\end{array}$ & $\begin{array}{l}\text { Non-Hispanic other, } \\
\text { or mixed race }\end{array}$ \\
\hline \multicolumn{7}{|c|}{ Maternal morbidities during pregnancy ${ }^{* * * *}$} \\
\hline None & $39.7(39.0,40.4)$ & $28.8(27.3,30.3)$ & $33.6(31.9,35.3)$ & $28.1(24.7,31.5)$ & $41.3(39.3,43.4)$ & $33.7(30.4,37.1)$ \\
\hline 1 & $30.4(29.7,31.0)$ & $30.1(28.7,31.5)$ & $29.8(28.2,31.4)$ & $29.4(25.9,33.0)$ & $33.3(31.3,35.3)$ & $31.6(28.3,34.9)$ \\
\hline 2 & $17.0(16.5,17.5)$ & $21.1(19.8,22.3)$ & $20.2(18.8,21.7)$ & $21.6(18.3,24.9)$ & $16.5(15.0,18.0)$ & $18.8(16.1,21.5)$ \\
\hline 3 & $8.2(7.8,8.6)$ & $11.6(10.7,12.5)$ & $10.0(8.9,11.0)$ & $12.1(9.8,14.5)$ & $5.7(4.9,6.6)$ & $9.1(7.1,11.2)$ \\
\hline $4+$ & $4.7(4.5,5.0)$ & $8.4(7.6,9.2)$ & $6.4(5.6,7.3)$ & $8.7(6.5,10.9)$ & $3.2(2.4,3.9)$ & $6.7(5.2,8.3)$ \\
\hline \multicolumn{7}{|c|}{ Insurance for PNC and delivery ${ }^{* * * *}$} \\
\hline Yes & $98.0(97.8,98.2)$ & $98.3(97.9,98.6)$ & $92.8(91.9,93.7)$ & $98.3(97.8,98.8)$ & $98.1(97.5,98.7)$ & $97.2(95.6,98.7)$ \\
\hline No (either/ both) & $2.0(1.8,2.2)$ & $1.7(1.4,2.1)$ & $7.2(6.3,8.1)$ & $1.7(1.2,2.2)$ & $1.9(1.3,2.5)$ & $2.8(1.3,4.4)$ \\
\hline \multicolumn{7}{|c|}{ Stressful events experienced during the 12 months prior to childbirth } \\
\hline \multicolumn{7}{|c|}{ A close family member was very sick and had to go to the hospital ${ }^{* * * *}$} \\
\hline No & $74.8(74.2,75.4)$ & $76.5(75.3,77.7)$ & $81.6(80.2,83.0)$ & $71.4(67.9,75.0)$ & $84.7(83.2,86.1)$ & $76.9(74.0,79.7)$ \\
\hline Yes & $25.2(24.6,25.8)$ & $23.5(22.3,24.7)$ & $18.4(17.0,19.8)$ & $28.6(25.0,32.1)$ & $15.3(13.9,16.8)$ & $23.1(20.3,26.0)$ \\
\hline \multicolumn{7}{|c|}{ She got separated or divorced from husband or partner ${ }^{* * * *}$} \\
\hline No & $94.1(93.7,94.4)$ & $87.4(86.4,88.5)$ & $89.6(88.5,90.7)$ & $86.5(83.6,89.5)$ & $97.5(97.0,98.1)$ & $91.9(90.0,93.8)$ \\
\hline Yes & $5.9(5.6,6.3)$ & $12.6(11.5,13.6)$ & $10.4(9.3,11.5)$ & $13.5(10.5,16.4)$ & $2.5(1.9,3.0)$ & $8.1(6.2,10.0)$ \\
\hline \multicolumn{7}{|c|}{ She moved to a new address ${ }^{* * * *}$} \\
\hline No & $66.9(66.3,67.6)$ & $62.9(61.5,64.4)$ & $67.1(65.5,68.8)$ & $58.0(54.2,61.7)$ & $71.5(70.0,73.3)$ & $61.2(57.7,64.6)$ \\
\hline Yes & $33.1(32.4,33.7)$ & $37.1(35.6,38.5)$ & $32.9(31.2,34.5)$ & $42.0(38.3,45.8)$ & $28.5(26.7,30.4)$ & $38.8(35.4,42.3)$ \\
\hline \multicolumn{7}{|c|}{ She was homeless ${ }^{* * * *}$} \\
\hline No & $98.2(98.0,98.4)$ & $94.8(94.2,95.4)$ & $92.6(91.7,93.6)$ & $94.5(93.2,95.9)$ & $99.4(99.2,99.6)$ & $96.7(95.7,97.8)$ \\
\hline Yes & $1.8(1.6,2.0)$ & $5.2(4.6,5.8)$ & $7.4(6.4,8.3)$ & $5.5(4.1,6.8)$ & $0.6(0.4,0.8)$ & $3.3(2.2,4.3)$ \\
\hline \multicolumn{7}{|c|}{ Her husband or partner lost his job ${ }^{* * * *}$} \\
\hline No & $87.1(86.6,87.5)$ & $84.5(83.4,85.6)$ & $81.0(79.6,82.4)$ & $82.7(79.8,85.5)$ & $91.0(89.8,92.2)$ & $83.9(81.3,86.5)$ \\
\hline Yes & $12.9(12.5,13.4)$ & $15.5(14.4,16.6)$ & $19.0(17.6,20.4)$ & $17.3(14.5,20.2)$ & $9.0(7.8,10.2)$ & $16.1(13.5,18.7)$ \\
\hline
\end{tabular}


Table 1: Racial and ethnic distribution of antenatal stressful life events (SLEs), postpartum depression (PPD), socio-demographic characteristics and pre-pregnancy and antenatal factors and all covariates among women in the United States, who have had a recent live birth (PRAMS, 2009-11)

\begin{tabular}{|c|c|c|c|c|c|c|}
\hline & $\begin{array}{l}\%(95 \% \mathrm{CI})^{\mathrm{a}} \\
\mathrm{N}=49,949\end{array}$ & $\begin{array}{l}\text { Non-Hispanic } \\
\text { black }\end{array}$ & $\begin{array}{l}\%(95 \% \text { CI })^{\mathrm{a}} \\
\mathrm{N}=11,874\end{array}$ & $\begin{array}{l}\text { American } \\
\text { Indian/Alaska } \\
\text { Native } \\
\%(95 \% \mathrm{CI})^{\mathrm{a}} \\
\mathrm{N}=2,757\end{array}$ & $\begin{array}{l}\text { Asian/Pacific } \\
\text { Islander }\end{array}$ & $\begin{array}{l}\text { Non-Hispanic other, } \\
\text { or mixed race }\end{array}$ \\
\hline \multicolumn{7}{|c|}{ She lost her job even though she wanted to continue working ${ }^{* * * *}$} \\
\hline No & $91.7(91.3,92.1)$ & $81.7(80.5,82.9)$ & $84.4(83.1,85.7)$ & $87.7(85.5,90.0)$ & $93.2(92.2,94.3)$ & $89.8(87.8,91.9)$ \\
\hline Yes & $8.3(7.9,8.7)$ & $18.3(17.1,19.5)$ & $15.6(14.3,16.9)$ & $12.3(10.0,14.5)$ & $6.8(5.7,7.8)$ & $10.2(8.1,12.2)$ \\
\hline \multicolumn{7}{|c|}{ She had more than usual arguments with husband or partner ${ }^{* * * *}$} \\
\hline No & $78.6(78.1,79.2)$ & $64.3(62.8,65.7)$ & $74.9(73.4,76.5)$ & $70.6(67.1,74.1)$ & $81.5(79.8,83.1)$ & $73.2(70.2,76.3)$ \\
\hline Yes & $21.4(20.8,21.9)$ & $35.7(34.3,37.2)$ & $25.1(23.5,26.6)$ & $29.4(25.9,32.9)$ & $18.5(16.9,20.2)$ & $26.8(23.7,29.8)$ \\
\hline \multicolumn{7}{|c|}{ Her husband/partner said that he did not want the pregnancy ${ }^{* * * *}$} \\
\hline No & $93.3(92.9,93.6)$ & $85.6(84.6,86.7)$ & $92.6(91.7,93.6)$ & $90.2(88.0,92.5)$ & $96.4(95.8,97.1)$ & $91.7(89.7,93.8)$ \\
\hline Yes & $6.7(6.4,7.1)$ & $14.4(13.3,15.4)$ & $7.4(6.4,8.3)$ & $9.8(7.5,12.0)$ & $3.6(2.9,4.2)$ & $8.3(6.2,10.3)$ \\
\hline \multicolumn{7}{|c|}{ She had a lot of bills that she could not pay ${ }^{* * * *}$} \\
\hline No & $79.9(79.3,80.4)$ & $69.1(67.7,70.5)$ & $73.1(71.5,74.7)$ & $71.5(68.0,75.0)$ & $89.0(87.8,90.3)$ & $73.5(70.4,76.6)$ \\
\hline Yes & $20.1(19.6,20.7)$ & $30.9(29.5,32.3)$ & $26.9(25.3,28.5)$ & $28.5(25.0,32.0)$ & $11.0(9.7,12.2)$ & $26.5(23.4,29.6)$ \\
\hline \multicolumn{7}{|c|}{ She was in a physical fight ${ }^{* * * *}$} \\
\hline No & $97.5(97.3,97.7)$ & $92.2(91.4,93.0)$ & $95.8(95.1,96.6)$ & $94.4(93.0,95.8)$ & $98.0(97.4,98.6)$ & $94.6(92.7,96.4)$ \\
\hline Yes & $2.5(2.3,2.7)$ & $7.8(7.0,8.6)$ & $4.2(3.4,4.9)$ & $5.8(4.2,7.0)$ & $2.0(1.4,2.6)$ & $5.4(3.6,7.3)$ \\
\hline \multicolumn{7}{|c|}{ Her husband or partner or she went to jail ${ }^{* * * *}$} \\
\hline No & $96.8(96.5,97.0)$ & $92.1(91.4,92.9)$ & $96.2(95.5,96.9)$ & $90.3(88.3,92.3)$ & $99.1(98.8,99.4)$ & $93.1(91.0,95.1)$ \\
\hline Yes & $3.2(3.0,3.5)$ & $7.9(7.1,8.6)$ & $3.8(3.1,4.5)$ & $9.7(7.7,11.7)$ & $0.9(0.6,1.2)$ & $6.9(4.9,9.0)$ \\
\hline \multicolumn{7}{|c|}{ Someone very close to her had a problem with drinking or drugs ${ }^{* * * *}$} \\
\hline No & $87.0(86.5,87.4)$ & $87.6(86.6,88.5)$ & $88.8(87.6,90.0)$ & $73.7(70.2,77.1)$ & $96.8(96.2,97.4)$ & $86.7(84.4,89.0)$ \\
\hline Yes & $13.0(12.6,13.5)$ & $12.4(11.5,13.4)$ & $11.2(10.0,12.4)$ & $26.3(22.9,29.8)$ & $3.2(2.6,3.8)$ & $13.3(11.0,15.6)$ \\
\hline \multicolumn{7}{|c|}{ Someone very close to her died ${ }^{* * * *}$} \\
\hline No & $83.9(83.4,84.4)$ & $78.7(77.5,79.9)$ & $82.7(81.3,84.0)$ & $72.6(69.0,76.1)$ & $90.9(89.7,92.0)$ & $85.8(83.5,88.1)$ \\
\hline Yes & $16.1(15.6,16.6)$ & $21.3(20.1,22.5)$ & $17.3(16.0,18.7)$ & $27.4(23.9,31.0)$ & $9.1(8.0,10.3)$ & $14.2(11.9,16.5)$ \\
\hline
\end{tabular}


Table 1: Racial and ethnic distribution of antenatal stressful life events (SLEs), postpartum depression (PPD), socio-demographic characteristics and pre-pregnancy and antenatal factors and all covariates among women in the United States, who have had a recent live birth (PRAMS, 2009-11)

\begin{tabular}{|c|c|c|c|c|c|c|}
\hline & $\begin{array}{l}\%(95 \% \mathrm{CI})^{\mathrm{a}} \\
\mathrm{N}=49,949\end{array}$ & $\begin{array}{l}\text { Non-Hispanic } \\
\text { black }\end{array}$ & $\begin{array}{l}\%(95 \% \mathrm{CI})^{\mathrm{a}} \\
\mathrm{N}=11,874\end{array}$ & $\begin{array}{l}\text { American } \\
\text { Indian/Alaska } \\
\text { Native } \\
\%(95 \% \mathrm{CI})^{\mathrm{a}} \\
\mathrm{N}=2,757\end{array}$ & $\begin{array}{l}\text { Asian/Pacific } \\
\text { Islander }\end{array}$ & $\begin{array}{l}\text { Non-Hispanic other } \\
\text { or mixed race }\end{array}$ \\
\hline \multicolumn{7}{|c|}{$\begin{array}{l}\text { Delivery and neonatal factors } \\
\text { Vaginal deliverv** }\end{array}$} \\
\hline No & $33.0(32.4,33.7)$ & $35.8(34.4,37.3)$ & $32.2(30.5,33.8)$ & $28.4(25.0,31.9)$ & $34.5(32.5,36.5)$ & $34.2(30.8,37.6)$ \\
\hline Yes & $67.0(66.3,67.6)$ & $64.2(62.7,65.6)$ & $67.8(66.2,69.5)$ & $71.6(68.1,75.0)$ & $65.5(63.5,67.5)$ & $65.8(62.4,69.2)$ \\
\hline \multicolumn{7}{|c|}{ Any adverse outcome(s) of the new baby ${ }^{* * * * *}$} \\
\hline $\begin{array}{l}\text { No } \\
\text { Yes }\end{array}$ & $\begin{array}{l}83.8(83.3,84.2) \\
16.2(15.8,16.7)\end{array}$ & $\begin{array}{l}76.4(75.4,77.5) \\
23.5(22.5,24.6)\end{array}$ & $\begin{array}{l}80.9(79.6,82.2) \\
19.1(17.8,20.4)\end{array}$ & $\begin{array}{l}83.3(80.9,85.8) \\
16.7(14.2,19.1)\end{array}$ & $\begin{array}{l}79.7(78.1,81.2) \\
20.3(18.8,21.9)\end{array}$ & $\begin{array}{l}80.1(77.4,82.8) \\
19.9(17.2,22.6)\end{array}$ \\
\hline \multicolumn{7}{|c|}{ Sex of the new baby } \\
\hline $\begin{array}{l}\text { Male } \\
\text { Female }\end{array}$ & $\begin{array}{l}51.6(50.9,52.2) \\
48.4(47.8,49.1)\end{array}$ & $\begin{array}{l}50.6(49.1,52.1) \\
49.4(47.9,50.9)\end{array}$ & $\begin{array}{l}49.7(47.9,51.5) \\
50.3(48.5,52.1)\end{array}$ & $\begin{array}{l}52.0(48.1,55.9) \\
48.0(44.1,51.9)\end{array}$ & $\begin{array}{l}50.3(48.2,52.4) \\
49.7(47.6,51.8)\end{array}$ & $\begin{array}{l}54.2(50.6,57.7) \\
45.8(42.3,49.4)\end{array}$ \\
\hline \multicolumn{7}{|c|}{ Postpartum depression ${ }^{* * * *}$} \\
\hline $\begin{array}{l}\text { No } \\
\text { Yes }\end{array}$ & $\begin{array}{l}89.0(88.5,89.4) \\
11.0(10.6,11.4)\end{array}$ & $\begin{array}{l}87.2(86.2,88.2) \\
12.8(11.8,13.8)\end{array}$ & $\begin{array}{l}89.1(88.0,90.2) \\
10.9(9.8,12.0)\end{array}$ & $\begin{array}{l}86.0(83.2,88.8) \\
14.0(11.2,16.8)\end{array}$ & $\begin{array}{l}92.1(91.0,93.2) \\
7.9(6.8,9.0)\end{array}$ & $\begin{array}{l}88.5(86.3,90.7) \\
11.5(9.3,13.7)\end{array}$ \\
\hline
\end{tabular}

a. Among women of a particular racial/ethnic group, proportion of women (\% and $95 \%$ confidence interval[CI]) within each category of the variable $*^{* *}:$ Chi-square $\mathrm{p}<0.01$ for relationship of the selected variable with race/ethnicity

${ }^{* * * *}:$ Chi-square $\mathrm{p}<0.0001$ for relationship of the selected variable with race/ethnicity 
Table 2: Distribution of postpartum depression among women in the United States, who have had a recent live birth (PRAMS 2009-11), by race/ethnicity

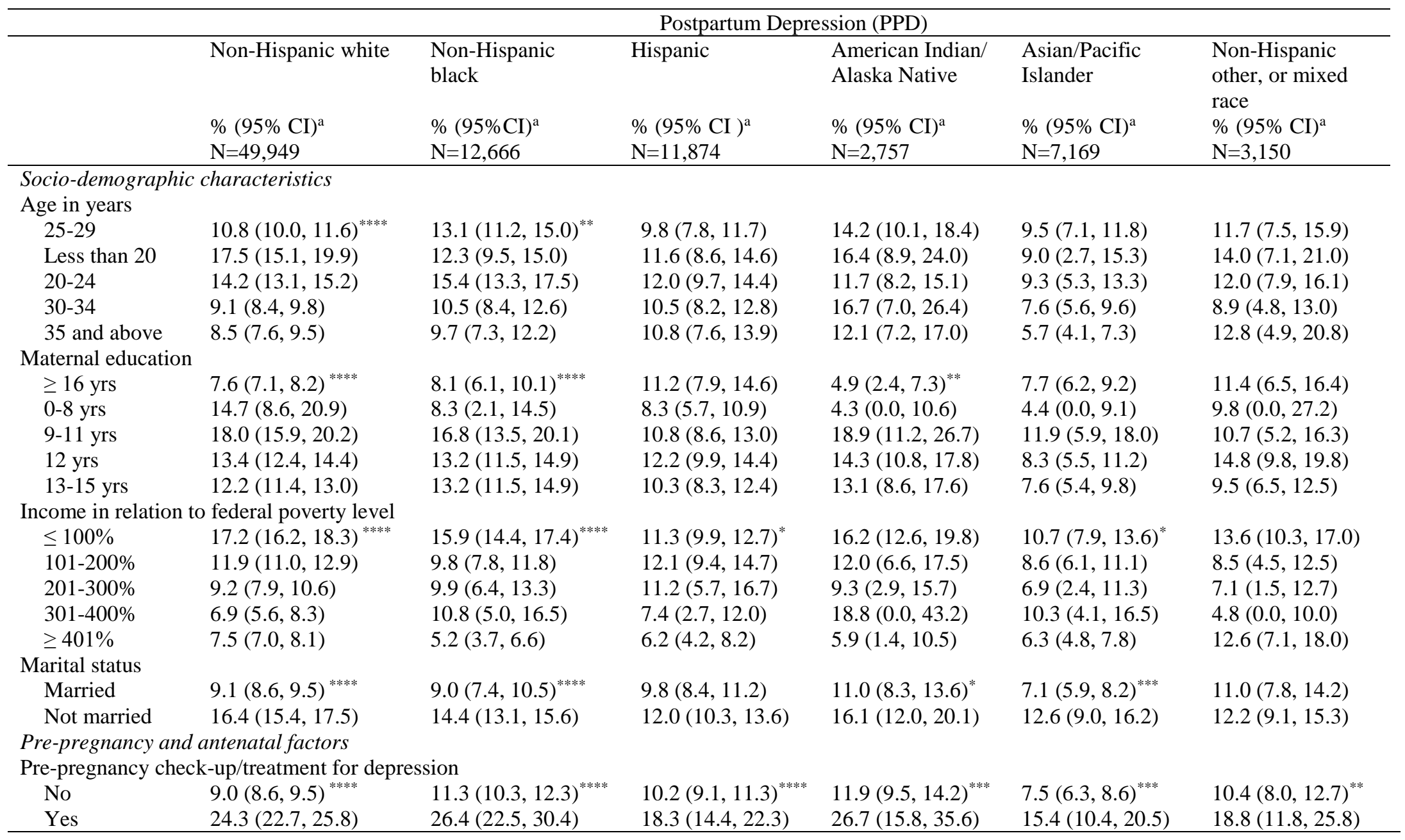


Table 2: Distribution of postpartum depression among women in the United States, who have had a recent live birth (PRAMS 2009-11), by race/ethnicity

\begin{tabular}{|c|c|c|c|c|c|c|}
\hline & \multicolumn{6}{|c|}{ Postpartum Depression (PPD) } \\
\hline & Non-Hispanic white & $\begin{array}{l}\text { Non-Hispanic } \\
\text { black }\end{array}$ & Hispanic & $\begin{array}{l}\text { American Indian/ } \\
\text { Alaska Native }\end{array}$ & $\begin{array}{l}\text { Asian/Pacific } \\
\text { Islander }\end{array}$ & $\begin{array}{l}\text { Non-Hispanic } \\
\text { other, or mixed } \\
\text { race }\end{array}$ \\
\hline & $\%(95 \% \mathrm{CI})^{\mathrm{a}}$ & $\%(95 \% \mathrm{CI})^{\mathrm{a}}$ & $\%(95 \% \mathrm{CI})^{\mathrm{a}}$ & $\%(95 \% \mathrm{CI})^{\mathrm{a}}$ & $\%(95 \% \mathrm{CI})^{\mathrm{a}}$ & $\%(95 \% \mathrm{CI})^{\mathrm{a}}$ \\
\hline & $\mathrm{N}=49,949$ & $\mathrm{~N}=12,666$ & $\mathrm{~N}=11,874$ & $\mathrm{~N}=2,757$ & $\mathrm{~N}=7,169$ & $\mathrm{~N}=3,150$ \\
\hline \multicolumn{7}{|c|}{ Previous number of live births } \\
\hline 0 & $10.8(10.1,11.4)$ & $11.0(9.5,12.6)^{*}$ & $9.8(8.2,11.5)$ & $10.8(7.3,14.4)$ & $8.7(6.9,10.5)$ & $11.2(8.0,14.4)$ \\
\hline 1 & $11.2(10.4,11.9)$ & $13.0(11.2,14.9)$ & $10.7(8.7,12.7)$ & $14.9(10.6,19.1)$ & $6.2(4.7,7.8)$ & $13.5(8.8,18.2)$ \\
\hline 2 & $11.2(10.1,12.3)$ & $15.3(12.6,18.1)$ & $10.7(8.3,13.0)$ & $20.0(10.0,30.0)$ & $8.3(4.8,11.7)$ & $8.7(3.9,13.5)$ \\
\hline $3+$ & $11.7(10.3,13.2)$ & $13.8(11.0,16.5)$ & $13.5(10.1,16.9)$ & $13.4(10.1,16.7)$ & $11.1(6.4,15.9)$ & $11.6(5.1,18.1)$ \\
\hline \multicolumn{7}{|c|}{ Intention to get pregnant before the most recent pregnancy } \\
\hline $\begin{array}{l}\text { Wanted then or } \\
\text { sooner }\end{array}$ & $8.5(8.0,8.9)^{* * * *}$ & $10.5(9.0,12.0)^{* * * *}$ & $8.5(7.2,9.8)^{* * * * *}$ & $10.3(6.3,14.4)^{*}$ & $6.8(5.4,8.1)^{* * * *}$ & $10.3(7.6,13.1)^{*}$ \\
\hline Wanted later & $14.5(13.5,15.5)$ & $12.5(10.9,14.0)$ & $11.5(9.6,13.3)$ & $15.9(11.7,20.1)$ & $8.6(6.3,10.9)$ & $10.0(6.5,13.6)$ \\
\hline $\begin{array}{l}\text { Did not want } \\
\text { even in future }\end{array}$ & $20.3(18.3,22.3)$ & $17.6(15.1,20.1)$ & $21.6(16.6,26.6)$ & $21.4(14.4,28.5)$ & $16.9(11.5,22.3)$ & $20.9(11.5,30.3)$ \\
\hline \multicolumn{7}{|c|}{ Prenatal care utilization } \\
\hline Adequate & $10.2(9.6,10.8)^{* * * *}$ & $10.9(9.4,12.5)^{*}$ & $9.7(8.1,11.3)$ & $13.5(8.2,18.7)$ & $7.1(5.5,8.7)$ & $10.4(7.1,13.6)$ \\
\hline Inadequate & $14.2(12.4,16.0)$ & $14.4(11.8,16.9)$ & $11.8(9.0,14.6)$ & $13.9(8.7,19.0)$ & $11.7(7.1,16.4)$ & $13.0(7.6,18.4)$ \\
\hline Intermediate & $10.9(9.7,12.2)$ & $15.1(12.3,17.9)$ & $11.7(8.6,14.7)$ & $9.7(4.9,14.6)$ & $8.0(5.4,10.5)$ & $6.7(3.3,10.0)$ \\
\hline Adequate plus & $11.6(10.8,12.4)$ & $13.3(11.4,15.1)$ & $11.8(9.6,14.0)$ & $17.4(12.2,22.5)$ & $7.9(5.8,9.9)$ & $14.3(9.4,19.1)$ \\
\hline \multicolumn{7}{|c|}{ Health care provider communication on perinatal depression } \\
\hline No & $12.2(11.3,13.0)^{* * * *}$ & $15.3(13.1,17.5)^{* *}$ & $12.8(10.7,14.9)^{*}$ & $13.1(9.1,17.1)$ & $8.6(6.8,10.5)$ & $11.5(7.9,15.1)$ \\
\hline Yes & $10.6(10.1,11.1)$ & $12.0(10.9,13.2)$ & $10.1(8.8,11.4)$ & $14.3(11.0,17.6)$ & $7.4(6.0,8.9)$ & $11.6(8.7,14.4)$ \\
\hline \multicolumn{7}{|c|}{ Experienced intimate partner physical violence during pregnancy } \\
\hline No & $10.6(10.2,11.0)^{* * * *}$ & $11.7(10.7,12.7)^{* * * *}$ & $9.9(8.8,10.9)^{* * * *}$ & $12.5(9.9,15.2)^{* * * *}$ & $7.5(6.4,8.6)^{* * * *}$ & $11.0(8.7,13.3)^{*}$ \\
\hline Yes & $32.5(28.8,37.1)$ & $31.3(25.6,37.1)$ & $38.1(28.7,47.7)$ & $41.7(27.0,56.5)$ & $26.4(14.8,37.9)$ & $23.0(10.4,35.6)$ \\
\hline \multicolumn{7}{|c|}{ Health care provider communication on intimate partner physical violence } \\
\hline No & $11.4(10.8,12.0)$ & $13.1(11.5,14.7)$ & $12.5(10.7,14.3)^{*}$ & $14.3(10.5,18.0)$ & $8.8(7.1,10.4)$ & $11.5(8.2,14.8)$ \\
\hline Yes & $10.6(10.0,11.2)$ & $12.6(11.3,13.9)$ & $9.8(8.4,11.1)$ & $13.8(10.2,17.4)$ & $6.7(5.3,8.1)$ & $11.5(8.4,14.6)$ \\
\hline
\end{tabular}


Table 2: Distribution of postpartum depression among women in the United States, who have had a recent live birth (PRAMS 2009-11), by race/ethnicity

\begin{tabular}{|c|c|c|c|c|c|c|}
\hline & \multicolumn{6}{|c|}{ Postpartum Depression (PPD) } \\
\hline & Non-Hispanic white & $\begin{array}{l}\text { Non-Hispanic } \\
\text { black }\end{array}$ & Hispanic & $\begin{array}{l}\text { American Indian/ } \\
\text { Alaska Native }\end{array}$ & $\begin{array}{l}\text { Asian/Pacific } \\
\text { Islander }\end{array}$ & $\begin{array}{l}\text { Non-Hispanic } \\
\text { other, or mixed } \\
\text { race }\end{array}$ \\
\hline & $\%(95 \% \mathrm{CI})^{\mathrm{a}}$ & $\%(95 \% \mathrm{CI})^{\mathrm{a}}$ & $\%(95 \% \mathrm{CI})^{\mathrm{a}}$ & $\%(95 \% \mathrm{CI})^{\mathrm{a}}$ & $\%(95 \% \mathrm{CI})^{\mathrm{a}}$ & $\%(95 \% \mathrm{CI})^{\mathrm{a}}$ \\
\hline & $\mathrm{N}=49,949$ & $\mathrm{~N}=12,666$ & $\mathrm{~N}=11,874$ & $\mathrm{~N}=2,757$ & $\mathrm{~N}=7,169$ & $\mathrm{~N}=3,150$ \\
\hline \multicolumn{7}{|c|}{ Maternal morbidities during pregnancy } \\
\hline None & $7.1(6.6,7.7)^{* * * * *}$ & $8.8(6.9,10.7)^{* * * *}$ & $9.0(7.2,10.9)^{* * *}$ & $5.8(4.3,7.4)^{* * * *}$ & $5.6(4.1,7.1)^{* * *}$ & $7.8(4.4,11.1)^{* * *}$ \\
\hline 1 & $10.4(9.6,11.1)$ & $11.2(9.4,13.0)$ & $9.1(7.2,11.0)$ & $12.0(8.1,15.8)$ & $8.0(5.9,10.1)$ & $8.9(5.2,12.5)$ \\
\hline 2 & $13.6(12.5,14.7)$ & $14.7(12.5,16.8)$ & $13.2(10.6,15.8)$ & $18.1(9.8,26.5)$ & $10.3(7.5,13.0)$ & $16.2(10.4,22.1)$ \\
\hline 3 & $20.0(18.0,21.9)$ & $17.2(14.3,20.1)$ & $13.8(10.0,17.5)$ & $18.0(11.6,24.4)$ & $12.0(6.0,18.0)$ & $13.6(6.8,20.5)$ \\
\hline $4+$ & $23.7(21.2,26.1)$ & $21.6(17.5,25.8)$ & $16.8(12.2,21.3)$ & $31.0(19.3,42.8)$ & $17.0(8.5,25.5)$ & $26.8(15.4,38.2)$ \\
\hline \multicolumn{7}{|c|}{ Insurance for PNC and delivery } \\
\hline Yes & $11.1(10.6,11.5)$ & $12.8(11.8,13.8)$ & $10.7(9.6,11.9)$ & $14.0(11.2,16.7)$ & $7.9(6.8,9.1)$ & $11.4(9.1,13.7)$ \\
\hline $\begin{array}{l}\text { No (either or } \\
\text { both) }\end{array}$ & $9.7(6.6,12.7)$ & $12.8(5.3,20.4)$ & $12.4(7.6,17.2)$ & $15.2(6.0,24.4)$ & $6.0(1.5,10.4)$ & $16.1(0.0,33.1)$ \\
\hline \multicolumn{7}{|c|}{ Stressful events experienced during the 12 months prior to childbirth } \\
\hline \multicolumn{7}{|c|}{ A close family member was very sick and had to go to the hospital } \\
\hline No & $10.0(9.6,10.5)^{* * * *}$ & $11.3(10.1,12.4)^{* * * *}$ & $10.1(8.9,11.2)^{* *}$ & $12.3(9.9,14.8)$ & $7.1(5.9,8.3)^{* * *}$ & $10.5(8.0,13.0)$ \\
\hline Yes & $14.0(13.1,15.0)$ & $17.8(15.6,20.1)$ & $14.4(11.4,17.3)$ & $18.1(11.3,24.8)$ & $12.2(9.0,15.4)$ & $14.9(10.0,19.9)$ \\
\hline \multicolumn{7}{|c|}{ She got separated or divorced from husband or partner } \\
\hline No & $10.3(9.9,10.8)^{* * * *}$ & $11.4(10.4,12.5)^{* * * *}$ & $9.7(8.6,10.8)^{* * * *}$ & $11.3(9.1,13.5)^{* * * *}$ & $7.7(6.5,8.8)^{* * *}$ & $11.2(8.8,13.6)$ \\
\hline Yes & $22.4(20.0,24.8)$ & $22.4(18.6,26.1)$ & $21.4(16.3,25.7)$ & $31.3(19.7,42.9)$ & $17.3(10.0,24.7)$ & $15.0(7.3,22.7)$ \\
\hline \multicolumn{7}{|c|}{ She moved to a new address } \\
\hline No & $9.5(9.0,10.0)^{* * * *}$ & $10.7(9.5,11.9)^{* * * *}$ & $9.7(8.4,10.9)^{* *}$ & $12.2(8.5,15.9)$ & $6.6(5.4,7.8)^{* * *}$ & $10.8(7.9,13.7)$ \\
\hline Yes & $14.2(13.3,15.0)$ & $16.4(14.6,18.2)$ & $13.3(11.2,15.4)$ & $16.4(12.6,20.2)$ & $11.1(8.6,13.6)$ & $12.6(9.1,16.2)$ \\
\hline \multicolumn{7}{|l|}{ She was homeless } \\
\hline No & $10.8(10.3,11.2)^{* * * *}$ & $12.1(11.0,13.1)^{* * * *}$ & $10.7(9.6,11.9)$ & $\begin{array}{l}12.8(10.1 \\
15.6)^{* * * *}\end{array}$ & $7.8(6.6,8.9)^{* * * *}$ & $11.0(8.7,13.2)^{* *}$ \\
\hline Yes & $26.2(21.8,30.6)$ & $26.5(21.1,32.0)$ & $12.4(8.3,16.5)$ & $33.5(23.4,43.6)$ & $27.3(13.4,41.1)$ & $27.8(11.9,43.6)$ \\
\hline \multicolumn{7}{|c|}{ Her husband or partner lost his job } \\
\hline No & $10.1(9.7,10.6)^{* * * *}$ & $11.7(10.7,12.8)^{* * * *}$ & $9.9(8.8,11.1)^{* * *}$ & $11.6(8.9,14.3)^{* * *}$ & $7.3(6.1,8.4)^{* *}$ & $11.2(8.8,13.6)$ \\
\hline Yes & $17.3(15.8,18.8)$ & $18.6(15.6,21.5)$ & $15.0(12.1,17.8)$ & $25.5(17.4,33.7)$ & $14.2(9.1,19.3)$ & $13.4(7.4,19.5)$ \\
\hline
\end{tabular}


Table 2: Distribution of postpartum depression among women in the United States, who have had a recent live birth (PRAMS 2009-11), by race/ethnicity

\begin{tabular}{|c|c|c|c|c|c|c|}
\hline & \multicolumn{6}{|c|}{ Postpartum Depression (PPD) } \\
\hline & Non-Hispanic white & $\begin{array}{l}\text { Non-Hispanic } \\
\text { black }\end{array}$ & Hispanic & $\begin{array}{l}\text { American Indian/ } \\
\text { Alaska Native }\end{array}$ & $\begin{array}{l}\text { Asian/Pacific } \\
\text { Islander }\end{array}$ & $\begin{array}{l}\text { Non-Hispanic } \\
\text { other, or mixed } \\
\text { race }\end{array}$ \\
\hline & $\%(95 \% \mathrm{CI})^{\mathrm{a}}$ & $\%(95 \% \mathrm{CI})^{\mathrm{a}}$ & $\%(95 \% \text { CI })^{\mathrm{a}}$ & $\%(95 \% \mathrm{CI})^{\mathrm{a}}$ & $\%(95 \% \mathrm{CI})^{\mathrm{a}}$ & $\%(95 \% \mathrm{CI})^{\mathrm{a}}$ \\
\hline & $\mathrm{N}=49,949$ & $\mathrm{~N}=12,666$ & $\mathrm{~N}=11,874$ & $\mathrm{~N}=2,757$ & $\mathrm{~N}=7,169$ & $\mathrm{~N}=3,150$ \\
\hline \multicolumn{7}{|c|}{ She lost her job even though she wanted to continue working } \\
\hline No & $10.3(9.9,10.7)^{* * * * *}$ & $11.6(10.5,12.6)^{* * * *}$ & $10.4(9.3,11.7)$ & $13.4(10.5,16.3)$ & $7.4(6.3,8.5)^{* * *}$ & $10.8(8.4,13.2)^{*}$ \\
\hline Yes & $19.3(17.4,21.2)$ & $18.3(15.5,21.2)$ & $13.0(10.3,16.0)$ & $18.0(11.7,24.3)$ & $15.2(8.4,22.0)$ & $18.2(10.8,25.7)$ \\
\hline \multicolumn{7}{|c|}{ She had more than usual arguments with husband or partner } \\
\hline No & $8.0(7.6,8.4)^{* * * * *}$ & $8.4(7.3,9.5)^{* * * *}$ & $6.8(5.8,7.8)^{* * * *}$ & $8.5(6.2,10.7)^{* * * *}$ & $4.8(3.9,5.8)^{* * * *}$ & $9.5(7.0,12.1)^{* *}$ \\
\hline Yes & $22.2(21.0,23.5)$ & $20.7(18.8,22.6)$ & $22.9(19.9,26.0)$ & $27.2(20.5,34.0)$ & $21.4(17.2,25.6)$ & $16.9(12.4,21.5)$ \\
\hline \multicolumn{7}{|c|}{ Her husband/partner said that he did not want the pregnancy } \\
\hline No & $10.2(9.7,10.6)^{* * * *}$ & $11.0(9.9,12.0)^{* * * *}$ & $9.7(8.7,10.8)^{* * * *}$ & $12.2(9.4,14.9)^{* * * *}$ & $7.5(6.3,8.6)^{* * * *}$ & $10.8(8.6,13.1)$ \\
\hline Yes & $23.2(21.0,25.5)$ & $23.8(20.4,27.3)$ & $25.1(19.3,30.8)$ & $30.4(20.6,40.2)$ & $20.0(13.2,26.9)$ & $19.1(8.5,29.8)$ \\
\hline \multicolumn{7}{|c|}{ She had a lot of bills that she could not pay } \\
\hline No & $8.7(8.3,9.1)^{* * * *}$ & $9.3(8.2,10.5)^{* * * *}$ & $8.0(6.9,9.1)^{* * * *}$ & $8.2(6.1,10.3)^{* * * *}$ & $6.1(5.1,7.1)^{* * * *}$ & $8.5(6.2,10.8)^{* * * *}$ \\
\hline \multicolumn{7}{|c|}{ She was in a physical fight } \\
\hline No & $10.5(10.1,11.0)^{* * * *}$ & $11.6(10.5,12.6)^{* * * *}$ & $10.1(9.1,11.2)^{* * * *}$ & $12.6(9.9,15.3)^{* * * *}$ & $7.6(6.5,8.7)^{* * * *}$ & $10.8(8.5,13.1)^{* *}$ \\
\hline Yes & $30.9(26.7,35.2)$ & $27.6(22.8,32.3)$ & $27.4(19.6,35.3)$ & $37.5(24.9,50.1)$ & $23.9(12.4,35.4)$ & $24.0(11.4,36.6)$ \\
\hline \multicolumn{7}{|c|}{ Her husband or partner or she went to jail } \\
\hline No & $10.5(10.1,11.0)^{* * * * *}$ & $11.8(10.7,12.8)^{* * * *}$ & $10.6(9.5,11.7)^{* *}$ & $11.8(9.1,14.5)^{* * * *}$ & $7.8(6.6,8.9)^{* * *}$ & $10.9(8.6,13.2)$ \\
\hline Yes & $26.2(22.8,29.7)$ & $25.0(20.7,29.3)$ & $18.0(11.7,24.8)$ & $34.0(23.5,44.5)$ & $21.4(10.1,32.7)$ & $20.0(8.8,31.1)$ \\
\hline \multicolumn{7}{|c|}{ Someone very close to her had a problem with drinking or drugs } \\
\hline No & $9.4(8.9,9.8)^{* * * *}$ & $11.3(10.2,12.3)^{* * * *}$ & $9.4(8.4,10.5)^{* * * *}$ & $10.1(7.8,12.5)^{* * * *}$ & $7.4(6.3,8.6)^{* * * *}$ & $10.9(8.5,13.4)$ \\
\hline Yes & $22.2(20.6,23.8)$ & $23.7(20.1,27.2)$ & $22.4(17.8,27.0)$ & $24.7(17.3,32.1)$ & $21.9(15.0,28.8)$ & $15.4(9.5,21.2)$ \\
\hline \multicolumn{7}{|c|}{ Someone very close to her died } \\
\hline No & $10.5(10.0,10.9)^{* * * *}$ & $11.5(10.4,12.7)^{* * * *}$ & $10.4(9.2,11.6)$ & $12.5(10.1,14.9)$ & $7.7(6.5,8.9)$ & $10.7(8.3,13.2)$ \\
\hline Yes & $14.0(12.9,15.2)$ & $17.5(15.1,19.8)$ & $13.0(10.1,16.0)$ & $17.8(10.7,24.9)$ & $10.3(7.0,13.6)$ & $16.2(10.3,22.2)$ \\
\hline
\end{tabular}


Table 2: Distribution of postpartum depression among women in the United States, who have had a recent live birth (PRAMS 2009-11), by race/ethnicity

\begin{tabular}{|c|c|c|c|c|c|c|}
\hline & \multicolumn{6}{|c|}{ Postpartum Depression (PPD) } \\
\hline & Non-Hispanic white & $\begin{array}{l}\text { Non-Hispanic } \\
\text { black }\end{array}$ & Hispanic & $\begin{array}{l}\text { American Indian/ } \\
\text { Alaska Native }\end{array}$ & $\begin{array}{l}\text { Asian/Pacific } \\
\text { Islander }\end{array}$ & $\begin{array}{l}\text { Non-Hispanic } \\
\text { other, or mixed } \\
\text { race }\end{array}$ \\
\hline & $\%(95 \% \mathrm{CI})^{\mathrm{a}}$ & $\%(95 \% \mathrm{CI})^{\mathrm{a}}$ & $\%(95 \% \text { CI })^{\mathrm{a}}$ & $\%(95 \% \mathrm{CI})^{\mathrm{a}}$ & $\%(95 \% \mathrm{CI})^{\mathrm{a}}$ & $\%(95 \% \mathrm{CI})^{\mathrm{a}}$ \\
\hline & $\mathrm{N}=49,949$ & $\mathrm{~N}=12,666$ & $\mathrm{~N}=11,874$ & $\mathrm{~N}=2,757$ & $\mathrm{~N}=7,169$ & $\mathrm{~N}=3,150$ \\
\hline \multicolumn{7}{|c|}{ Delivery and neonatal factors } \\
\hline \multicolumn{7}{|c|}{ Vaginal delivery } \\
\hline No & $12.8(12.0,13.6)^{* * * *}$ & $14.3(12.6,16.1)^{*}$ & $11.0(9.2,12.8)$ & $15.7(9.3,22.1)$ & $8.7(6.6,10.8)$ & $13.0(9.4,16.6)$ \\
\hline Yes & $10.2(9.7,10.7)$ & $12.0(10.7,13.2)$ & $10.8(9.4,12.2)$ & $13.3(10.6,16.0)$ & $7.5(6.1,8.8)$ & $10.7(7.9,13.6)$ \\
\hline \multicolumn{7}{|c|}{ Any adverse outcome(s) of the new baby } \\
\hline No & $10.6(10.0,11.0)^{* * * * *}$ & $12.4(11.2,13.6)$ & $10.7(9.4,12.0)$ & $13.8(10.6,17.0)$ & $7.3(6.1,8.6)^{*}$ & $11.0(8.4,13.5)$ \\
\hline Yes & $13.8(12.8,14.8)$ & $14.1(12.5,15.7)$ & $11.6(9.6,13.6)$ & $14.9(11.8,17.9)$ & $10.3(7.6,12.9)$ & $13.8(8.8,18.8)$ \\
\hline \multicolumn{7}{|c|}{ Sex of the new baby } \\
\hline Male & $11.1(10.5,11.7)$ & $13.4(11.9,15.0)$ & $12.1(10.4,13.7)^{*}$ & $12.5(9.8,15.2)$ & $7.2(5.7,8.8)$ & $10.6(8.0,13.3)$ \\
\hline Female & $11.0(10.4,11.6)$ & $12.2(10.8,13.5)$ & $9.7(8.3,11.1)$ & $15.6(11.1,20.0)$ & $8.6(7.0,10.2)$ & $12.6(8.9,16.3)$ \\
\hline \multicolumn{7}{|c|}{$\begin{array}{l}\text { a: Among the total number of respondents in each category for each racial/ethnic group, proportion (weighted percentage and } 95 \% \text { Confidence Interval } \\
\text { having PPD }\end{array}$} \\
\hline
\end{tabular}


Table 3: Results of multivariable logistic regression analyses: adjusted odds ratios (aORs) ${ }^{\mathrm{a}}$ and $95 \%$ confidence intervals (CIs) for postpartum depression among women in the United States (U.S.) who have had a recent live birth, by race/ethnicity ${ }^{\mathrm{a}}$

\begin{tabular}{|c|c|c|c|c|c|c|}
\hline & $\begin{array}{l}\text { aOR }(95 \% \text { CI }) \\
N=49,949\end{array}$ & $\begin{array}{l}\mathrm{aOR}(95 \% \mathrm{CI}) \\
\mathrm{N}=12,666\end{array}$ & $\begin{array}{l}\text { aOR }(95 \% \text { CI }) \\
\mathrm{N}=11,874\end{array}$ & $\begin{array}{l}\text { American } \\
\text { Indian/Alaska } \\
\text { Native } \\
\text { aOR }(95 \% \mathrm{CI}) \\
\mathrm{N}=2,757\end{array}$ & $\begin{array}{l}\text { aOR }(95 \% \mathrm{CI}) \\
\mathrm{N}=7,169\end{array}$ & $\begin{array}{l}\text { Non-Hispanic } \\
\text { other, or mixed } \\
\text { race } \\
\text { aOR }(95 \% \mathrm{CI}) \\
\mathrm{N}=3,150\end{array}$ \\
\hline \multicolumn{7}{|c|}{ Socio-demographic characteristics } \\
\hline \multicolumn{7}{|c|}{ Age in years } \\
\hline $25-29$ & Ref & Ref & - & - & - & - \\
\hline Less than 20 & $1.06(0.84,1.34)$ & $0.95(0.63,1.42)$ & - & - & - & - \\
\hline $20-24$ & $0.96(0.84,1.10)$ & $1.08(0.81,1.44)$ & - & - & - & - \\
\hline $30-34$ & $0.95(0.84,1.08)$ & $0.89(0.66,1.20)$ & - & - & - & - \\
\hline 35 and above & $0.88(0.75,1.03)$ & $0.97(0.67,1.42)$ & - & - & - & - \\
\hline \multicolumn{7}{|c|}{ Maternal education } \\
\hline$\geq 16 \mathrm{yrs}$ & Ref & Ref & - & Ref & - & - \\
\hline $0-8$ yrs & $1.08(0.62,1.88)$ & $0.48(0.19,1.18)$ & - & $0.56(0.08,3.77)$ & - & - \\
\hline $9-11$ yrs & $1.08(0.87,1.33)$ & $1.15(0.73,1.80)$ & - & $2.45(1.03,5.82)$ & - & - \\
\hline $12 \mathrm{yrs}$ & $1.01(0.87,1.17)$ & $0.92(0.62,1.37)$ & - & $2.20(1.01,4.80)$ & - & - \\
\hline 13-15 yrs & $1.03(0.91,1.17)$ & $0.97(0.68,1.40)$ & - & $1.91(0.85,4.27)$ & - & - \\
\hline$\leq 100 \%$ & Ref & Ref & Ref & - & Ref & - \\
\hline $101-200 \%$ & $0.92(0.80,1.05)$ & $0.65(0.50,0.86)$ & $1.14(0.85,1.54)$ & - & $0.99(0.60,1.64)$ & - \\
\hline $201-300 \%$ & $0.82(0.67,1.00)$ & $0.74(0.49,1.11)$ & $0.98(0.57,1.68)$ & - & $0.77(0.32,1.85)$ & - \\
\hline $301-400 \%$ & $0.65(0.51,0.84)$ & $0.84(0.45,1.56)$ & $0.78(0.38,1.58)$ & - & $1.83(0.77,4.33)$ & - \\
\hline$\geq 401 \%$ & $0.83(0.70,0.97)$ & $0.46(0.31,0.69)$ & $0.74(0.49,1.13)$ & - & $0.99(0.59,1.69)$ & - \\
\hline \multicolumn{7}{|l|}{ Marital status } \\
\hline Married 1 & Ref & Ref & - & Ref & Ref & - \\
\hline Not married 2 & $0.99(0.87,1.12)$ & $1.09(0.82,1.44)$ & - & $1.06(0.70,1.61)$ & $1.14(0.72,1.81)$ & - \\
\hline \multicolumn{7}{|c|}{ Pre-pregnancy and antenatal factors } \\
\hline \multicolumn{7}{|c|}{ Pre-pregnancy check-up/treatment for depression } \\
\hline No & Ref & Ref & Ref & Ref & Ref & Ref \\
\hline Yes & $2.33(2.09,2.61)$ & $2.11(1.64,2.73)$ & $1.41(1.05,1.89)$ & $2.09(1.24,3.55)$ & $1.52(0.92,2.49)$ & $1.45(0.82,2.55)$ \\
\hline
\end{tabular}


Table 3: Results of multivariable logistic regression analyses: adjusted odds ratios (aORs) ${ }^{\mathrm{a}}$ and $95 \%$ confidence intervals (CIs) for postpartum depression among women in the United States (U.S.) who have had a recent live birth, by race/ethnicity ${ }^{\mathrm{a}}$

\begin{tabular}{|c|c|c|c|c|c|c|}
\hline & $\begin{array}{l}\text { aOR }(95 \% \text { CI }) \\
\mathrm{N}=49,949\end{array}$ & $\begin{array}{l}\text { aOR }(95 \% \mathrm{CI}) \\
\mathrm{N}=12,666\end{array}$ & $\begin{array}{l}\text { aOR }(95 \% \text { CI }) \\
\mathrm{N}=11,874\end{array}$ & $\begin{array}{l}\text { American } \\
\text { Indian/Alaska } \\
\text { Native } \\
\text { aOR }(95 \% \mathrm{CI}) \\
\mathrm{N}=2,757\end{array}$ & $\begin{array}{l}\text { aOR }(95 \% \mathrm{CI}) \\
\mathrm{N}=7,169\end{array}$ & $\begin{array}{l}\text { Non-Hispanic } \\
\text { other, or mixed } \\
\text { race } \\
\text { aOR }(95 \% \mathrm{CI}) \\
\mathrm{N}=3,150\end{array}$ \\
\hline \multicolumn{7}{|c|}{ Previous number of live births } \\
\hline 0 & - & Ref & - & - & - & - \\
\hline 1 & - & $1.13(0.87,1.47)$ & - & - & - & - \\
\hline 2 & - & $1.30(0.93,1.81)$ & - & - & - & - \\
\hline $3+$ & - & $0.92(0.63,1.33)$ & - & - & - & - \\
\hline \multicolumn{7}{|c|}{ Intention to get pregnant before the most recent pregnancy (when did she intend to be pregnant) ${ }^{* * * *}$} \\
\hline Then or sooner & Ref & Ref & Ref & Ref & Ref & Ref \\
\hline Later & $1.26(1.13,1.41)$ & $0.99(0.77,1.28)$ & $1.11(0.85,1.44)$ & $1.38(0.87,2.21)$ & $0.81(0.56,1.18)$ & $0.79(0.47,1.32)$ \\
\hline Never & $1.65(1.41,1.92)$ & $1.17(0.89,1.54)$ & $1.88(1.31,2.70)$ & $1.37(0.72,2.60)$ & $1.70(1.05,2.75)$ & $1.41(0.70,2.85)$ \\
\hline \multicolumn{7}{|c|}{ Prenatal care utilization } \\
\hline Adequate & Ref & Ref & - & - & - & - \\
\hline Inadequate & $0.98(0.82,1.17)$ & $1.05(0.78,1.41)$ & - & - & - & - \\
\hline Intermediate & $1.06(0.91,1.23)$ & $1.41(1.06,1.89)$ & - & - & - & - \\
\hline \multicolumn{7}{|c|}{ Health care provider communication on perinatal depression } \\
\hline No & Ref & Ref & Ref & - & - & - \\
\hline Yes & $0.77(0.69,0.85)$ & $0.74(0.60,0.93)$ & $0.96(0.73,1.27)$ & - & - & - \\
\hline \multicolumn{7}{|c|}{ Experienced intimate partner physical violence during pregnancy } \\
\hline No & Ref & Ref & Ref & Ref & Ref & Ref \\
\hline Yes & $1.38(1.04,1.82)$ & $1.55(1.09,2.20)$ & $2.42(1.58,3.70)$ & $2.46(1.26,4.78)$ & $1.41(0.57,3.50)$ & $1.21(0.51,2.86)$ \\
\hline \multicolumn{7}{|c|}{ Health care provider communication on intimate partner physical violence } \\
\hline No & - & - & Ref & - & - & - \\
\hline Yes & - & - & $0.84(0.64,1.11)$ & - & - & - \\
\hline \multicolumn{7}{|c|}{ Maternal morbidities during pregnancy ${ }^{* * * *}$} \\
\hline None & Ref & Ref & Ref & Ref & Ref & Ref \\
\hline 1 & $1.29(1.14,1.46)$ & $1.11(0.81,1.52)$ & $0.91(0.65,1.27)$ & $2.31(1.36,3.92)$ & $1.29(0.86,1.93)$ & $1.06(0.55,2.04)$ \\
\hline 2 & $1.53(1.33,1.75)$ & $1.27(0.93,1.72)$ & $1.19(0.86,1.64)$ & $3.05(1.74,5.34)$ & $1.37(0.88,2.14)$ & $1.92(0.99,3.74)$ \\
\hline 3 & $2.11(1.78,2.49)$ & $1.46(1.06,2.01)$ & $1.09(0.74,1.61)$ & $2.76(1.62,4.70)$ & $1.42(0.81,2.46)$ & $1.42(0.71,2.86)$ \\
\hline $4+$ & $2.18(1.81,2.62)$ & $1.54(1.08,2.20)$ & $1.35(0.86,2.12)$ & $4.55(2.15,9.63)$ & $1.89(0.80,4.45)$ & $3.31(1.49,7.36)$ \\
\hline
\end{tabular}


Table 3: Results of multivariable logistic regression analyses: adjusted odds ratios (aORs) ${ }^{\mathrm{a}}$ and $95 \%$ confidence intervals (CIs) for postpartum depression among women in the United States (U.S.) who have had a recent live birth, by race/ethnicity ${ }^{\mathrm{a}}$

\begin{tabular}{|c|c|c|c|c|c|c|}
\hline & $\begin{array}{l}\text { aOR }(95 \% \mathrm{CI}) \\
\mathrm{N}=49,949\end{array}$ & $\begin{array}{l}\mathrm{aOR}(95 \% \mathrm{CI}) \\
\mathrm{N}=12,666\end{array}$ & $\begin{array}{l}\mathrm{aOR}(95 \% \text { CI }) \\
\mathrm{N}=11,874\end{array}$ & $\begin{array}{l}\text { American } \\
\text { Indian/Alaska } \\
\text { Native } \\
\text { aOR }(95 \% \mathrm{CI}) \\
\mathrm{N}=2,757\end{array}$ & $\begin{array}{l}\text { aOR }(95 \% \mathrm{CI}) \\
\mathrm{N}=7,169\end{array}$ & $\begin{array}{l}\text { Non-Hispanic } \\
\text { other, or mixed } \\
\text { race } \\
\text { aOR }(95 \% \mathrm{CI}) \\
\mathrm{N}=3,150\end{array}$ \\
\hline \multicolumn{7}{|c|}{ Stressful events experienced during the 12 months prior to childbirth } \\
\hline \multicolumn{7}{|c|}{ A close family member was very sick and had to go to the hospital } \\
\hline No & Ref & Ref & Ref & - & Ref & - \\
\hline Yes & $1.16(1.04,1.29)$ & $1.16(0.94,1.45)$ & $1.15(0.86,1.54)$ & - & $1.38(0.94,2.03)$ & - \\
\hline \multicolumn{7}{|c|}{ She got separated or divorced from husband or partner } \\
\hline No & Ref & Ref & Ref & Ref & Ref & - \\
\hline Yes & $0.86(0.72,1.03)$ & $1.00(0.76,1.33)$ & $1.00(0.69,1.45)$ & $1.26(0.71,2.26)$ & $0.80(0.39,1.65)$ & - \\
\hline \multicolumn{7}{|c|}{ She moved to a new address } \\
\hline No & Ref & Ref & Ref & - & Ref & - \\
\hline Yes & $1.07(0.96,1.19)$ & $1.23(0.99,1.51)$ & $1.02(0.79,1.32)$ & - & $1.38(0.99,1.92)$ & - \\
\hline \multicolumn{7}{|c|}{ She was homeless } \\
\hline No & Ref & Ref & - & Ref & Ref & Ref \\
\hline Yes & $0.94(0.72,1.22)$ & $1.13(0.81,1.57)$ & - & $1.07(0.59,1.94)$ & $1.30(0.57,2.97)$ & $1.43(0.58,3.52)$ \\
\hline No & Ref & Ref & Ref & Ref & Ref & - \\
\hline Yes & $1.01(0.88,1.15)$ & $1.08(0.84,1.40)$ & $1.05(0.79,1.41)$ & $1.13(0.61,2.11)$ & $0.93(0.57,1.49)$ & - \\
\hline \multicolumn{7}{|c|}{ She lost her job even though she wanted to continue working } \\
\hline No & Ref & Ref & - & - & Ref & Ref \\
\hline Yes & $1.10(0.95,1.28)$ & $1.02(0.79,1.32)$ & - & - & $1.20(0.74,1.94)$ & $1.19(0.67,2.09)$ \\
\hline \multicolumn{7}{|c|}{ She had more than usual arguments with husband or partner } \\
\hline No & Ref & Ref & Ref & Ref & Ref & Ref \\
\hline Yes & $1.92(1.72,2.15)$ & $1.69(1.37,2.08)$ & $2.60(1.99,3.41)$ & $1.69(1.07,2.67)$ & $3.86(2.71,5.49)$ & $1.16(0.71,1.89)$ \\
\hline \multicolumn{7}{|c|}{ Her husband/partner said that he did not want the pregnancy } \\
\hline No & Ref & Ref & Ref & Ref & Ref & - \\
\hline Yes & $1.16(0.99,1.37)$ & $1.47(1.14,1.90)$ & $1.35(0.94,1.93)$ & $1.55(0.83,2.89)$ & $1.01(0.61,1.65)$ & - \\
\hline \multicolumn{7}{|c|}{ She had a lot of bills that she could not pay } \\
\hline No & Ref & Ref & Ref & Ref & Ref & Ref \\
\hline Yes & $1.35(1.20,1.51)$ & $1.63(1.29,2.07)$ & $1.67(1.27,2.18)$ & $2.56(1.65,3.96)$ & $2.25(1.44,3.52)$ & $2.04(1.19,3.48)$ \\
\hline
\end{tabular}


Table 3: Results of multivariable logistic regression analyses: adjusted odds ratios (aORs) ${ }^{\mathrm{a}}$ and $95 \%$ confidence intervals (CIs) for postpartum depression among women in the United States (U.S.) who have had a recent live birth, by race/ethnicity ${ }^{\mathrm{a}}$

\begin{tabular}{|c|c|c|c|c|c|c|}
\hline & $\begin{array}{l}\text { Non-Hispanic } \\
\text { white } \\
\text { aOR }(95 \% \text { CI }) \\
\mathrm{N}=49,949\end{array}$ & $\begin{array}{l}\text { Non-Hispanic } \\
\text { black } \\
\text { aOR }(95 \% \mathrm{CI}) \\
\mathrm{N}=12,666\end{array}$ & $\begin{array}{l}\mathrm{aOR}(95 \% \mathrm{CI}) \\
\mathrm{N}=11,874\end{array}$ & $\begin{array}{l}\text { American } \\
\text { Indian/Alaska } \\
\text { Native } \\
\text { aOR }(95 \% \mathrm{CI}) \\
\mathrm{N}=2,757\end{array}$ & $\begin{array}{l}\text { aOR }(95 \% \mathrm{CI}) \\
\mathrm{N}=7,169\end{array}$ & $\begin{array}{l}\text { Non-Hispanic } \\
\text { other, or mixed } \\
\text { race } \\
\text { aOR }(95 \% \mathrm{CI}) \\
\mathrm{N}=3,150\end{array}$ \\
\hline \multicolumn{7}{|c|}{ She was in a physical fight } \\
\hline No & Ref & Ref & Ref & Ref & Ref & Ref \\
\hline Yes & $1.14(0.86,1.51)$ & $1.12(0.80,1.57)$ & $1.18(0.75,1.85)$ & $1.13(0.60,2.16)$ & $0.86(0.38,1.93)$ & $1.16(0.52,2.56)$ \\
\hline \multicolumn{7}{|c|}{ Her husband or partner or she went to jail } \\
\hline No & Ref & Ref & Ref & Ref & Ref & - \\
\hline Yes & $1.15(0.94,1.42)$ & $1.18(0.87,1.59)$ & $0.83(0.47,1.44)$ & $1.58(0.88,2.87)$ & $1.04(0.50,2.16)$ & - \\
\hline \multicolumn{7}{|c|}{ Someone very close to her had a problem with drinking or drugs } \\
\hline No & Ref & Ref & Ref & Ref & Ref & - \\
\hline Yes & $1.37(1.21,1.55)$ & $1.21(0.93,1.59)$ & $1.29(0.91,1.83)$ & $1.32(0.86,2.02)$ & $1.01(0.57,1.79)$ & - \\
\hline \multicolumn{7}{|c|}{ Someone very close to her died } \\
\hline No & Ref & Ref & - & - & - & - \\
\hline Yes & $0.94(0.83,1.07)$ & $1.08(0.87,1.34)$ & - & - & - & - \\
\hline \multicolumn{7}{|c|}{ Delivery and neonatal factors } \\
\hline No & Ref & Ref & Ref & - & - & - \\
\hline Yes & $0.80(0.73,0.88)$ & $0.80(0.65,0.99)$ & $0.99(0.76,1.27)$ & - & - & - \\
\hline \multicolumn{7}{|c|}{ Any adverse outcome(s) of the new baby } \\
\hline No & Ref & - & - & - & Ref & - \\
\hline Yes & $1.05(0.94,1.18)$ & - & - & - & $1.36(0.93,1.97)$ & - \\
\hline \multicolumn{7}{|c|}{ Sex of the new baby } \\
\hline Male & - & - & Ref & - & - & - \\
\hline Female & - & - & $0.81(0.64,1.02)$ & - & - & - \\
\hline
\end{tabular}




\section{CONCLUSIONS}

To our knowledge, this is the first study examining how women with similar antenatal stressful life event experiences can be grouped together, and differentiated from other such groups, using the latent class analysis (LCA) approach. Moreover, this is the first study to examine women's state-level socioeconomic status indices in the context of postpartum depressive symptoms. We have also looked at the racial/ethnic disparities in the relationship between antenatal stressful life events and postpartum depressive symptoms. Whether antenatal health care provider communication on perinatal depression had any impact on postpartum depressive symptoms was also of interest.

Our study found that women could be grouped into a low stress; an illness/deathrelated stress; and a multiple stress class, with more than one out of every five women being in this class. The proportion of women experiencing severe nausea/vomiting; preterm labor; and postpartum depressive symptoms progressively increased from the low-, to the illness/death related-, to the multiple-stress class. The stressful life events were also clustered into emotional, traumatic, partner-related, and financial stressors. More than $11 \%$ of our sample experienced postpartum depressive symptoms, the prevalence ranging from $7 \%$ in Illinois to $17 \%$ to Arkansas. Women who experienced all four types of stressors, including traumatic, emotional, partner-related, and financial stressors, were at the highest risk of postpartum depressive symptoms. Women residing in states with higher women's socioeconomic status indices had lower odds of postpartum depressive symptoms. In addition, state-level socioeconomic autonomy status index had a moderating effect; women experiencing antenatal stressors were more likely 
to have postpartum depressive symptoms, if they lived in a state with lower index. There were substantial racial/ethnic disparities in the prevalence of postpartum depression symptoms, ranging from $8 \%$ among Asians/Pacific Islanders to 14\% among American Indian/Alaska Natives. Among the antenatal stressful life events, having more than usual arguments with husband/partner, and having a lot of bills that she was unable to pay were common risk factors of postpartum depressive symptoms, irrespective of race/ethnicity. Husband/partner not wanting the pregnancy significantly increased the adjusted odds of postpartum depressive symptoms, especially for the non-Hispanic blacks. Provider communication on perinatal depression significantly reduced the adjusted odds of postpartum depressive symptoms among non-Hispanic whites and non-Hispanic blacks.

The aforementioned results suggest the importance of an antenatal care-giver being vigilant about the antenatal stressful life event experiences of their patients; and recommending the multiple-stress group for comprehensive psychological care and support if necessary, in order to mitigate the adverse outcomes. Screening for antenatal stressful life events can help identify women at risk for postpartum depression. The finding that the odds of postpartum depressive symptoms decrease with increasing women's state-level social/economic autonomy could have policy implications and motivate efforts to improve these indices in the states that are below average. Moreover, the interactions between antenatal stressors and state-level social/economic autonomy suggests that women residing in states with lower indices are more vulnerable to the impacts of antenatal stressors. It would be especially important to identify the at-risk women in these states so as to mitigate the impacts of antenatal stressors and reduce their probability of experiencing depressive symptoms after childbirth. The finding of 
racial/ethnic disparities in the relationship between antenatal stressful life events and postpartum depressive symptoms indicates the importance of taking into account the race/ethnicity-specific vulnerabilities of different racial/ethnic groups. Furthermore, this study points out the benefits of health care provider communication on perinatal depression during antenatal check-ups. However, the race/ethnicity-specific benefits of antenatal health care provider communication merit further investigation and might suggest the need to make this communication more culturally appropriate. Together with a growing emphasis on the screening for perinatal mental health issues, knowledge of antenatal stressors and the relative vulnerabilities of different racial/ethnic groups can aid in identifying women at-risk of experiencing perinatal stressors. This, in turn, can increase the women's chances of getting the necessary support and intervention, thereby preventing adverse maternal and infant health consequences, such as preterm birth, low birth weight, and postpartum depression. 
VITA

\section{SOUMYADEEP MUKHERJEE}

Born, Bankura, West Bengal, India

$2001-2007$

Bachelor of Medicine, Bachelor of Surgery (M.B.B.S.)

Medical College Kolkata

Kolkata, West Bengal, India

2009-2011

Diploma in Public Health (D.P.H.)

All India Institute of Hygiene and Public Health

Kolkata, West Bengal, India

$2011-2014$

Presidential Fellowship Award

University Graduate School

Florida International University

Miami, Florida

2013-2014

Graduate Assistant

Florida International University

Miami, Florida

2014-2016

Research Assistant

Florida International University

Miami, Florida

2016-present Dissertation Year Fellowship, summer 2016

University Graduate School

Florida International University

Miami, Florida

2014-present

Doctoral Candidate

Florida International University 
Miami, Florida

PUBLICATIONS AND PRESENTATIONS (Selected)

Madhivanan, P., Srinivas, V., Marlow, L., Mukherjee, S., Narayanappa, D., Mysore, S., Arun, A., Krupp, K. (2014): Indian parents prefer vaccinating their daughters against HPV at older ages. Asian Pacific Journal of Cancer Prevention, 15(1), 107-110.

Madhivanan, P., Li, T., Srinivas, V., Marlow, L., Mukherjee, S., \& Krupp, K. (2014). Human papillomavirus vaccine acceptability among parents of adolescent girls: Obstacles and challenges in Mysore, India. Preventive Medicine, 64 (2014), 69-74.

Mukherjee, S., Madhivanan, P., Li, T., Srinivas, V., Jaykrishna, P., Arun, A., \& Krupp, K. (2014). Correlates of completing routine vaccination among children in Mysore, India. Journal of Infection and Public Health, 8(1), 62-71.

Mukherjee, S., Pierre-Victor, D., Bahelah, R., \& Madhivanan, P. (2014). Mental Health issues among Pregnant Women in Correctional Facilities: A systematic review. Women and Health, 54(8), 816-842.

Pierre-Victor, D., Mukherjee, S., Bahelah, R., \& Madhivanan, P. (2014). Human Papillomavirus Vaccine Uptake among Males 11-26 Years in United States: Findings from the National Health and Nutrition Examination Survey, 2011-2012. Vaccine, $32(49), 6655-6658$

Mukherjee, S., Trepka, M., Pierre-Victor, D., Bahelah, R., \& Avent, T. (2016). Racial/Ethnic Disparities in Antenatal Depression in the United States: A Systematic Review. Maternal and Child Health Journal, 2016 Mar 25. doi: 10.1007/s10995-0161989-x [Epub ahead of print]

Trepka, M., Mukherjee, S., Fennie, K., Sheehan, D., Maddox, L., Poschman, K. (2016, May). Linkage and retention in care among homeless people diagnosed with human immunodeficiency virus infection, 2004-2013, Florida. Poster presentation at the 11th International Conference on HIV Treatment and Prevention Adherence, Ft. Lauderdale, FL.

Mukherjee, S., Coxe, S., Fennie, K., Madhivanan, P., \& Trepka, M. (2016, June). Stressful life event experiences of pregnant women in the United States: A latent class analysis. Accepted for poster presentation at the Epidemiology Congress of the Americas, Miami, FL. 